Florida International University FIU Digital Commons

$10-2-2017$

\title{
Refugees Welcome: a Multilevel Analysis of Refugee Labor Market Integration in the Swedish Welfare State
}

Jeffrey D. Maslanik

jmasl001@fiu.edu

DOI: $10.25148 /$ etd.FIDC004012

Follow this and additional works at: https:// digitalcommons.fiu.edu/etd

Part of the International Relations Commons, and the Other International and Area Studies Commons

\section{Recommended Citation}

Maslanik, Jeffrey D., "Refugees Welcome: a Multilevel Analysis of Refugee Labor Market Integration in the Swedish Welfare State" (2017). FIU Electronic Theses and Dissertations. 3555.

https://digitalcommons.fiu.edu/etd/3555 


\section{FLORIDA INTERNATIONAL UNIVERSITY \\ Miami, Florida}

REFUGEES WELCOME: A MULTILEVEL ANALYSIS OF REFUGEE LABOR MARKET INTEGRATION IN THE SWEDISH WELFARE STATE

A dissertation submitted in partial fulfillment of

the requirements for the degree of

DOCTOR OF PHILOSOPHY

in

INTERNATIONAL RELATIONS

by

Jeffrey D. Maslanik 
To: Dean John F. Stack, Jr.

Green School of International and Public Affairs

This dissertation, written by Jeffrey D. Maslanik, and entitled Refugees Welcome: A Multilevel Analysis of Refugee Labor Market Integration in the Swedish Welfare State, having been approved in respect to style and intellectual content, is referred to you for judgment.

We have read this dissertation and recommend that it be approved.

$\begin{array}{r}\text { Rebecca Friedman } \\ \hline \text { Harry Gould } \\ \hline \text { Susanne Zwingel } \\ \hline \text { Markus Thiel, Major Professor }\end{array}$

Date of Defense: October 2, 2017

The dissertation of Jeffrey D. Maslanik is approved.

Dean John F. Stack, Jr. Green School of International and Public Affairs

Andrés G. Gil Vice President for Research and Economic Development and Dean of the University Graduate School

Florida International University, 2017 
C Copyright 2017 by Jeffrey D. Maslanik

All rights reserved. 


\section{DEDICATION}

To the plight of the refugee and to working together to find viable solutions to real challenges. 


\section{ACKNOWLEDGMENTS}

First, I would like to express sincere gratitude to my advisor, Dr. Markus Thiel. His immense knowledge in the field of International Relations, European Studies, and the social sciences, coupled with his work-ethic and direct, yet kind critique, has made this scholarly endeavor possible. From my arrival in the department, to the completion of my dissertation, it has been not only a privilege but also a pleasure to work with Dr. Thiel, thank you!

Besides my advisor, I would like to thank the rest of my committee: Dr. Harry Gould, Dr. Rebecca Friedman, and Dr. Susanne Zwingel, for their astute comments and encouragement, as well as for their well-informed questions which encouraged me to reflect upon my research and reassess it in a way that I would not have been able to do so otherwise. Each of you have impacted my academic career in various ways, for which I am massively beholden to you each.

Aside from those at FIU, my profound thanks must go to Dr. Moira Nelson at Lund University. Throughout the entire duration of my fieldwork, Dr. Nelson provided me an inexplicably vast amount of her personal time to meet over numerous fika to discuss my progress. Without her willingness to host me at Lund, continual support (both professionally as well as personally), throughout my time in Sweden and since, and her profound knowledge of Sweden, political science, and keen eye for detail more generally, none of this would have been possible. I am beyond grateful to her, and to the Department of Political Science at Lund University, for allowing me to spend as much time, and receive as much support as I did there, tack så mycket! 
In addition to Dr. Moira Neslon, I must also thank the Refugees Studies Center at the University of Oxford. My sincere thanks to Dr. Alexander Betts for his critique, insight, and support, as well as to several scholars within the Department of International Development who helped me think about the aims of the project, in particular, Dr. Ruben Andersson. In addition, I must also thank Dr. Bruce Collett for all the encouragement, refreshingly candid insight, and guidance to becoming and navigating life as an academic. In sum, my time with the Refugees Studies Center was exceptionally influential.

Lastly, my deepest thanks to the Miami-Florida Jean-Monnet European Center of Excellence for their generous support during my fieldwork, and the write-up phase of this research as well as Mrs. Christine Caley-Sanchez for her tremendous level of support, advice, and guidance; and finally, to the Broad Fellowship for their generous support during my fieldwork. To everyone, thank you for all of your commitment in helping me address an extremely salient and pressing matter affecting the international system. 


\title{
ABSTRACT OF THE DISSERTATION \\ REFUGEES WELCOME: A MULTILEVEL ANALYSIS OF REFUGEE LABOR MARKET INTEGRATION IN THE SWEDISH WELFARE STATE
}

\author{
by \\ Jeffrey D. Maslanik \\ Florida International University, 2017 \\ Miami, Florida

\section{Professor Markus Thiel, Major Professor}

To explore the complexities of refugee labor market integration in Sweden, the research performed a multi-level analysis of refugee labor market integration: from the perspective of civil society (meso-level) and from that of the refugee (micro-level). Sweden was ideal for this task because historically, it has been Europe's most generous welfare state and during the height of the crisis, received the highest number of refugees of any European Member State (163,000 or 1,600 per 100,000 people).

The research was guided by two primary research questions: First, how have the roles of the state and civil society adjusted over time in relation to the process of integrating refugees, especially since the founding of the first integration policy in 1975 ? Second, how are resources actually provided by each element of society, and accessed by the refugees themselves? Analytically, the research first performed a historical institutional breakdown, separating Sweden's integration policy by sociopolitical and economically significant junctures: 1970-1990, 1990-2010, and 2010-present day. Subsequently, seventy first-person, semi-structured interviews were conducted with political-elites, civil society representatives, and refugees from different sending 
countries, who arrived no earlier than 2000 . The findings suggest that while civil society is becoming more systematic in its operations, its utility remains under-utilized. Next, meeting human capital requirements (e.g., country specific and post-secondary education and training) does not guarantee employment. Instead, given the alteration of its labor market, it seems social capital may play a more significant role in determining employment outcomes for refugees. In other words, it seems difficulties in accessing employment for refugees are more attached to institutional constraints than they are human capital itself. Finally, given the visible segregation and low refugee labor market participation, the research supports the assumption that a highly accessible and comprehensive welfare state may not be the most efficient socioeconomic orientation for integrating refugees. 


\section{TABLE OF CONTENTS}

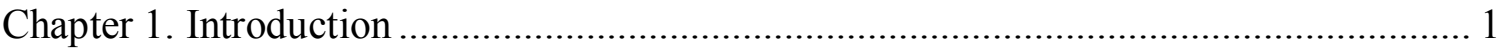

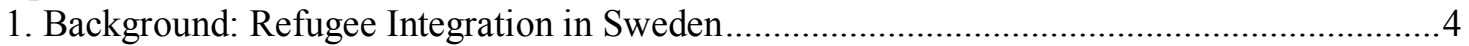

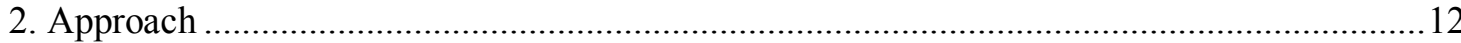

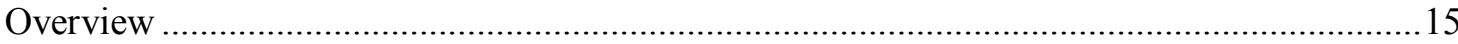

Chapter 2. Theorizing Labor Market Integration for Refugees in Sweden .................... 21

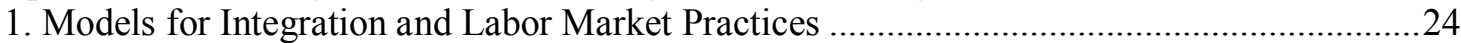

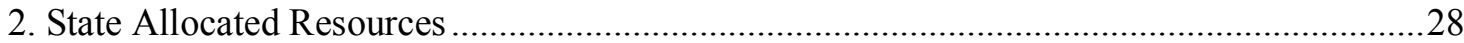

3. Civil Society: Associational Membership and Social Networking ........................................34

4. Employment Outcomes: Private Sector, Public Sector, or Self-Employment .......................39

Conclusion: Towards a Theoretical Middle Range for understanding the Economic

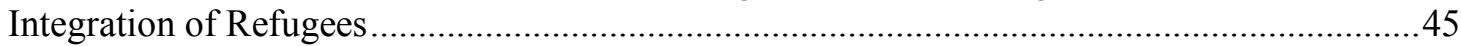

Chapter 3. Researching Labor Market Integration of Refugees in Sweden .................... 50

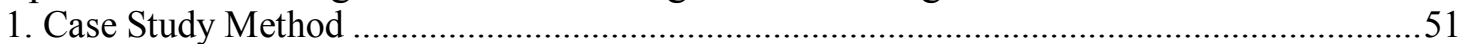

2. Historical Institutionalist Approach: Political \& Economic Institutions and their Influence 53

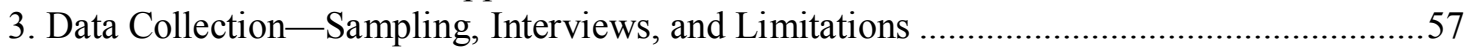

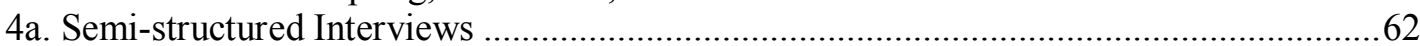

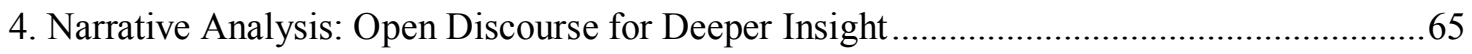

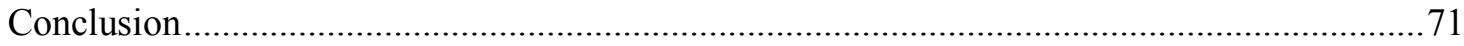

Chapter 4. Refugee Integration: A Historical Analysis of Norms and Trends Impacting

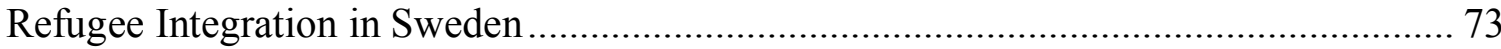

1. Generating Norms: Establishment of the SAP, Folkhemmet and Equality and Openness for

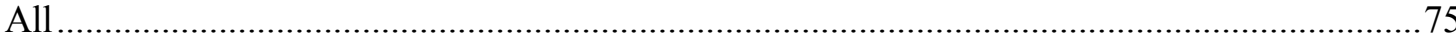

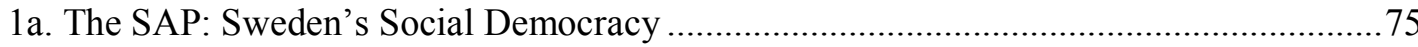

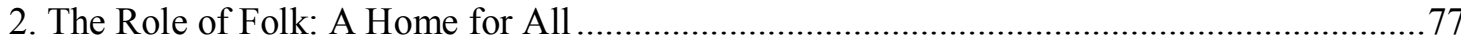

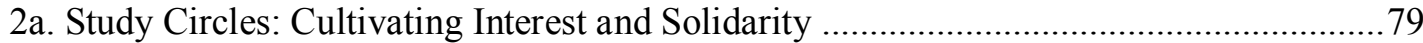

3. 1970-1990: The Birth of Integration in the Swedish Welfare State .....................................83

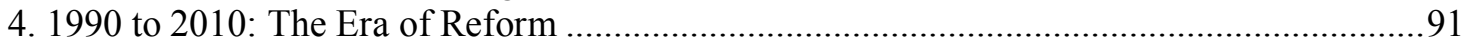

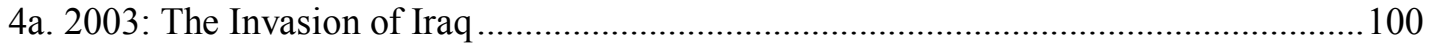

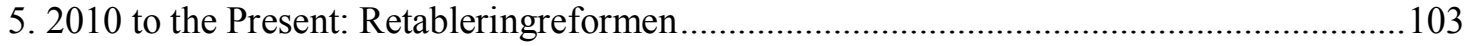

Conclusion: Asylum, Social Democracy and its Challenges ...............................................112

Chapter 5. Labor Market Integration: Civil Society and Social Democratic Central

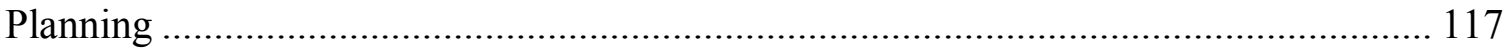

1. Selecting and Accessing CSOs: The Welfare State, Civil Society, and Refugee Labor

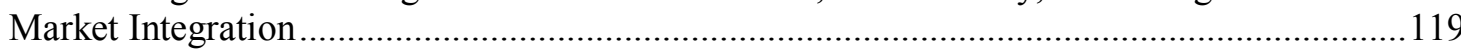

2. The Changing Role of Civil Society and the Types of Organizations in Sweden ..............120

2a. How has the role of Civil Society changed since the 1990s? ......................................121

3. The Role of Native Actors: Relationship Building \& Education.........................................126

3a. From the Top-Down: Folkbildining and networking among Native CSOs ...................126

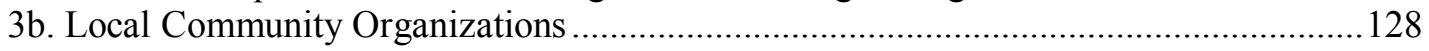

4. Ethnic Associations: Bonded Support within Ethnic Enclaves (Iraqi, Assyrian, Somali,

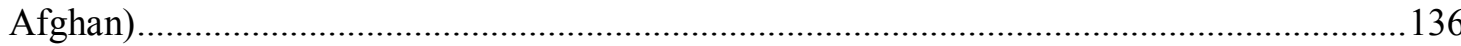


5. The Role of the Swedish Church and other non-Formal Faith-Based Organizations ..........139

6. Availability and Access: Challenges of Participation in Civil Society ….............................142

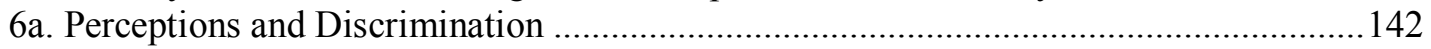

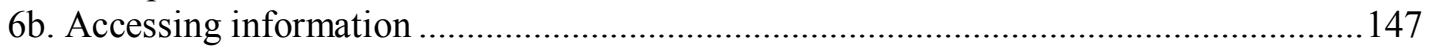

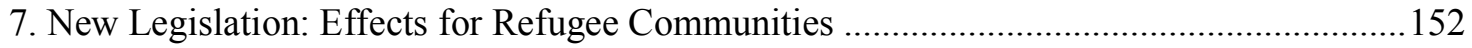

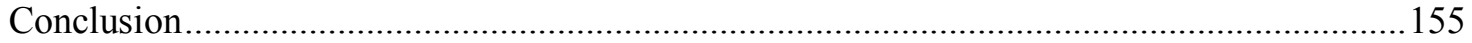

Chapter 6. Employment Challenges: Individual Experiences with Labor Market Access

for High-Skilled Refugees in Sweden (2000 to 2016) .............................................. 160

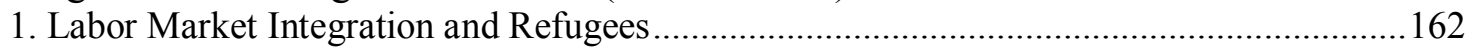

2. Method and Material: Selecting and Interviewing Participants .........................................164

3. Challenges Embedded in Sweden's Labor Market: A Backdrop to Individual Experience 168

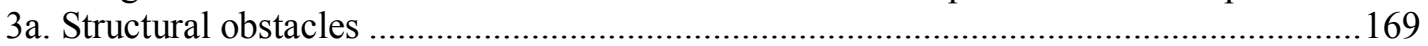

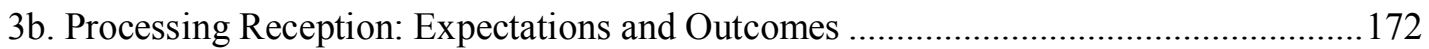

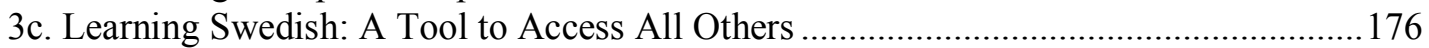

4a. Intercultural Contact: Experience Networks and Market Access .................................179

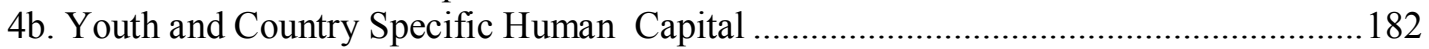

4c. The Plight of Older Refugees: Degree Qualifications/Equivalency Examinations/ and

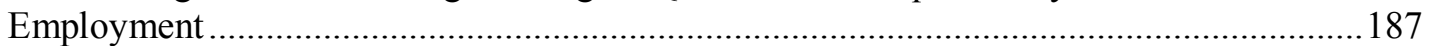

4d. Non-Swedish Human Capital: Accessing Social Capital and Employment ...................194

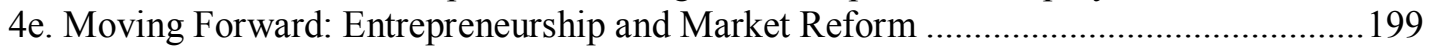

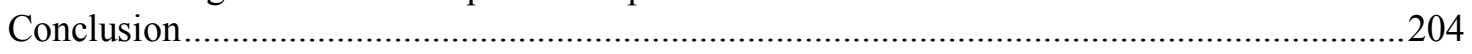

Chapter 7. What Can We Say About Refugee's Labor Market Integration Today? ...... 211

1. Approach to the Study of Refugee Labor Market Integration ..........................................213

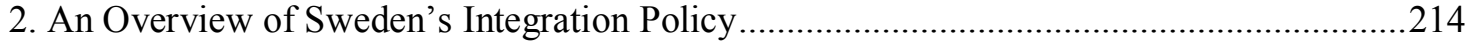

3. Adapting to the Retreat of the State: The Rise of Civil Society ........................................219

4. Micro Refugee Perspective: Social Networking, Obstacles, and Employment ..................226

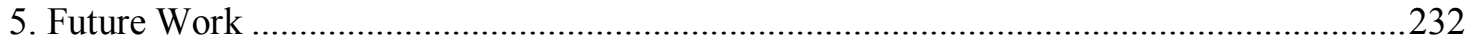

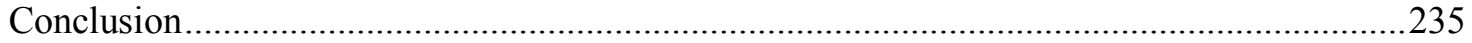

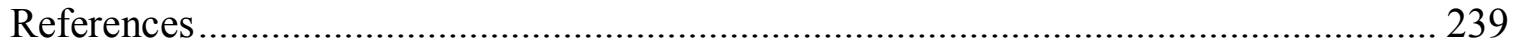

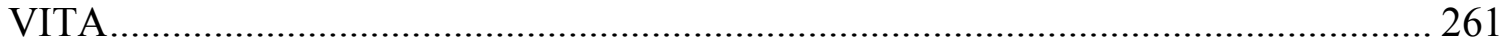




\section{Chapter 1. Introduction}

With the most recent refugee crisis initiated by the war in Syria in 2011, Europe has received an unprecedented number of refugees from outside, in particular from the Middle East and northern Africa. Remarkably, the number of displaced people today has outpaced that of the end of World War II (Bevelander 2016; Pew Research Study). Irrespective of the size and complexity of this most recent crisis, all European Member States (EMS) ratified the United Nations Convention Relating to the Status of Refugees (1951/1957 ratification). Hence, all are required to protect asylum seekers fleeing out of fear of individual persecution. Notwithstanding, with the rise of national populism, competing sovereign agendas among EMS, and point-of-arrival issues such as the ineffectiveness of the EU's Dublin II refugee reception agreement, the common approach to redistribution and resettlement (resulting in a quasi-legal, though, ineffective agreement with Turkey) never gained enough support to become fully implemented. Yet the Union prides itself on its normative actions, and the free movement of people and goods is central to the European project. While labor market integration of refugees has been the topic of an ongoing debate, the high number of asylum seekers coming to Europe in the past few years and high-levels of unemployment among these groups, has made it one of the most salient topics facing the European Union and respectively, the international community today.

The challenge of asylum, indeed, arises within sovereign state boundaries. War,

crimes against humanity (such as genocide), as well as natural disaster force individuals to flee for the protection and safety of themselves and loved ones. Given the sovereign 
orientation of where the challenge (war, famine, etc.), emanates, and the view of where refugees arrive i.e., in one host nation, the challenge of asylum seekers and subsequently refugees, is often viewed as a sovereign challenge. However, internal displacement directly affects the international system. In other words, the challenge of providing protection and subsequently facilitating refugee integration is an international matter.

In response to crises and displaced persons, the international community has worked to develop cooperative measures to, at the very least, mitigate potential human rights crises. Barbara Harrell-Bond (1995) aptly noted, "refugees represent a fundamental challenge to sovereignty, by forcing international actors to consider ethical principles and issues of fundamental human rights, which are in part of their international obligations, over and above the interests of a tidy system of sovereign states" (Skran 1988, 278; Srkan 1995, 70-1). In addition to human rights challenges, determining when a group may safely return is unknowable. Therefore, while regulations have become more strict, we may, or rather, should assume that refugees are likely to receive permanent residency in the EU. Moreover, as highlighted by Article 127 of the European Economic Area (EEA) agreement (e.g., free movement of people and goods) and Schengen, a requirement of providing refuge is also perceivably economic in nature. This is because once one receives refugee status, and meets the requirements of obtaining permanent-residency and their integration requirements, they may move anywhere within the Schengen. Regardless of where refugees seek asylum, the success of their integration will likely affect all Member States.

To provide proxy to the challenge of refugee integration in a European context, Sweden was selected to serve as the case study of this research. Sweden is ideal for this 
task because historically, it has been Europe's most expansive welfare state. While the nation has seen considerable economic liberalization (i.e., the transfer of state owned and operated enterprises and opportunities to the private sector), these changes have not completely altered this status (Bergh \& Erlingson 2009; Kjellberg 2009; Bergh 2010, 2014). Yet the high unemployment rate among refugees raises important questions concerning Sweden's capacity to address the wellbeing of this population in a more liberal, market-oriented economy. Moreover, during the most recent crisis, Sweden received the highest number of asylum seekers per population $(163,000$ or 1,600 per 100,000 people in the country's population ${ }^{1}$ ) and is considered a vanguard of European social democracy. Welfare regimes differ (Esping-Andersen 1990, 2013; Arts \& Gelissen 2002), but the extent of Sweden's system and openness of its policy will allow this study to unearth information useful for future comparative work.

Given Sweden's economic liberalization and the steep rise in asylum applications, this work assumes civil society organizations (CSO), local native Swedish organizations and ethnic organizations, will play a necessary role in labor market integration. Tangentially, this research also assumes regardless of the available resources, skill-sets and education of any individual (human capital), that social capital, defined as relationship-building between refugee communities and native Swedes (e.g., bridging), also plays a vital role in determining refugee labor market integration. Notably, the extent to which civil society provides for and engages with refugees and the effects of social capital on the labor market integration process, remains largely unknown. To situate the research, the investigation asks: (1) How have the Swedish government and civil society

\footnotetext{
${ }^{1}$ Data provided by Pew Research Center.
} 
approached the economic integration of its refugees over time? (2) How are resources accessed by the refugees themselves?

Because of the socioeconomic and political shifts within Sweden, subsequent questions of concern include: what are the roles of CSOs in the process of refugee labor market integration, and how have they transformed (if at all) since the 1990s? What are the obstacles they face in engaging with the refugee community? How do refugees gain access to the resources provided? What are the difficulties experienced in this process, and to what extent does the relationship between human capital and social capital effect and individual's rate of successful labor market integration? While these individual elements (programs and activities in civil society and the process of socialization) are not categorically labor market oriented, this research approaches the study of labor market integration via the belief that all are pertinent to the overall labor market integration process. Given that the central focus of integration today is employment, this research regards all steps throughout this process as being related to an end goal of obtaining work. In other words, from an intuitive perspective, all steps throughout a refugee's integration process should lead to a sense of autonomy within their host society, of which becoming gainfully employed is arguably the most important signifier. Though qualitative in form, this multilevel analysis hopes to shed light on this complicated issue.

\section{Background: Refugee Integration in Sweden}

Since the 1990s, Sweden's open asylum policy has resulted in a significant influx of refugees. In addition, due to globalization and a series of financial crises (for example, the banking crisis of the 1990s; Englund 1999; Jonung \& Hagberg 2005), Sweden's 
economy has become considerably more privatized. Contrary to ardent defenders of the free market who would equate this change with more job opportunities (Baumol 2002; Friedman 2009), the unemployment figures for refugees from outside of Europe remain staggering (around 22.5 percent, according to the Economist). ${ }^{2}$ Looking at employment outcomes over the previous decades (from 1975 to 2000), this figure is considerably higher than when the state allocated jobs to newly arriving refugees.

Historically, the central government guided refugee labor market integration (Brochmann and Hagelund 2011). Since the 1990s, a shift in Sweden's economic structure toward greater liberalization has altered this process. Today, the market requires much higher levels of specialization and education. While the state remains the primary actor in the integration process, one visible challenge is that only 5 percent of jobs in Sweden are considered low-skilled (figure provided by $\mathrm{OECD}^{3}$ ). The challenge is perceivably two-fold. First, increased privatization means less direct forms of employment. In other words, the state can no longer directly place refugees in stable employment as easy as they once had. Second, along with having specific skill-sets, we should also expect refugees now must cultivate make new inroads with locals (build social capital with those outside of their ethnic community). For those without suitable skills, and education (at least some tertiary education e.g., those deemed low-skilled), finding stable employment may be increasingly difficult.

\footnotetext{
2 "Refugees in Sweden: Seeking Asylum - and Jobs," Economist, November 5, 2016, accessed January 10, 2017, http://www.economist.com/news/finance-economics/21709511-too-few-refugees-not-too-many-areworking-europe-refugees-sweden-are.

3 "Sweden in a Strong Position to Integrate Refugees, but Support for the Low Skilled Needs to be Strengthened," OECD, May 15, 2016, accessed January 10, 2017, http://www.oecd.org/employment/sweden-in-a-strong-position-to-integrate-refugees-but-support-for-thelow-skilled-needs-to-be-strengthened.htm.
} 
Irrespective of a less government-controlled market's ability to create work positions, unemployment levels among refugees became increasingly central to the integration debate. Early in 2016, The Financial Times reported that even after more than a decade in Sweden, upwards of half of all refugees remained out of work (Milne 2016). ${ }^{4}$ Such high levels of unemployment raise several important questions about the effects of reduced ability of the Swedish welfare state to integrate refugees. Chief among them is whether highly advanced welfare states are able to sustain such increased levels of migration (Joppke 2007, Brown 2009; Koopmans 2010. Some have described these developments as the end of Swedish exceptionalism (Linvall \& Rothstein 2006; Rothstein 2014).

To address the challenge of forced migration on the international system, IR research has developed a number of theories regarding refugee management and the international politics of forced migration (Betts \& Loescher 2011). However, these theoretical modes are not sufficient for analyzing the current state of refugee labor market integration. While an investigation of this process must be focused at the state level, the project is inherently international because the flow of asylum seekers impacts the EU, and even global system. Studying how this affects Sweden will provide insight into potential outcomes and solutions for other European member states and add to the body of IR literature concerning transnational actors and their effects on the host societies (Viotti et al. 1997; Malet \& Anderson 2017; Thiel \& Maslanik 2017) Thus, this study applies a midrange approach that relies upon mixed-embeddedness (Portes 1995;

\footnotetext{
${ }^{4}$ Richard Milne, "Sweden's Immigrant's Struggle with Jobs and Integration," Financial Times, March 26, 2017, https://www.ft.com/content/838d60c2-0961-11e7-97d1-5e720a26771b.
} 
Kloosterman et al. 1999) as a framework. Operationally, the framing analyzes labor market integration from two perspectives: the meso-(the welfare state and civil society) and micro- (refugees' lived experiences) levels. To accomplish this goal, this work draws upon two primary bodies of literature: that of the welfare state (the meso-perspective) and of economic sociology, which gives perspective on the phenomena (employment) from the micro, lived perspective.

Applying a theoretical middle ground (Merton 1949) to this type of investigation (by determining how resources provided by the state and civil society are accessed by refugees) will allow for a more nuanced analysis of how CSO participation is maturing and, likewise, how refugees are gaining access to the programs available. This approach brings together welfare state literature and current research in economic sociology. While work on the welfare state has looked to policies and institutions (a more macro-level approach) as points of inquiry, economic sociology has drawn on the daily micro-level interactions and relationships that are most often attached to social capital.

To operationalize this study and step beyond a purely theoretical approach, this work looks to resource provisions and how they are accessed by refugees within the contemporary, globalized Swedish socio-political setting. Put differently, given the centralized position of Sweden's economic and political structure, the state has and therefore, we should expect it to continue to have, a strong role in the labor market integration process. To flesh out the intricate relationship between the state and civil society in an increasingly private and highly-educated welfare regime, such as Sweden's, and moreover, how refugees reorient in, this study is interested in uncovering the role of 
the "third sector" and the everyday realities of how refugees navigate the Swedish labor structure, as these are relatively unknown.

To properly consider any transformations currently taking place, we must first understand the history and objectives of the world's highly regulated welfare regimes. Welfare administrations differ considerably from country to country, but they all share certain inherent qualities. A decommodification of education, healthcare, and pensions is prevalent among European welfare states. These benefits are provided by the government in order to avoid certain drawbacks associated with a purely market-based capitalist system. Scandinavian nations are most closely aligned with the social democratic welfare type, which is considered to be the most comprehensive (Esping-Andersen 1990; Arts \& Gelissen 2002). This type of administration is characterized by high taxes and a strong, centralized government, as well as a relatively substantial level of equality. Scandinavia, and in particular, Sweden, has some of the most comprehensive safety nets of all of the welfare regimes (Lister 2009; Borevi 2014).

Given what we know about the role of the state in social democratic regimes and the extent to which refugees have difficulties finding employment, the question remains: if a highly-regulated integration process is insufficient to produce positive outcomes for a diverse group of refugees in an increasingly market-based system such as Sweden, how should the state adjust its relations to civil society? To explore this question, this research addresses the "third sector" and its role in this process. In political theory, there are two distinct ways of defining civil society (Somers 1995). The first is based on a two-sphere model, a definition that is closely related to the theories expressed in Hegel's The Philosophy of Right (2003), first published in 1821. The Hegelian worldview depicts civil 
society as composed by the market, associations, and the justice system, alongside a second sphere: the state. In this regard, the state is the principal guarantor of the desires, needs, and actions of the individual. Corporations (associations) facilitate the grouping together of interests into larger units; however, the state remains the primary actor throughout this process (Hegel 2003, 94; see also Trägårdh 2007, 17). In more contemporary terms, a second approach (Thiel 2017, 25) notes, "civil society in Europe is marked by the prevalence of liberal-democratic freedoms, governmental support patterns, and a dense organizational space." The structure of Sweden's political makeup, a strong central government authority combined with the freedom to create and operate associations (förenings, that echo the interests of a group of individuals), closely reflect Hegel's and Thiel's conceptions of civil society. Nevertheless, as noted by Trägårdh (2007), civil society is a relatively new term in Sweden; it first came into political prominence in the 1990s.

Civil society provides information and networks (social capital) that assists in providing relative and pertinent information regarding the available resources for refugees. Aside from straightforward involvement on behalf of the state, it is through social capital networks (Edwards \& Foley 1998; Woolcock 1998; Portes 2000) that resources can be accessed. Notably, the primary role of civil society in the area under research here is to provide refugees with direct needs such as health care and other types of assistance, as well as to introduce them with networks of social mobility. In theory, therefore, one facet of civil society is to provide asylum seekers with the social capital they need to integrate into their host society. This may be done through associational groups, or via informal means and networks. To conceptualize the role of civil society in 
the integration process, we may think of it as an extension of policies and programs initiated by the state. While the state does not directly administer activities conducted by CSOs, it does set the legal framework and often allocates the funding upon which these organizations rely. Along these lines, whereas the state is less hands-on, CSOs may establish pathways via personal relationships or connections to help refugees settle and find employment.

It is in this conceptual space where we may begin to consider the construction of relationships and their potential effects on employment. Because of globalization and the movement of people, culture, and goods, immigration has been a strong focus of economic sociology (Portes 1995; Alba \& Nee 1997; Portes \& Rumbaut 2006). Migration scholars have begun to explore the impact and usefulness of social capital for migrant communities (Nannestand et al. 2008; Haug 2008; Evergeti \& Zontini 2006; Goulbourne et al. 2010; Ryan 2011, Griffin 2012). Because this research is focused on the acquisition of resources, it is important to investigate through interviews how key pieces of information are accessed and uncover the barriers impeding greater social capital building and mobilization. Throughout the process of integrating into Sweden's culture and finding gainful employment, individuals must cultivate and adapt to different types of information. The most easily accessible knowledge comes from within one's direct community, whereas counsel from those outside is more difficult to come by. Therefore in the latter case, as a means of operationalizing the analysis of social capital, this research is interested in gaining insight into bridging via the weak ties that form between different (native) cultural and ethnic groups, rather than bonding within ethnic- 
enclaves. For refugees, these weak ties may be the most effective means of bridging social-cultural distance (Granovetter 1973, 208).

Directly related to social capital is human capital defined as "knowledge, information, ideas, skills, health" (Becker 2002, 3) as well as country specific knowledge such as language and cultural awareness. Looking at the changing patterns between 1973 and 1990, Scott (1999) and Becker (2009) examined employment and income rates among male immigrants to Sweden. Since the 1970s, there has been a slowdown in laborbased migrants, in part due to policy and in part due to changes in the economic structures of surrounding nations. Thus, immigrants to Sweden are now almost always refugees or those arriving through family reunification. Scott (1999) found that immigrants were having an increasingly difficult time integrating into Sweden's economy. He argued that the difficulty was not the result of the "quality" of the newcomer, but rather a shift in the type of labor the Swedish economy had begun to demand. He categorized this shift as a move toward more country-specific skills and argued that those more culturally aligned with native Swedes performed much better than those with greater cultural and educational distance.

Two distinct gaps in the literature persist. First, concerning the role of civil society in this process, and second, looking at the extent to which social capital (bridging-relationship building with the local community) affects labor market integration for refugees. It is clear that employment is acquired through a series of resources. These may be direct (from the state or civil society), in-kind, or via social capital. Yet how these resources are accessed and how they lead to employment remains less understood. Accordingly, the current research not only addresses questions 
surrounding the welfare state and the participation of civil society, but also considers the refugees themselves.

This work contributes to the existing literature in three ways. First, it outlines what the Swedish state and civil society currently provide to refugees. Next, it offers information that will assist researchers and policymakers in conceptualizing the ways in which the relationship between the two spheres has changed. Thus, the framework allows for scholars to examine and conceptualize how and if a transference of responsibility occurs between the state and civil society. Moreover, by learning about individual experiences, we may also come to a fuller understanding of how resources in both spheres are actually accessed. Finally, by analyzing this complex process of integration, this work will also serve as a basis for improving the policy mechanisms related to the refugee crises being experienced by other members of the European Union. In sum, using closely related though disparate bodies of literature, this research frames a middle ground for the study of the economic integration of refugees, and contributes to welfare state literature, economic sociology and, more broadly (given the nature of the international impact of asylum seekers and refugees), the scholarly body of international relations.

\section{Approach}

The goal of my research is twofold. First, as seen in Chapter 2, this work constructs an historical institutionalist narrative regarding how Swedish integration policy has matured since its initial formation in 1975, focusing especially on the last 25 years when welfare reform began. It is worth noting that this endeavor was not directly focused on policy development per se, but rather on how resources are provided and accessed by these 
groups, as well as to better understand outcomes in relation to the economic and political environment of the time. This investigation fostered the theoretical assumptions outlined in Chapter 2, which argue that due to the transformation of Sweden's socioeconomic and political structure since the 1990 s, other actors, such as civil society, have begun to play a larger role in determining how refugees access resources and integrate into the labor market. Correspondingly, this analysis places special emphasis on the utility of social capital fostered through community networks and associated civil society groups.

The overall aim was not only to understand what resources have been made available and are currently accessible, but also to gather first person accounts of refugees' experiences in utilizing them. While it remains undetermined whether a small $n$ qualitative study can yield generalizable results (Checkel and Bennet 2012), it may be possible to use individuals as a proxy for others, or at least as a means of accessing individual, micro-level details related to the greater phenomenon under examination. Consequently, this work offers substantial nuance and a detailed frame of reference for understanding the situation in a "thicker" (Geertz 1972), more interpretive manner. Importantly, while HI seeks to establish a certain degree of causality, using this analytical tool, determining causality in the social sciences is extremely improbable (Babones 2013, 133). Instead, by embedding the study of refugee labor market integration in a historical institutionalist case study, this research provides correlated knowledge of how policy has evolved, as well as why some refugees are successful while others are not.

To select research participants, I began by contacting individuals at the organizational level (CSOs); from there, I engaged in contacts with CSO representatives and asylum seekers/refugees. To access additional organization members and 
participants, I contacted groups throughout Sweden (Malmö, Stockholm, Gothenburg, and Växjö). Organizations were chosen for their active visibility with the refugee community (such as Yalla Sofielund, Open Skåne, and the Somali Business Center, among others). To gain an institutional, state-based perspective, I also reached out to state agencies prominent in the labor market integration process, such as Arbetsförmedlingen (Public Employment Service), ALMI (a state-run business development and microloan agency aimed almost entirely at the refugee community), and Migrationsverket (Sweden's migration board).

From the civil society groups, interviewees were chosen to highlight the different types of active organizations (e.g., native, ethnic, and international). As for refugees, interviewees were selected according to their age, gender, ethnicity, and time since arrival in Sweden. My empirical examination of civil society organizations was in line with the Johns Hopkins Comparative Nonprofit Sector Project, which formulated structural-operational definitions of "civil society sector" and "civil society organization." In this framework, civil society is divided into three components, based on the social configuration and identity of the organization. They include: 1) ethnic (one foreign, national, or ethnic group); 2) inter-ethnic (more than one foreign, national, or ethnic group); and 3) hybrid organizations (immigrants, but with a significant component from the host society). This also takes into account international organizations (IO) and faith-based organizations (FBO). Because of logistical difficulties such as those related to language, all participants in the current research had a minimum level of education, including some English and/or Swedish language abilities and post-secondary 
educational training. Because the study focused on gathering lived experiences (e.g., personal narratives), the questioning was largely left in open form.

Narrative inquiry is well suited to addressing the intricacies of refugee experiences, the complex process by which they access the labor market, and their personal experiences and interactions with existing structures such as social/ethnic communities, the "native" Swedish labor market, and society more generally. Narrative analysis was chosen because it allowed me to study the intersection of the personal and the political (Riessman 2005). As a complement to HI, it lends itself to a deeper analysis of the lived experience of labor market integration. In this research, the interviews were first conducted and then transcribed. Direct quotes are used throughout this dissertation, to show in detail the effects of resource acquisition (e.g., the challenges described by civil society members in accessing the refugee population and those defined by refugees navigating the Swedish opportunity structure) in Sweden; however, no significant coding was applied. Rather, narrative quotes were carefully selected to illustrate how civil society is participating in the labor market integration process and the order in which refugees accessed particular resources as well as to highlight the difficulties experienced throughout the process of obtaining employment.

\section{Overview}

Given the centralized orientation of its economy and the recent effects of globalization (such as international financial pressures and immigration), this study analyzes how refugee labor market integration takes place in an ever-evolving, highly advanced European welfare regime; for this purpose, Sweden was selected as the sole case study. In 
2015, per population, Sweden received its highest number of asylum applications in Europe to date. Several complications resulted from this intake, but these have largely been overcome in the reception phase. Notwithstanding, refugee labor market integration remains a serious long-term issue not only for Sweden, but for the entirety of the EU.

Due to the obvious difficulties refugees face with increasing welfare restrictions (e.g., high levels of unemployment, potential segregation, and suitable skills and education for local markets), this research assumes that CSOs will continue to play an increased and more systematic role in integration. How these groups work with refugees (e.g., how they cultivate skills and relationships that may help asylum seekers achieve employment) and the difficulties they experience in reaching communities and facilitating projects remains under-studied. To better understand the difficulties they face, this research combines an analysis of civil society with a micro-level analysis of refugees' individual lived experiences. As noted above, the primary questions of concern include: What role do CSOs occupy in the process of refugee labor market integration? How has this position transformed (if at all) since the 1990s? How do refugees gain access to available resources? What difficulties do they experience throughout this process? To what extent are they able to bridge out of their ethnic/refugee community and into the local/native Swedish community?

This method takes into consideration the state, civil sector, and individual communities. Because of Sweden's political orientation, this study relies upon two central bodies of literature, one that addresses the welfare state and one that focuses on economic sociology, with a specific emphasis on social capital. While each school of thought can offer important insights into the process of labor market integration, they are 
best utilized when joined together. Welfare state literature often examines how institutions impact policy, concluding that the more comprehensive the welfare regime, the less likely it is that integration will take place (Koopmans 2005; Hjerm 2005). Directly related are those who question the ability of the welfare state to survive in spite of competing global pressures (Joppke 2007). In Sweden, some see the end of an era. The perception of the Swedish model as exceptional is no longer prominent (Green-Pedersen 2008; Rydgren 2004; Rothstein 2014).

In alignment with the diverging opinions, my work will divide its examination of labor market outcomes for highly skilled refugees into two foci: those who received their human capital (education and skills) in Sweden and those who received theirs elsewhere. In addition, to provide greater nuance, it will also take into consideration the factors of age and gender. Finally, because of this study's core assumptions and its goal of providing a more holistic interpretation of the labor market integration process, it will also analyze how the role of civil society has evolved in this process and shed light on the extent to which social capital (bridging with native Swedes) affects employment.

Structurally, this dissertation contains five core chapters. The following chapter lays out the theoretical approach. Relying upon a midrange method, I bring together two bodies of literature: research on the welfare state and economic sociology. This was done to explore and help answer two central questions about the refugee integration experience. First, what do civil society actors contribute to this process, and how are the resources they offer accessed (or not) by refugees? Second, from a lived-perspective, how have some refugees (since 2000) navigated the Swedish labor market and found employment, or have they not yet been able to do so, and why? Chapter Three describes 
the methods employed in this study. In short, it provides an overview of and justification for the use of Sweden as the research's test case, the design for accessing and selecting participants and the utility of purposeful sampling.

Chapter Four provides the historical narrative, painting a picture of the influence of folkhemmet and the evolution of Sweden's refugee integration policy. To situate the research in Sweden, this chapter first gives a brief overview of the formation of Sweden's social democracy and the foundation of its Social Democratic Party (SAP). Highlighting the normative framing that emerged at the turn of the $20^{\text {th }}$ century illustrates how the SAP guided Sweden's integration policy over the last four decades. Next is an examination of Sweden's integration policy, divided by historically significant junctures: 1970 to 1990 , 1990 to 2010, and 2010 to the present. Each represents a political and socioeconomic period of scholarly note, presenting different waves of refugees, amendments to the official integration policy, and significant political and economic circumstances. The chapter comprehensively discusses Sweden's integration methods since the 1970s, beginning at the height of its welfare state (when it was first enacted) and ending with the present integration platform, etableringsplan (the establishment plan).

Moving beyond the historical framework, Chapter Five delves into questions related to civil society and its role in the refugee integration process. Historically, Sweden and other European nations have relied on the state to integrate refugees; however, as the situation has become more complex (e.g., greater liberalization and larger waves of newcomers), non-state CSOs have begun playing an increasingly significant role. An examination of CSOs, then, is included to assist in our understanding of how the state is adapting to these challenges. Organizationally, the chapter is divided into three 
types of local CSOs: native Swedish organizations, ethnic groups, and faith-based institutions. After an overview of these associations, the chapter explores the challenges CSOs face and the particular resources they provide (information, training, and social networking). Following this exploration of the role of civil society, Chapter Six presents my findings from the perspective of the refugee. To analyze the data, this chapter is divided according to the following variables: age, time of arrival, and origin of education. This is done first to highlight how those who receive the majority of their human capital in the host country have fared as compared to those who did not, and second to better understand how certain factors (e.g., age, personal outlook, and gender) assist or stall bridging with the local host community. The chapter concludes with a discussion of the potential benefits of utility entrepreneurship in expediting entrance to the labor market. Chapter 7 bookends the research by bringing together the findings from both the meso and the micro level, namely highlighting how civil society may participate in the integration process, as well as the challenges therein, and how social capital varied among the participants. Moreover, it revisits a discussion of the diverging employment realities among participants given their age, where they received their education, as well as whether they were able to bridge with Swedes or not (e.g., cultivate weak-ties). Finally, the study calls for additional research concerning the shrouded issue of discrimination within Sweden and an increasingly diverse European, more generally. In other words, it beckons future research to take into greater consideration more nuanced details related to multiculturalism, advancing liberal economic policies and the social, political, and economic circumstances they beget; and subsequently, how this will alter welfare priorities in a more diverse and globalized European setting. 
This research provides insights for academics and policymakers seeking to better understand the role of civil society, to conceptualize how it may be cultivated by marginalized groups such as refugees, and to more adequately realize the utility of social capital. The overarching goal is to alleviate some of the pressure on the state, especially in heavily regulated, universal welfare models. The rise of international competition among countries has moved the European welfare state towards greater liberalization. This, coupled with the increase in refugees and general absence of a solution to the refugee problem, as well the ability to move freely throughout the Schengen and the precarious nature of the current political climate in Sweden and the EU, makes this research both timely and necessary. 


\section{Chapter 2. Theorizing Labor Market Integration for Refugees in Sweden}

This chapter offers a theoretical framework for approaching the study of economic integration of refugees into the labor market. The framework posits that studying the roles and resources provided by the state and civil society, as well as how those resources are accessed by refugees, will give much needed insight into how labor market integration truly takes place. Moreover, by considering both public policy and civil society activities throughout this process, this framework sheds light on the conditions underlying public policy initiatives (how they are influenced by market liberalization and other external factors, such as increased waves of asylum seekers), as well as the roles of less-discussed actors in this process (namely, those active in civil society). As noted in the previous chapter, the framework operationalizes two primary questions. First, how have the roles of the state and civil society adjusted over time in relation to the process of integrating refugees, especially since the founding of the first integration policy in 1975 ? Second, how are resources actually provided by each element of society, and accessed by the refugees themselves? Understanding what resources are available and how they are accessed will improve our theoretical understanding of the integration process.

Since the 1990s, Sweden's open asylum policy has resulted in a significant influx

of refugees. In addition, due to globalization and a series of financial crises (Drees and Pazarbasioglu 1998; Englund 1999; Jonung \& Hagberg 2005), Sweden’s economy is increasingly competitive, liberal (private) and global in stature (Blomqvist 2004). Yet, high levels of unemployment among its refugee population raises several important questions about the effects of the reduction of Sweden's welfare state and its impact on 
integration. Approaching the study of refugee integration through a middle-range approach - the analysis of resources and their accessibility - will allow researchers and policymakers to assess how Sweden addresses the challenge of economically integrating its refugees, and understand the challenges such refugees face in the current market structure.

Several similar studies concerning labor market integration have already been conducted. Scholars have researched the impact of human capital (Scott 1999; Becker 2009), effects of education levels and skillsets on labor market integration in Sweden (Hauff \& Vaglum 1993; Bevelander 2011), and the consequences of the same on labor market integration in general (Rooth 1999; Colic-Peisker \& Walker 2003; Lamba 2003). To extrapolate to the international level, and more keenly understand how this may effect the regional and international system, an examination of a unique sovereign case is useful. Hence, this study calls for a theoretical middle ground (Merton 1949), which aims to study the process of labor market integration by understanding how the resources provided by the state and civil society are accessed by refugees. It brings together welfare state policy literature and economic sociology. While policy literature studies the impact of policy and institutions (a more macro level approach), economic sociology focuses on social reality (micro level daily interactions and relationships). Mixed-embeddedness (Kloosterman et al. 1999), an already existing framework, offers some guidance and justification in bringing these two literatures together.

Expanding from Portes (1995), mixed-embeddedness brings in two targeted areas of study: institutional constraints and effects, and social reality. At the micro-level groups and individuals are embedded in their own individual interactions of every day activity. 
At the meso-level individuals and groups are embedded into social forces, such as traditions and ethnic heritage. And at the macro level, communities and individuals are embedded into the surrounding economy and legal framework expressed through a.) the economic interactions of other participants within the market and b.) public policy. Kloosterman's theoretical expansion is useful for researching the economic integration of refugees in Sweden as well as to a greater extent Europe, as it takes into account the forces of a more state directed, social democratic political setting. Hence, looking into resource provisions and access helps to operationalize and contextualize the study of refugee labor market integration in the Swedish setting and justifies a tiered analysis of meso (civil society) and micro (personal relationships and lived experience) affect refugee labor market integration.

Correspondingly, this work will contribute to the existing literature in three ways. First, it outlines what the state and civil society provide to refugees. Next, it will assist in conceptualizing the ways in which the relationship between the two spheres has changed. In other words, shedding light on how civil societies have evolved in an increasingly liberalized welfare state. Thus, the framework allows for researchers to examine how and even if a transfer of responsibility occurs between the state and civil society. Finally, by analyzing the complex process of integration, this work will also improve policy mechanisms related to refugee crises experienced by other members of the European Union. In sum, this research frames a middle-ground of approaching the study of the economic integration of refugees. For clarity and flow, this chapter is divided into four main sections. The first discusses displays modes for integration and situates the Swedish 
approach, the second section describes the roles and resources of the state, the third theorizes the same for civil society, and the final section puts forth potential outcomes.

\section{Models for Integration and Labor Market Practices}

Approaches to and definitions of successful integration vary. Through a in depth survey of related literature and primary fieldwork concerning refugee resettlement in the UK, Ager \& Strang $(2008,169)$ identified four themes that determine successful integration:

Achievement and access the sectors of employment, housing, education, and health; assumptions and practice regarding citizenship and rights; processes of social connection within and between groups within the community; and structural barriers to such connection related to language, culture and local environment.

Given the complexity and inconsistent modes for determining integration (Robinson $1998,118)$, many now look to employment as a consistent indicator in the long road to becoming completely "integrated" (Castles et al. 2001). If for anything else, we may assume that employment should lead to a sense of autonomy and a sense of belonging. Theoretically, employment (or economic integration) should lead to other more nuanced types of integration.

Despite much of the debate concerning refugee resettlement, Article 15(1) of Directive 20133/22/EU, requires all Members States to ensure asylum seekers have access to respective labor markets not later than nine months after applying for protection. ${ }^{5}$ Conceivably, Member States may adhere to two broad approaches to refugee integration. On one hand, they may apply a less hands-on approach, or contrarily they

\footnotetext{
5 "Approaches towards the labour market integration of refugees in the EU," Eurofound, 07 January 2016, https://www.eurofound.europa.eu/observatories/eurwork/articles/industrial-relations/approaches-towardsthe-labour-market-integration-of-refugees-in-the-eu.
} 
may provide a lot of protection and assistance. Put differently, some states may be more restrictive (they are not allowed to work, and assistance is limited) while others may be more generous (full access to social insurances and equal rights as natives) toward their refugee populations (Jacobsen 1996, 655). Comparing how labor market access for refugees is legislated in various Member States, highlights the competing differences between these two approaches (restrictive vs. non). By doing so, we can begin to conceive why a common European asylum system remains out of reach.

Several Member States apply a more restrictive approach to labor market access. In Germany, for instance, one needs to receive refugee status before they can work. To provide those waiting a decision on their status with something to do, controversial "oneeuro" jobs were created. Asylum seekers work menial jobs (pruning plants, cleaning sidewalks, repairing bicycles etc.), for a little over one euro an hour. While many have called for a relaxation of asylum seeker labor policy, refugee access to the German labor market remains slow. There are several explanations for this, some of which are: 1.) priority is given to EU citizens; 2.) only certain professions can relax regulatory measures for the highly qualified and skilled refugees;3.) and validating foreign qualifications are slow. Other EMS (Denmark and Austria), are even more restrictive. In an attempt to motivate and expedite labor market entrance in Denmark, a measure was passed to reduce the amount of assistance refugees receive. In Austria labor market opportunities has been limited to certain types of employment: seasonal work in certain industries, non-profit work, and various kinds of self-employment. ${ }^{6}$

${ }^{6}$ Ibid, "Approaches towards the labour market integration of refugees in the EU," Eurofound, 07 January 2016, https://www.eurofound.europa.eu/observatories/eurwork/articles/industrial-relations/approachestowards-the-labour-market-integration-of-refugees-in-the-eu. 
Other Member States provide high-levels of assistance. These states typically offer full access to social assistance insurances and are less restrictive in allowing refugees into their respective labor markets. Valenta and Bunar (2010), define integration policies in Sweden and Norway as extensive state assisted programs. While Sweden has been characterized as generous, it is now moving more toward a more mixed-approach to refugee integration. For example, starting in June 2016, Sweden opted to rescind permanent residency. While refugees continue to receive the same social benefits and rights as natives, they are now limited to a three-year temporary residence permit. During this time, the new legislation mandates that they must find sustainable employment. In addition, during this period, they are not allowed to apply for family relocation. Onlookers often place Sweden under a "Scandinavian" umbrella, and assume approaches, practices, and policy are closely reflected throughout the Norden. However, as revealed in the Danish case above, and notably in Norway, where refugee reception is rather limited, this is becoming less and less true.

A challenge which seems to have developed in the Swedish case is as its labor market has evolved toward greater free-market principles and dealt with the challenges of globalization, its approach to refugee labor market integration seems to have not. Discussed in greater depth in chapter 4, while the state was able to sufficiently employ refugees throughout the 1970s up until the 1990s, it is no longer capable for doing so. Today, refugee labor integration is one of Sweden's and Europe's most pressing matters. This is visible in the rise of the far right during the most recent election cycle throughout the EU. As recent as June 2017, a poll by Statistics Sweden found support for Sweden 
Democrats garnered 18.4 percent of Swedish voters. ${ }^{7}$ While security is a major issue, much of the far-right rhetoric hinges on high unemployment among refugee populations.

In line with the most recent establishment policy, the central focus of integration is now employment. However, it appears the heavy reliance on a centralized approach is not sufficient for doing so in the present high-skilled, globalized, and private setting. Given many expect refugees will become permanent members of their given host society (especially when we consider the negative birthrates throughout Europe), the duty of asylum today is theoretically and even legalistically (according to the EU directive), much more than protection. Thinking more critically about potential requirements is essential to the wellbeing of each host's refugee population and consequentially to the overall wellbeing of their respective societies and the larger economic community (the EU).

In exploring this topic, we must first consider the needs of refugees upon their arrival in Sweden. It is important to note that conceptually, even though this research analyzes "economic integration," it is not economic policy alone that impacts new arrivals. One must also consider refugees' basic needs. These may include (but are certainly not limited to) food, shelter, immediate medical care, clothing, clean water, and additional support in caring for their young. This approach first assumes that everyone needs to become stable in terms of everyday needs and basic human security before they can begin to search for avenues of employment, or conceivably begin to seek out avenues and services to enhance their employability. Understandably, when outlining the

\footnotetext{
7 "Support for Swedish Government, Sweden Democrats Rise in Poll," Reuters, 1 June 2017, https://www.reuters.com/article/us-sweden-politics-poll/support-for-swedish-government-swedendemocrats-rise-in-poll-idUSKBN18S466.
} 
resources of the state, this work also takes into account the resources that the state offers asylum seekers before they become accepted refugees.

\section{State Allocated Resources}

Upon their arrival, the state offers asylum seekers certain resources to meet their most pressing needs. These services include food, shelter, and immediate healthcare, among other things. In addition, depending upon the time of the year, supplementary clothing may be made available, and for those with children, childcare may be provided. It is fair to say that the state has been successful in their subsidization of these basic needs. Some may point to the 2015 housing shortfall as a failure to meet the needs of incoming refugees, but it was short lived. To a large extent, sufficient standards for temporary housing and reception have been maintained. After their initial reception, refugees' needs transform and become more complex. As a consequence, these needs often become more difficult to meet. One reason for this is that people may carry with them a wide variety of human capital, and thus have very different capabilities and requirements. Evaluating abilities and matching skill sets with potential employment is a very complex and often slow process. This issue has persisted in Sweden since the 1990s with the arrival of refugees from the former Republic of Yugoslavia, and has since then only increased.

After asylum seekers have arrived in Sweden, applied for asylum, and accessed ways of meeting their most essential needs, the next theoretical phase is "rebuilding." This stage may be extremely difficult. For one, there is likely to be an indeterminable amount of time needed to adjust. Every individual has potentially had different 
experiences in their journey to Sweden. After this period of adjustment, assuming the individual is not under immense stress or suffering from trauma, they should be able to begin building skills such as learning the local language and engaging in supplementary education programs. Ideally, these will help the individual to gain the confidence and skills necessary to enter the labor market. In an attempt to meet these more complex and varied needs, policymakers have created programs and services such as Svenska för Invandrare (SFI, or Swedish for Immigrants) and other vocational services embedded in etableringsreformen. Conceivably, the state provides refugees with a wealth of resources.

In Sweden, the central government offers significant assistance to refugees seeking resettlement and integration. Historically, in Sweden the labor market integration of its refugee population has primarily been left to the state. As noted by Valenta and Bunar (2010), the two main pillars of integration are housing and employment. While integration measures have principally focused on facilitating employment, it was not until December of 2010, with the introduction of Etableringsreformen (Establishment Reform), that the focus shifted to labor market activities. This new initiative moved the responsibility of integration from municipalities to the state via the public employment service (OECD Report 2014). However, as shown by the existing data on unemployment and testimonials regarding how difficult some have found these programs to be, many existing state resources may not effectively be accessible to refugee groups.

According to Statistics Sweden, cited in a report by Radio Sweden, 1 of every 3 Syrians that arrived in 2014 had a university education. ${ }^{8}$ Despite attaining a high level of

\footnotetext{
8 "Higher Education Common Among Syrian Refugees," Radio Sweden, June 3, 2015. http://sverigesradio.se/sida/artikel.aspx?programid=2054\&artikel=6181412
} 
education, many still work jobs (if they are employed at all) that require only minimal skillsets (for example, in restaurants or other service roles). Thus, it can be assumed that many of the available employment options within Sweden's economic opportunity structure (including both public and private sector opportunities) may be highly dissatisfying to the refugee community. Aldén and Hammerstedt (2014) noted two potential reasons for this dissatisfaction. Like Scott (1999), these researchers found that the refugees they studied typically did not acquire their human capital in Sweden. In other words, while the refugees did have access to language classes and supplementary vocational education, their primary learning did not occur in the host country. Hence, they often lacked access to native networks.

Lacking key cultural-ties is potentially detrimental from both sides. Not possessing cultural similarities, may make it difficult to make new relationships, which may lead to different sources of income and preferential employment. Second, refugees have also reported high levels of labor market discrimination; a potential byproduct of cultural bias from native Swedes. Measures have been taken to help curb discrimination, such as the 2009 Swedish Anti-Discrimination Act, under the aegis of the Equality Ombudsman (DO), which provides new penalties for discriminatory acts. This legislation is an effort to deter discrimination and compensate those harmed by the offending act. In effect, individuals suffering from discrimination may file complaints with the DO and be represented in court free of charge. "In 2012, 1,559 complaints were received by the DO, representing a reduction of 20 percent compared with 2011, and 40 percent compared with 2010" (Farchy \& Liebig 2014, 13). Additionally, the government has also implemented a handful of measures to help refugees access employment opportunities. 
One example is the aforementioned etableringsplan, whereby the state has counselors develop portfolios and activities for refugees. Other services also exist, such as arbetsformedlingen (the public employment service), which helps all new migrants connecting with potential employers, at no cost.

Along with these far-reaching programs, since 2010, other more targeted programs have also been put in place. For example, one of these programs, the korta vägen course, was launched to fast track refugees with at least three years of completed college coursework. In an interview with The Locale ${ }^{9}$, Rami Sabbagh, a former financial analyst from Syria, discussed how he was able to find employment with Spotify, a technology company based in Stockholm. ${ }^{10}$ Nevertheless, it seems that for many refugees with higher levels of educational and technical skills, programs such as korta vägen are often hard to find and may not be as effective as hoped. For instance, Stefan Cavallius (2014) noted that "out of the 201 participants who attended the course from 2010 to 2013 , only about 15 percent have found work related to education." Evan Albadry, a former researcher and professor from Iraq, explained how it was completely through happenstance that he found the government's vocational program utländska lärares vidareutbildning (ULV) (which translates roughly to complimentary education for foreign teachers). It is clear that the state has attempted to provide refugees with access to goods and subsidized educational programs. However, these programs may be difficult to

\footnotetext{
9 "Syrian refugees speed into top jobs in Sweden," The Local Sweden, June 14, 2015. https://www.thelocal.se/20150614/syrian-refugees-take-sweden-fast-track

10 "Syrian Refugees Speed into Top Jobs in Sweden" http://www.thelocal.se/20150614/syrian-refugeestake-sweden-fast-track, accessed May 4, 2016.
} 
find. This begs the question: how can refugees gain access to these programs more swiftly? And what are the modes by which refugees do find these programs?

Because it may be difficult to gain access to the array of available resources available to them, a sense of dissatisfaction may permeate the refugee community. Consequently, a reduced level of trust toward the host government and society may evolve. One repercussion could be that refugees take it upon themselves to look for employment outside the opportunities provided by the state (Slavnic 2004). This reduction in trust could then curb their desire to integrate into the local community and labor market. As a consequence, many might enter into ethnically-based micro-forms of employment (Portes 1995; Hjerm 2004) or find other informal types of work (Khosravi 2012) such as those associated with the informal market. Notably, a large body of literature already exists on the issue of community diversification, multiculturalism, and segregation (Carlborn 2003; Andersson 2007; Kymlicka 1995, 2014). Within Sweden, some scholars (Linström 2006; Andersson 2007; Åslund 2007; Lindgren 2010; Andersson et al. 2010) are finding segregation is becoming more pronounced in suburbs surrounding large cities, such as Stockholm, Gothenburg, and Malmö; three areas in particular are Rosengård (in southern Malmö) Sodertalje (south of Stockholm), and Angers (a suburb of Gothenburg). Of the migrant areas, Rosengård and Sodertalje are the most well-known. In particular, both have experienced substantial social unrest, such as the riots in Sodertalje in May of 2013. Segregation often leads to lower education outcomes, reduced employment opportunities, and less interaction with the native population (Musterd \& Ostendorf 2013). While there are several other potential deleterious factors, these three alone will result in lower levels of inclusion. 
To summarize, the central actor in integrating refugees in Sweden is the state. From arrival to employment (or unemployment), the government offers direct contributions, as well as programs and services, to facilitate refugees forming new lives in Sweden. However, we seem to lack understanding in how refugees actually find their way into the labor market. While policies exist, and adapt with each crisis, we should refrain from taking their accessibility as a given. Put differently, regardless of the policies in place, extreme levels of unemployment still persist for non-native Swedes, especially refugees (Bevelander 2011; Lundborg 2013). To help uncover some of the associative issues and better understand how social capital influences the process, more research is needed on the role and resources of civil society. Additionally, the European welfare state model is known for its expansive programs; thus, we must also consider how certain policies may dissuade individuals from seeking employment and instead encourage them to rely on the state. To prevent welfare dependency among the refugee population, the distribution of direct cash transfers and in-kind benefits must be properly monitored (Vu 1990; Blume \& Verner 2007).

This is not to discount the utility of a strong social safety net. Determining how this welfare is allocated can be difficult, because there is no definite timeframe within which people are expected to become active in the labor market. Moreover, people arrive in the host country after a variety of different experiences, some more traumatic than others. Since one of the major prerequisites for asylum is to be actively fleeing conflict or direct threats of potential harm due to the political structure of the home country or social orientation of the individual, many refugees may not be mentally fit to move straight into gainful employment. Those who experience psychological or physical harm may have an 
even more difficult time integrating into a new society. Without question, there are a number of potential variables that surround each individual and affect their likelihood of eventual employment. Certainly, many of the answers to the complex question of refugee integration can be addressed via an analysis of the roles and social realities of civil society.

\section{Civil Society: Associational Membership and Social Networking}

While the primary actor facilitating integration in Sweden is the state, it appears additional help is needed. In theory, civil society provides information and networks (social capital) that either directly offer resources or provide information regarding resources offered by the state. Aside from direct involvement on behalf of the state, it is through social capital (Edwards \& Foley 1998; Woolcock 1998; Portes 2000) that resources can be accessed. In Sweden, civil society is often associated with associational memberships and voluntary organizations. In Andersson and Hoff's (2001) typology, associations are broken into a number of sub-categories, such as: housing and community, environmental, religious and moral associations, political associations, humanitarian, leisure and culture, and other associations. However, to a large extent civil society continues to be viewed as a realm dealing with social rather than economic issues.

To simplify and operationalize the role of civil society in relation to labor market integration, the primary resource can be seen as providing refugees with social capital. Several scholars have used social capital theory (Coleman 1988) to explain the evolution

of certain political and economic systems. Conceptually, social capital contains facets of social structures and promotes the actions of certain actors within those structures. "Like 
other forms of capital, social capital is productive, making possible the achievement of certain ends that in its absence would not be possible" (Coleman 1988, S98). Similarly, when examining Sweden, we find a plethora of local organizations that help refugees integrate into the labor market. By studying the utility of civil society for the refugee community in Sweden, researchers can more clearly understand how organizations and social networks at the societal level contribute to the economic integration of individuals and groups. Moreover, researchers should also be able to analyze outcomes at the macro level, as well as the micro (individual) level. As a point of clarification, studying social capital at the macro level gives insight into the evolution of the socialization and formation of trust between groups. In effect, it gives greater insight into the formation of the larger structure, community, or society. Micro-level analyses concentrate on individual outcomes (e.g., studying individual outcomes regarding how one uses a social network to gain access to other parts of society, such as with a new job). Notably, microlevel analysis gives insight into how the policies are carried out and sheds light on other factors which may or may not be shaping a refugee's integration experience.

Through various platforms, civil society organizations and individual actors are able to help bring about social capital, its main resource. Social capital may emerge via participation and through organizations (native and non-native) that may not consider themselves to be "economic" in nature, but that help refugees gain access to and understand the resources available to them. Put another way, many within civil society may not readily identify their organization or service as strictly "economic." Their role may be far removed from an actual transaction or direct employment. Nevertheless, as this framework assumes that the primary role of civil society is to provide refugees with 
social capital, researchers should view all interactions in socio-economic terms. If all economic activity is embedded in social relationships (Granovetter 1985; Portes 1995), then even something as far removed as sporting activities, cooking classes, or other community activities may indirectly lead to some form of employment. While the state puts mechanisms in place, it is through civil society that these programs are most often accessed. Notably, the policies and resources available to refugees are only as useful as they are accessible.

Despite their efforts, however, many incoming groups still remain marginalized and unemployed. In theory, one facet of civil society is to provide refugees with the social capital they need to integrate into their new society. This may be done through associational groups or via informal means and networks. Typically, we may think of this as pathways established through personal relationships or connections, either in existence prior to arriving in the host country or cultivated shortly thereafter. Both pathways, however, are linked to social capital. Nevertheless, there remain several competing arguments regarding social capital's utility. These include those who find social capital to be useful (Paxton 2002; Inkpen \& Tsang 2005), and others (Adler \& Kwon 2000; Adhikary \& Goldey 2009; Portes 2014) who find that social capital has a downside. This latter group argues that social capital may act as a barrier to social mobility, thereby dividing communities rather than uniting them, facilitating rather than reducing crime, and increasing the likelihood of educational underachievement (Aldridge et al. 2002). Portes and Landolt (1996) contested the then recent "enchantment" with the concept of social capital, which was theorized a potential cure-all for many social and economic issues. However, it seems there is middle ground as bridging and bonding are both 
recognized types of social capital. Because employment is often a result of relationships, then theoretically, we may assume inner-ethnic bonding is hypothetically inutile, or at least less useful than the latter form of the concept (bridging), which could lead to greater opportunity.

If social capital is the primary resource provided by civil society, then it must be researched to a wider extent so that we may more adequately understand its role in hindering or improving refugees' integration into the labor market. Civil society acts an intermediary between the formalized legal structure of the state and the informal sphere of social networks and associations (Lundberg et al. 2011). Networks are typically cultivated out of personal social relations, while associations are existing institutions or organizations already in place to help refugees.

It is well documented that the role of civil society in relation to the state is twofold (Mair 1994; Chambers and Kopstein 2005). It offers expert insight into policy formation, and helps carry out those policies once they have been approved. For refugees, civil society provides two types of resources. First, it offers access to goods similar to those provided by the state (for example, medical attention and necessary items such as clothing provided by groups such as the Red Cross). Second, it provides access to social networks that help newcomers settle in and provide them with information that might lead to employment, either in the native Swedish labor sector or non-native areas dominated by immigrant ethnic groups.

Based on a 2015 statement released by Sweden's government offices, it is clear that the state views civil society as an essential actor in the process of integrating refugees into the labor market. This brief release highlights how civil society already 
plays a large role in the Swedish culture, and that "many people do what they can to give new arrivals a warm reception." 11 However, I believe that through the study of social capital, civil society's role can be understood with greater precision. Even though it is clear that the state recognizes the utility of native and non-native civil society organizations (CSO) and social capital, the current body of research assumes that civil society is still not taking a direct, hands-on approach to ushering refugees into employment. A potential reason for the fuzziness around civil society's role in labor market integration may be based on cultural and/or psychological confusion. For example, many in Sweden may not view economic integration as the appropriate role of civil society, and the state may not be willing to relinquish the responsibility to private organizations, specifically local and ethnically-based establishments. Nevertheless, its role in direct outcomes remains insufficiently documented and the need for further empirical research is clear.

Separate from the state but linked to it, civil society in Sweden also offers a number of resources to refugees. While its role is not always linked to economic outcomes, this research hypothesizes that it is a vital aspect of refugees' economic integration. Importantly, participating organizations may or may not be native to Sweden. To clarify, native organizations may either be larger bodies such as Caritas, faith based organizations (FBO) such as Svenska Kyrkan (Sweden's national Evangelical Lutheran Church), or other ethnically-based foundations such as the Somali Information and

\footnotetext{
11 "Establishment of new arrivals to Sweden to be reformed," Government Offices of Sweden http://www.government.se/opinion-pieces/2015/02/establishment-of-new-arrivals-to-sweden-to-bereformed/
} 
Business Centre. Non-native organizations are often associated with large international bodies such as the Red Cross and UNHCR.

In sum, this research theorizes civil society's main role, whether through organizations or less formal routes such as family and friends, is to provide social capital. As noted previously, CSOs are either native or non-native organizations. While the more significant non-native organizations tackle large-scale problems abroad, native ethnic organizations theoretically have a more direct impact at the micro-level. This is because these types of organizations typically exist only for a particular group, while larger organizations usually function in relation to a specific issue. Thus, we may then assume that local ethnic organizations (up to a certain extent) and FBOs are better suited for cultivating social capital, whereas larger international organizations such as the Red Cross are more useful in addressing immediate needs. Along with some smaller groups such as Refugees Welcome, the Red Cross and Amnesty International have been visible at reception centers throughout Sweden. Accordingly, CSOs play various roles, some related to the duties of the state. In addition, because this framework assumes that it is through social capital that individuals and groups gain access to information allowing them utilize resources provided by the state, it is the native/ethnic organizations that are of primary interest to this research.

\section{Employment Outcomes: Private Sector, Public Sector, or Self-Employment}

As discussed throughout this chapter, the state and civil society jointly provide refugees with resources to help them navigate the process of integrating into Sweden's labor market. However, due to the high level of unemployment among refugees in Sweden 
(currently around 23 percent), my research argues that there is a gap between policy and practice. While the resources may exist on paper, they may not always be available to incoming groups.

Aside from individual reasons for low levels of integration (such as culture), this research highlights two larger, overarching causes for the current high level of unemployment. First, Sweden's economic structure has markedly transformed since the 1990s, reducing the state's ability to properly integrate its refugees (Korpi \& Tåhlin 2009; Schnyder 2012). Second, the sheer magnitude of the number of refugees arriving in Sweden is unprecedented. This work argues that Sweden should look to civil society to help address this conflict between policy and practice. Put another way, as Sweden becomes less state-reliant, more market-oriented, and the overall size of the refugee community increases, civil society should become an essential component in the process of economic integration. In theory, the state and civil society should work together to help bring the nation's refugees into the labor market.

For refugees, research suggests location and type of employment are correlated. One study found that refugees in urban, cosmopolitan city centers had greater access to private employment whereas those in rural settings had greater access to public provided forms of employment (Bevelander \& Lundh 2007). Though, as noted by the authors, one regional caveat with the lowest rate of employment are rural areas with high-density of human capital (e.g., university centers outside of major city centers). Considering the private sector, the theoretical framework assumes that there are three possible avenues for employment. Actors may gain employment in native firms, non-native (multinational) firms, or as or with entrepreneurial ventures within their own ethnic enclaves. In 
accordance with Article 45 of the European Union Charter of Fundamental Rights, every citizen of the Union is allowed to move and reside freely within the confines of other member states. This comports with the treaty establishing the European Community with the 'four freedoms' of movement (along with goods, services, and capital) [of] the free movement of labor" (Givens \& Luedtke 2004, 145). Ergo, in hypothetical terms, any EU citizen (or in the case of Sweden, resident) can currently establish an enterprise and employ refugees, so long as all of the legal strictures are met (e.g., appropriate tax requirements are met). Non-native firms are typically started by non-EU economic migrants, previous refugees who employ those in search of work, or EU member state citizens. To be concise, in the private sector refugees may theoretically become employed by already existing private firms, or, because of the conceivable difficulty in doing so, another viable avenue for refugees is to start their own enterprises (Waulters \& Lambrecht 2006; Sak et al. 2017). Ergo, if possible, entrepreneurship should help abate the high rate of unemployment among those who are either a.) dissatisfied with the employment offered by the state or other work obtained in the private sector; b.) merely unable to find any form of employment in their EU host society or ethnic enclave.

Conceptually, ethnic entrepreneurship, is rather straightforward. It is "a set of connections and regular patterns of interaction among people sharing [a] common national background or migration experiences" (Waldinger et al. 1990a, 112). As a potential outcome, ethnic entrepreneurship is essentially a space where refugees can find employment presumably via social capital (networks, family, friends, and communitybased organizations) and create industries based on the particular needs of the community (Hammarstedt 2001; Hjerm 2004; Pio 2010). The more well-documented formal 
outcomes of these types of entrepreneurial activities are restaurants, ethnically-oriented vendors, repair shops, etc., which fulfill locally-based demands. However, while welldocumented ventures operate within the legal boundaries of Sweden, the more likely outcome of entrepreneurship lies in the informal sector (Slavnic 2004).

The term "informal" was brought into academic literature in the 1970s (Hart 1973, 1985; Williams and Windebank 1999), who described it as the part of the labor force that operates separately from the formal market. He argued that informal networks are a paradigm within which many small, self-employed individuals operate. Due to legal issues surrounding many informal activities, it is difficult to access accurate data. Nevertheless, because it is a potential form of employment for refugees, researchers must make a greater effort to find ways of accessing such information and incorporating it into the larger discussion of refugee integration. If Hart is correct and many marginalized immigrants are finding their way to less formal industries, it is plausible that the data on unemployment for refugees in Sweden is incomplete. To put it another way, if refugees are gravitating toward the informal market then the current data on unemployment must certainly be considered incomplete. As it is very difficult to gather data on those operating outside of social convention and the rule of law. Large numbers of individuals working outside of the formal economy would be a significant issue for a country like Sweden that depends upon full employment to support its robust welfare state.

While private sector employment is difficult to navigate, the public sector is a bit more maneuverable and certainly better documented. Various forms of employment are available in the public sector. These range from low to high skill positions. Of course, these types of jobs may take longer to enter into, as there may be tougher points of entry 
rather than mere relational interactions visible throughout much of private enterprise. Namely, many individuals must fulfill routine integration programs such as language and other cultural courses (typically requiring a minimum of two-years, Wiesbrock 2011). Due to these more formal requirements, it is conceivable that the private sector may, overall, be more desirable.

Due to the many complications that refugees face, it is useful to assume there is a desirability factor towards more entrepreneurial routes of employment (Andersson \& Hammarstedt 2015). This may be true because refugees (and immigrants in general) have historically had a difficult time succeeding outside of their particular ethnic communities. Robert Putnam (2007) referred to this phenomenon as "hunkering down." If refugees are "hunkering down," researchers and policymakers must ask whether a truly multicultural approach is the most appropriate way to address labor market integration of the refugee population (Borevi, in Kivisto \& Wahlbeck 2013, 141). Based on data reported by the OECD (the unemployment rate for the foreign born rests at around 23 percent) and the formation of enclaves such as Rosengård, Sodertalje, and Angered, it is important to note that Sweden, to a certain extent, has become segregated (Andersson 2007; Åslund \& Nordström-Skan 2010; Grundström \& Molina 2016). Since this is a relatively recent phenomenon, its full weight and effect is not fully understood.

If Sweden is no longer as social-democratic as it once was (due to the liberalization of its market stemming from the broader effects of the international marketplace), and if Sweden is far more diverse (its foreign-born population currently sits at around 18 percent, making it one of the most diverse member in the OECD, Farchy \& Leibig 2014), then researchers must begin to reframe how integration for refugees is 
carried out in Sweden. In other words, will Sweden continue to be a state characterized by high levels of tolerance and liberal principles that respect the idea of groups being allowed to live in separate and distinct ways? Or will these Swedish characteristics of tolerance and openness eventually decline? Will its future look more like that of its neighbor, Denmark, and their mainland European neighbors? Will they ultimately represent a reality that aligns existing scholarship (Wigerfelt \& Wigerfelt; Malik 2015), who argue that multiculturalism has failed and instead leads to a more segregated society? Finally, with foreign-born unemployment at such high levels, is it safe to assume a widespread dissatisfaction within ethnic communities that will lead to further discouragement of refugees eventually entering mainstream society? We may assume higher levels of segregation to be one explanation for refugees not learning and incorporating Swedish-specific skills and adapting other cultural attributes (such as equality and respect for women's rights) into their daily lives. If these pervading issues continue to spread and if unemployment remains relatively high, then Sweden may become more segregated and move further away from its socially democratic foundation (Knocke 2000; Lindvall \& Rothstein 2006; Green-Pedersen \& Krogstrup 2008; Rydgren 2004).

Irrespective of the sector of employment, refugees' entrance into it is not as streamlined as many would expect. Public employment directly provided by the state is an effective measure; however, due to several tangential political and economic issues that have been evolving since the 1990s including the cutting back of public sector expenditures, such jobs may no longer be a readily available option. However, private sector employment, the more likely outcome for refugees, presents a multitude of issues. 
First, there is the matter of how private native firms interact with the refugee population. One must ask: to what extent do native firms interact with refugees? And how can Sweden, or any other country receiving high numbers of refugees, mend the gap between the human capital (e.g., education and cultural attributes) of the newcomers and the greater needs of society, and thus guide individuals toward means of achieving their full potential and meaningful employment? Lastly, since many will opt for entrepreneurship (Soininen 1999; Ålund 2003; Hjerm 2004; Andersson \& Hammarstedt 2015), what measures should be in place to help guide this process? How can the national and local governments, along with civil society, help refugees begin and maintain steady industry? In sum, each avenue presents researchers with its own new set of questions. Since the challenge persists in Sweden and certainly has increased with the most recent wave of refugees, to adapt to the presence of this group and aid them in the employment process, researchers and policymakers must first understand how the existing process leads to certain outcomes.

\section{Conclusion: Towards a Theoretical Middle Range for understanding the Economic Integration of Refugees}

This research offers a multi-level approach to analyzing the economic integration of refugees in Sweden. By understanding the transformation of the roles and resources of the state and civil society since the 1990s through a historical institutionalist approach (developed in chapter 4), this study offers one way forward for researchers to evaluate how the economic integration of refugees occurs in a domestic and European context. Put 
simply, the framework is situated around a single a priori regard: there is a vast difference between integration policy and practice. Irrespective of the existing legislation, resources are not always accessible or useful to incoming groups. Moreover, as popularized by Robert K. Merton, the outcomes may yield several unintended consequences such as segregation or welfare dependency (as seen in other studies previously mentioned). When studying labor market integration, it is essential that researchers consider an element not regularly accounted for by the state: the social relationships between individuals and the structure itself, otherwise known as the role of social capital. Accordingly, along with examining policy, social scientists should also evaluate the function of civil society and the embedded social relationships therein. These relationships often produce social capital and play a strong role in the integration process. Finally, by researching labor market integration through this tiered approach, researchers will gain insight into the meso (or institutional) level, as well as the micro (or individual) level.

To summarily illustrate my theoretical understanding of how refugees enter Sweden's labor market (as shown in Figure 1, below), I acknowledge that the state is the principle architect of Sweden's integration framework. Indeed, this is part and parcel of all European welfare states. However, when we take into consideration the reduction of the welfare state, informed primarily by the overarching narrative of the liberalization of the labor market and the economic transformations that took place throughout the 1990s, this work argues that the role of civil society has become more active in the process of labor market integration. It is within this theoretical intersection (below) that resources are accessed (where state policy collaborates with civil society, human capital is 
expended, and social capital e.g., new relationships are cultivated) and labor market integration takes place. In recent times, as the state is no longer as capable of integrating refugee groups as they once were, this framework assumes that while the state remains the primary facilitator of economic integration via the public employment service, the role of civil society is ever-increasing.

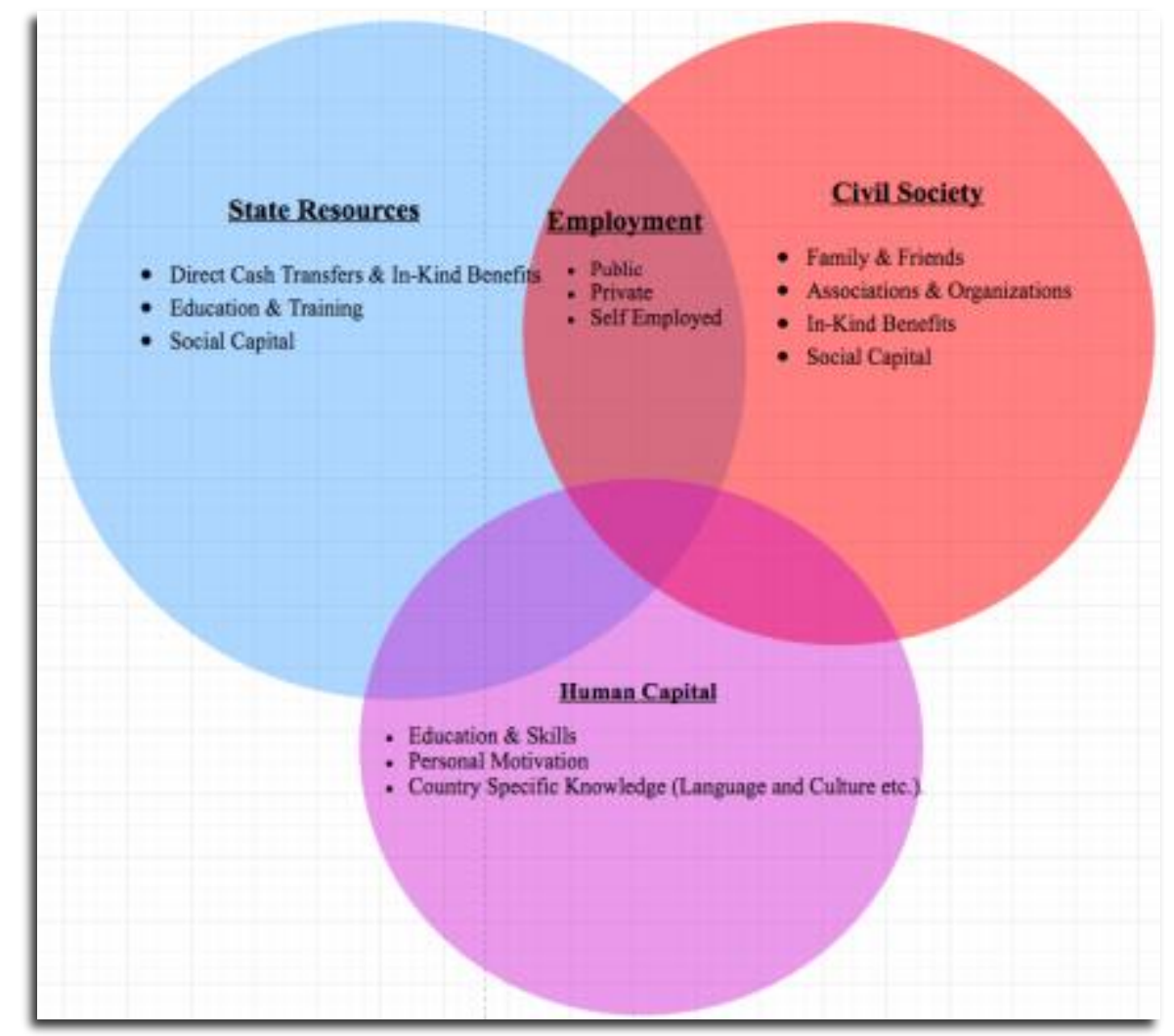

Figure 1Theoretical Resource Access \& Possible Outcomes for Refugees

To summarize the above, in order to properly conceptualize the labor market integration process, this research begins by examining refugees' arrival in Sweden. Following their initial reception, they must proceed to the next stage of resettlement. Aside from receiving the daily essentials, they must make a place for themselves in existing society. Becoming a contributing (autonomous) member to society is very 
important, not least for maintaining Sweden's expansive welfare state, but also to cultivate productive lives. Understanding and amending future policies and practices to efficiently introduce refugees to gainful employment is, arguably, the most essential step in the integration process. Refugees suffer from more than double the rate of unemployment among natives; thus, there is clearly a gap between policy and practice. By studying the roles and resources of the state and civil society, this research offers a novel theoretical framework for conceptualizing how refugees utilize existing policies, organizations, and other groups as they cultivate pathways to future employment.

In any system of democratic governance, public policy mechanisms (through the use of law) dictate the framework by which organizations, firms, and agents legitimately operate. Government-led initiatives, while at times effective, are in no way exclusively sufficient. The goal of this research is to bring together a study of policy and civil society as it relates to the integration of refugees into the labor market. For example, this work serves to create a space for considering how an individual's social network (civil society) might inform the individual of useful educational programs provided by the state that could, ultimately, lead to employment in a public or privately-run entity, or alternatively to a form of entrepreneurship. Throughout the process of labor market integration, these kinds of interrelated progressions play a significant role. Notwithstanding, they continue to be understudied. Past research has tended to observe the phenomenon of economic integration through the lens of a single academic field or specific body of literature.

In sum, this chapter offers an approach to theorizing about the labor market integration of refugees in Sweden. Its central claim is that in order for refugees to integrate into Sweden's labor market, they must access resources from both the state and 
civil society. Moreover, this work argues that due to the increased liberalization of Sweden's labor market and the increased number of refugees, the state can no longer provide for newly-arriving groups, at least not to the extent it did prior to the 1990s. This approach highlights that researchers should refrain from taking policies as given, and greater attention should be paid to the role of civil society and its resources. By conceptualizing economic integration via a study of the different roles of the state and civil society, we can begin to systematically uncover the existing pathways available to refugees within the Swedish labor market. The ultimate aim is to work toward improving the policy mechanisms already in place, and consider a wider array of factors when facilitating the economic integration of its refugee population. 


\section{Chapter 3. Researching Labor Market Integration of Refugees in Sweden}

In order to address the question of how refugees are economically integrated into the labor market in a European welfare state and shed light on factors that might facilitate the process, my research uses Sweden as a primary case study. This work applies a historical institutional analysis to sequentially present the transitions taking place since the 1970 s. Finally, this research also incorporates a number of interviews that were conducted in an effort to better understand the evolution of the process on three levels: first, from an elite, macro perspective (such as that of political representatives), looking at how policy formation has evolved in Sweden, second from the meso, civil society perspective and how its role has changed in the integration process, and third, from the micro perspective of the refugees themselves, to understand their experiences. To analyze the interview data, narrative analysis (NA) was employed.

The aim of this methodological approach is to uncover: a) what resources are provided by the state and civil society; b) how these resources are accessed; and c) how the roles of the state and civil society have transformed since the 1990s (the starting point of the welfare reform era), with particular emphasis on the active role of civil society in the process of integration. Fundamentally, the goal of my research is twofold. First, as seen in Chapter 2, this work constructs a historical institutionalist narrative regarding how Swedish integration policy has matured since its initial formation in 1975, with particular attention paid to the last 25 years when welfare reforms started to take place. This investigation fostered the theoretical assumptions outlined in Chapter 2, which argued that due to the transformation of Sweden's socioeconomic and political structure since the 1990s other actors, such as civil society, have begun to play a larger role in 
determining how refugees access resources and become integrated into the labor market. Correspondingly, this analysis placed special emphasis on the utility of social capital fostered through community networks and associational civil society groups. The overall aim was not only to understand what resources were made available and are currently accessible, but also to gather first person accounts of refugees' experiences in utilizing them. While it remains undetermined whether a small $n$ qualitative study can yield generalizable results (Checkel and Bennet 2012), it may be possible to use individuals as a proxy for others, or at least to provide individual or micro-level detail to the greater phenomenon under examination. Nevertheless, this work offers substantial nuance and a detailed frame of reference for understanding the situation in a "thicker" (Geertz 1972), more interpretive manner.

This chapter is divided into four sections justifying the use of different methods, from the more general to more the specific one: the case study, the historical institutional approach, data collection through ethnographic interviews and narrative analysis. The combination of these methods offers a comprehensive insight into the actual experiences of refugees and how they access essential resources provided by the state and civil society throughout their process of economic integration.

\section{Case Study Method}

This research utilized a primary case study to formulate an in-depth analytical approach to examining the economic integration of refugees. Yin (2013) argued for the appropriateness of case studies "in situations when (1) the main research questions are "how" or why" questions; (2) a researcher has little or no control over behavioral events; 
and (3) the focus of study is a contemporary (as opposed to entirely historical) phenomenon. All of these criteria apply to this research project, and in particular, its research design, which asks the following two questions: (1) How have the Swedish government and civil society approached the economic integration of its refugees over time? (2) How are resources accessed by the refugees themselves?

In addition to framing the research questions, the case study method can also "generate richly detailed, thick and holistic elaborations and understanding of instances or variants of bounded social phenomenon" (Snow and Trom 2002, 151-152). Sweden was chosen as the primary case because it is widely regarded as being at the vanguard of policy concerning equal rights, welfare, and humanitarianism, and is lauded for its openness toward other countries. For instance, in a 2015 article in the Telegraph, Sweden was referred to as "the most open country in the world." 12 As a result of its liberal approach, in 2015 it received the second ${ }^{13}$ highest number of refugees per 100,000 people (156,000 asylum applications or 1,600 per every 100,000 people), double the total number of Bosnian refugees who were allowed to emigrate to Sweden in $1992 .{ }^{14}$ Until 2014, the Bosnian wave in 1992 represented the highest number of asylum applications in Sweden. To a certain extent, with the closing of the Øresund bridge in January of 2016 and a new law that passed in June which reinstated temporary residency conditions,

\footnotetext{
${ }^{12}$ Fraser Nelson. How Sweden, the Most Open Country in the World, was Overwhelmed by Migrants. The Telegraph 12 November 2015

http://www.telegraph.co.uk/news/worldnews/europe/sweden/11992479/How-Sweden-the-most-opencountry-in-the-world-was-overwhelmed-by-migrants.html (accessed July 13, 2016).

${ }^{13}$ In 2015, Hungary received the highest number of first-time asylum applications per 100,000 people, with 1,770 out of every 100,000 (data provided by the Pew Research Center).

${ }^{14}$ Data provided by Migrationsverket http://www.migrationsverket.se/English/About-the-MigrationAgency/News-archive/News-archive-2016/2016-01-12-Nearly-163000-people-sought-asylum-in-Swedenin-2015.html (accessed August 1, 2016).
} 
Sweden has become now more restrictive. Nevertheless, the country remains comparatively open to those in need of asylum. Thus, Sweden is a critical test case for the rest of Europe. Despite the large wave of asylum seekers and irrespective of the strains put on the country (some of which are yet to be felt), Sweden continues to maintain an extensive welfare state and its primary goal of establishing equality among all of its residents and citizens. In other words, its openness, number of refugees, and approach to labor market access makes it a pertinent case for the rest of the EU.

\section{Historical Institutionalist Approach: Political \& Economic Institutions and their Influence}

A historical institutional approach is complementary to case study methods. Typically, "most HI [analyzes] the impact of variations in institutional forms and configurations on a particular outcome or set of outcomes" (Lieberman 2001, 1012-1013) over time. This method requires the compartmentalization of case studies into analytically significant periods (referred to as periodization). Periodization is the linchpin of practically all historical analysis. It provides a simplified depiction of relevant historical events or processes used to explain how certain institutions offer varying explanations for the outcomes of processes and phenomena (Katznelson 1997a). For this study, periodization is particularly useful as it separates distinct historical junctures of political, economic, and demographic alterations. These alterations provide insight into historical

contingencies which have impacted norms among political actors and altered the 
opportunity structure from its redistributive "third way," to a more liberal market economy.

Lieberman (2001) defined institutions "as the formal organizations and the informal but widely accepted rules of conduct that structure a decision-making or political process" (Lieberman 2001, 1011). This definition is intrinsically vague; it is left to the researcher to define institutions according to their specific research aims. For the historical analysis portion of this research, institutions are defined as the private sector and governmental policy mechanisms. Through the analysis of these institutions over time, the research highlights historical sequences which have shaped Sweden's approach to refugee labor market integration. This research adds to the body of HI literature which has already:

Cultivated deep insights into a wide range of issues. These include studies which pose questions about the sources of variation in labor policy, welfare policy, taxation, and state-labor relations across both time and space. (Lieberman 2001, 1011)

In this research, HI shapes the analysis of the various processes for integrating refugees. Methodologically, this separates the research into significant events called junctures (e.g., transition points in the economy, political shifts, and spikes in the number of asylum seekers). The historical basis of this analysis comports with those of many other "analysts [who] argue that once constructed at a moment in history, institutions typically endure for significant periods of time, influencing political dynamics and associated outcomes in subsequent periods" (Lieberman 2001, 1013). The fundamental idea expressed here is that institutions have long lasting effects to a degree that it is really impossible to "start 
from scratch"/ do something completely new, as every new influence is embedded in the historical layers of conventions and institutions.

Due to the long lasting political majority of the Swedish Social Democratic Party (SAP), and its influence on norms and socioeconomic policy design, a historical overview is well-suited for any study of Sweden. Pierson (2000), in particular, notes the strong influence of the Swedish Social Democratic Party (SAP) and the development of path dependent policy outcomes in Sweden. Other scholars, for example Tilton (1990), have found that historical developments in Sweden tend to be long lasting and foundational for explaining future policy decisions, their outcomes, and the greater social order. ${ }^{15}$ Tilton posited that to understand what shapes contemporary outcomes in Sweden, researchers should take into consideration the political and economic developments taking place throughout the $20^{\text {th }}$ century, and specifically the rise and sustained dominance of the SAP since the early 1930s.

Historical institutionalism strives to make assessments with as much specificity as possible about the types of changes created by institutions and other influences. "Institutions constrain and refract politics but they are [never] the sole 'cause' of outcomes. Institutional analyses do not deny the broad political forces that animate various theories of politics...Instead, they point to the ways that institutions structure those battles and in so doing, influence outcomes" (Thelen and Steinmo 1992, 3). This approach has been used for analyzing the effects of global financial rifts and humanitarian crises (caused by war, sectarian violence, and other forms of persecution)

\footnotetext{
${ }^{15}$ The SAP in Sweden is unique, and is viewed by many as the most successful postwar socially democratic society to exist (Hicks 1999). It is important, therefore, to take into consideration its historical foundations when studying any element of its society, especially the duty to provide asylum and labor market integration.
} 
on Swedish political formation, as well as on integration policy and the tangential outcomes for its refugee population since the 1970s (Eastmond 1998; Peters et al 2005; Eger 2009; Lidén \& Nyhlén 2014)

Thus, it was important to situate the study of the economic integration of refugees, particularly in Sweden, within a context conceptualized via important historical moments. To analytically piece together the evolution of this integration, the HI approach necessitates the separation of the research into corresponding decades (particularly since the 1970s). By subdividing Sweden's history into economically and politically significant moments in time, greater insight is available into why and how certain policies came about. In other words, HI offers a necessary descriptive element to understanding the evolution of this process, particularly when faced with novel circumstances such as the more recent refugee waves, where causal explanations require data that does not exist yet (Gerring 2012). By analyzing the key players, political settings, economic conditions and critical junctures during each decade, comparisons can be drawn and insights gleaned from historical developments, as well as potential explanations for present realities. Due to the required level of detail and added structural value, $\mathrm{HI}$ is a well suited methodological approach for analyzing the Swedish case.

To understand how integration policy and practice has transformed and analyze how it impacts today's refugees (and in particular, how resources are accessed), this research employed what Lieberman (2001) referred to as the institutional change strategy of periodization. For comparative work, an analysis "of sequences of events, processes, and outcomes provides opportunities to generate much higher levels of confidence that observed correlations are truly causal relations because, by definition, causes must 
precede effects" (Lieberman 2001, 1017). As compared to other methodological approaches, and "unlike in statistical analyses in which estimates of causal effects are presented as numerical parameter coefficients, comparative historical analysis is generally presented in terms of narrative description of the nature and magnitude of effects, often through the specification of counterfactuals" (Lieberman 2001, 1018). The approach yields narrative-based accounts of sequence; thus, narrative analysis was an appropriate next step in this evaluation of labor market integration. Importantly, while HI seeks to establish a certain degree of causality, I believe that accurately determining causality in the social sciences is extremely improbable, if not impossible (Babones 2013, 133). Instead, by embedding the study of refugee labor market integration in a historical institutionalist case study, the study provides insight into possible solutions and correlated knowledge of how policy has evolved and why some refugees are successful, while others are not. Notably, the junctures are: 1970-1990, 1990-2010, and 2010-present day.

\section{Data Collection-Sampling, Interviews, and Limitations}

This research project selected participants according to two basic characteristics: first, by country of origin, and second, an arrival date between 2000 and 2015. When possible, participants were also selected based on gender. To achieve a balance between groups, I intended to interview an equal number of participants per group (e.g., 10 Iraqis, 10 Syrians, 10 Somalis, and 10 Afghans). However, due to certain limitations of time and funding, while an even balance of the sample in terms of origin and arrival in Sweden was strived for, it was not perfectly achieved. Gaining access to insular groups such as 
refugee asylum seekers can be time consuming and difficult. Therefore, I formulated an initial approach that relied on purposeful (non-probability) and snowball (chain referral) sampling. At the outset, I selected participants from specific ethnic backgrounds as well as approached organizations that work directly with refugee communities. After establishing a relationship with a representative member specific to a particular group or through an actor working in civil society, to gain additional participants, I employed a snowball sampling technique. As explained by Coleman, snowball sampling is "a method used for sociological research [that] allows for the sampling of natural interactional units" (1958; Berg 1988, 1). Via snowball sampling, the body of participants builds from one interview to the next. In essence, each participant identifies new "respondents who [are] then used to refer ... other respondents" (Atkinson and Flint 2001, 1). In other words, I used initial participants to acquire other contacts useful to the study.

Along with interviews carried out with refugees, from late fall 2015 to October of 2016, 25 semi-structured interviews were conducted with representatives of CSOs in an effort to shed light on their role in the process of refugee integration. First, I attempted to contact potential participants via email. However, this method was not particularly effective. Next, I began to seek participants in person by visiting CSOs or ethnic organizations of interest. After contact was made, I scheduled a formal interview for a later date. These interviews usually took place between three days and two months after first connecting with the organization. In the interviews, I asked about how representatives worked with refugees, what the most significant resource they found they provide refugees, what their most significant challenges were (both for them and their 
projects), how they felt the role of civil society had adapted over the last two decades, and how they viewed the most recent legislative changes.

For a small-n qualitative approach, purposeful sampling is an appropriate method for selecting initial candidates. The approach allows the researcher to select informationrich cases to study in depth (Patton 1990, 169). As stated by Palys, the "general principle" of purposeful sampling is to "think of the person or place or situation that has the largest potential for advancing your understanding and look there" $(2008,698)$. This research method operates under the general principle that not all participants will be of the same value to the research goal. "One well-placed articulate informant will often advance the research far better than any randomly chosen sample of 50" (Palys 2008, 697). Several different types of purposeful sampling exist; their usefulness depends upon the researcher's goal. Criterion sampling was selected for this study. It involves selecting cases or individuals who meet a certain criterion such as having a particular life experience, in this case, arriving in Sweden as a refugee, being of a certain gender, having a certain level of human capital (e.g., educational attainment and work experience) or serving as a representative of an ethnicity, organization, or political party.

The utility of purposeful sampling is that it acknowledges subjectivity is inherent to qualitative research. This allows the researcher to select particular participants, rather than forcing them to adhere to an arbitrary requirement of "randomness." Purposeful sampling also allows the research to select organizations based on specific characteristics. In this research, organizations were selected based on the community they served (e.g., Somalis, Iraqis, Syrians, Afghanis, etc.). Purposeful sampling was used to establish a 
basis for reaching out to particular individuals, and snowball sampling brought about additional participants for interviews. The two sampling techniques together allowed for the research to grow and adjust as needed. I conducted semi-structured interviews for each participant selected. Semi-structured interviewing allowed for the collection of indepth details of experiences and outcomes.

Gaining access to useful groups proved to be challenging. The primary way was through contacts within Swedish communities or organizations that worked with the refugee populations. These were based primarily in Skåne (Malmö, Lund, and Helsingborg), Stockholm, or Växjö. Aside from finding participants through personal interactions and participation in local activities (such as meeting people at local cafes, and other non-formal interactions e.g., social networking through Meetup and Facebook groups), organizations offered greater access to groups that might otherwise have been difficult to reach. This does not mean that other contacts were not utilized, such as those gained through personal experience, but the use of organizations proved more systematic.

For the selection procedure of CSO representatives and policy elites, I proceed through the fieldwork in a hierarchical fashion. I began by contacting individuals at the organizational level (CSOs), and gained individual contacts to CSO representatives as well as asylum seekers/refugees from there. To access members and other participants, I contacted organizations throughout Sweden (Malmö, Stockholm and Växjö). The organizations chosen were either representative of a particular political party or known for their work with the refugee community (such as Yalla Sofielund, Open Skåne, and Somali Business Center). In terms of choosing political parties and state representatives, participants were selected with the general goal of obtaining an expansive overview of 
the different political factions in Sweden. I therefore, approached an MP from each of the eight parties represented in the Riksdag (Sweden's Parliament). In addition, I reached out to other state organizations visible in the labor market integration process, such as Arbetsförmedlingen (Public Employment Service), ALMI (a state-run business development and microloan agency aimed almost entirely at the refugee community), and Migrationsverket (Sweden's Migration Board).

For participant selections within the refugee community, my intention was for this to be as ethnically diverse as possible, and thus the basis for the study included Iraqis, Syrians, Somalis, Afghanis, and Pakistanis in roughly even numbers. Of course, this was dependent upon their accessibility. Since this research was a small $n$ qualitative study, the saturation was not very large. Guest, Brunce, and Johnson (2006) found saturation occurred in the first twelve interviews in studies using non-probalistic techniques and meta-themes become present in as early as six interviews. Because the level of diversity among the sample size, the total number of interviews directly with refugees was 45 . In addition, my research included 20 interviews with representatives within civil society and 5 additional interviews with political elites and state run organizations, for 70 interviews altogether.

During this process, three difficulties presented themselves. First, gaining access to individuals was difficult, largely because one must first establish trust, but also because any discussion of employment can often be sensitive. Second, the language barrier presented several difficulties. While there are indeed many refugees who speak Swedish or English, there are many who speak neither. Therefore, in some instances, a translator was used in the interview process. The third challenge was targeting unknown 
elements. It was often not possible to know specific qualities of individual refugees prior to conducting an interview. For instance, prior to an interview, it is often not possible to not know when the refugee arrived, what level of education they have, or even the specific country they came from. While snowball sampling does help one gain additional contacts, it is often difficult to ask the liaison to find people with specific particularities. Despite these challenges, non-probability sampling is useful for this study and has been successfully practiced by several scholars, in a variation of studies and fields (Guest, Brunce and Johnson 2006; Tongco 2007). For example, Ager, Ager and Long (1995) used purposive sampling techniques to study the differences in the experiences of Mozambican women and men in refugee camps in Malawi in the late 1990s, with a particular focus on the impact of assistance policies and programs. In addition to Ager, Ager and Long (1995), several other studies have relied on this technique to select the individuals most useful for study (Spring et al 2003; Colic-Peisker and Tilbury 2006; Ives 2007; Redwood-Campbell and Thind 2008; Kalengayi et al. 2016). Although nonprobability samples are less likely than probability samples to be representative, they are useful for researchers with limited resources, and in particular for studies that face difficulties identifying members of the desired population, or when one is conducting exploratory research (Adler and Clark 2014).

\section{4a. Semi-structured Interviews}

Many scholars have classified "the narrative interview" as a qualitative research method (Hatch and Wisnieswski 1995; Riessman 1993). "It is considered a form of unstructured, in-depth interview with specific features" (Jovchelovitch and Bauer 2000, 4). While the 
interview process for this research followed the basic premise of unstructured interviewing (e.g., open-ended questions), it relied on a semi-structured approach that helped guide the interview with some initial, structured questions that provided background details on the informants (their country of origin, how long they had been in Sweden, their level of education, and their current occupation). The overall questionnaire design emphasized open-ended questions that elicited information (narrative and experience) that would otherwise not have been available through more structured interviews (Drever 1995). At the same time, this process retained a certain amount of structure to keep the interviews as efficient as possible. Importantly, it was through these open-ended questions that the refugees were able to provide their narratives. Notably, as described by Fylan:

Semi-structured interviews are simply conversations in which you know what you want to find out about. [They may] vary tremendously. At one extreme the questions are very simple and the order of questions easily adhered to. At the other, the questions can be very open, and the conversation can take many directions before all the areas you want to address are covered (2005, 64-65).

More specifically the questions posed to refugees asked very basic, yet essential questions, such as: when did you arrive and are you employed, as well as more open questions such as: What has been your biggest challenge in Sweden? What is has been the most important resource for integrating into Sweden? Where have you received the most help from (social networks, the state, or from organizations)? Do you find the system to be navigable (e.g. are the resources provided by the state and civil society accessible?) What are your future aspirations for life here/do you plan to stay? Different questions were posed to political elites and civil society representatives. For example: Do you find the available information and resources from the state and civil society as 
accessible to refugees? How has the role of civil society, in the process of labor market integration, changed since the 1990s? What have been some of the major factors influencing policy change? How do you find the state is currently managing the current crisis? What are your views on the latest policy revoking permanent residency? Using a semi-structured, open-ended approach gave structure to the conversations, yet at the same time, allowed respondents to speak openly and add insight which may not have been specifically requested by the question itself.

While similar in its narrative perspective, the interviews conducted with elite stakeholders were more structured. The goal of the refugee interviews was to tease out how they actually accessed the integration resources made available to them by the Swedish government. The elite stakeholder interviews, however, were different. While the questions were still semi-structured and open-ended, the aims of the questions were focused on institutional characteristics. Instead of addressing individual processes and resource acquisition, they dealt with how integration policy had evolved and the system was viewed in macro-terms. In other words, they were designed to analyze the interviewees' views of the transitions in policy and practice in relation to the transformation of the economic atmosphere. These elite stakeholder interviewees were accessed through purposeful and snowball sampling, but it was through these elites, especially those working in civil society, that many of the refugee interviewees were acquired. Thus, they were the first point of access. Overall, semi-structured interviews result in thicker, richer data for use in determining how interdependent processes functioned to illustrate how in Sweden the integration process has evolved and how some have accessed resources in a more private and less supply-oriented form of integration. 


\section{Narrative Analysis: Open Discourse for Deeper Insight}

Narrative analysis is complimentary to HI and case study methods, in that it adds depth and narrows the frame of research questions. How has integration policy in Sweden shifted since the 1970s, in response to a more liberal economic structure? How are resources accessed by refugees in Sweden? How do non-state, non-refugee actors participate in this process? What are some explanations for the current levels of economic integration? While the case study positions this research and the historical institutional approach offers a macro-overview of the historical developments that influenced the subject outcomes, the narrative analysis allows for the analysis of the recorded interviews and helps develop a comprehensive account of past and current events.

Researchers using narrative analysis -also referred to as narrative inquiryfundamentally believe that all humans engage in storytelling (the recounting of specific events that shape their current attitudes toward a particular political system and society). Developing and interpreting narratives has long been an integral part of social scientific inquiry. Roland Barthes and Lionel Dusit noted that "narrative [began] with the very history of mankind; there is not, there has never been anywhere, any people without narrative, all classes, all human groups have their stories, and very often those stories are enjoyed by men of different and even opposite cultural backgrounds" $(1975,237)$. It is through narrative that individuals reflect on their personal interpretations of social and political relations.

At its core, "narrative is ... a basic and universal mode of verbal expression" (Smith 2000, 327). For researchers, it permits a holistic approach to analyzing discourse, 
while preserving context and particularity (Riessman 1993). In research, it is often used as a method of inquiry into the human experience (Freeman 2015, 22). Narratives "are loosely defined as a sequence of events, experiences or actions with a plot that ties together different parts into a meaningful whole" (Feldman et al. 2004, 148; Czarniawska 2004). They emerge orally or through the written word (Linde 2001; Elliot 2005; Coffey and Atkinson 1996). The examination and construction of narratives produces a form of detailed knowledge of life experience. By recounting the experiences gathered through interviewing informants, narratives help to make sense of the complex nature of important events. The methodological approach is well suited for research seeking to gain deeper insight into how people engage with societal constraints (for example, how refugees succeed or fail at entering Sweden's labor market). Language allows for the study of social phenomena by introducing how the world is accessed through verbally constructed practice.

Through the use of narrative, this research utilizes first-hand refugee accounts, "story-like constructions containing description, interpretation, emotion, expectations, and related material" (Harvey et al 1995, 3). Narrative inquiry emphasizes the importance of subjectivity and rejects the "objective," "realist," "positivist-empiricist," and "mechanistic" assumptions of traditional science that pervade the social sciences (Gergen 1985; Mishler 1995; Polkinghorne 1988; Riessman 1993). It remains in line with Foucault's (1980) point, that truth-seeking and establishing "absolutes" are not the aims of this type of research.

Narrative analysis rests on the primary assumption that subjectively recounting specific events will provide information not otherwise available. Over the last two 
decades, narrative analysis in the social sciences has grown (Webster and Mertova 2007). Based upon the work of C. Wright Mills (1951), narrative analysis allows for researchers to build an understanding of an individual's personal history and the social structure with which it interacts. Narrative analysis begins with the belief that individuals make sense of their reality by articulating the events that shape their lives. People live surrounded by their experiences, as well as the experiences of others. It is up to social science researchers to systematize and make sense of these expressions, to better learn about the core experiences. As described by Somers $(1992 ; 1994)$ and Andrews et al. (2013), narratives are ontological conditions of social reality.

In sum, the narratives of individual experiences of refugees entering Sweden's labor market and those from civil society representatives and policy makers, which allows for less polished, yet more personal and reflexive responses, serves as an appropriate analytical method for gaining deeper insight into and interpreting the effects of institutions. Like other qualitative approaches, narrative analysis does not set out to provide sweeping generalizations; instead, as articulated by Andrews et al. (2015), the mode of inquiry strives to interpret the worldview and meanings of the storyteller (e.g., the refugee). Accordingly, the method sets out to serve several functions. To begin, narrative provides meaning and coherence to, and perspectives on, experience and social tradition (Bruner 1990). Next, it constructs a personal knowledge (Daiute 2013), which includes an individual's expression of identity (McAdams 1993; Miller 1994). After this, it may also bring about an organizing principle for human action (Polkinghorne 1988). Lastly, the methodology is well suited for a study of labor market integration as it is 
reflective of social constructivism (e.g., Gergen 1985) and an interpretative approach to culture (e.g., Geertz 1973).

Polkinghorne's work on understanding narrative inquiry and configuration in qualitative research is a useful entry point into the narrative mode of analysis. Polkinghorne remarked, "narrative reasoning operates by noticing the differences and diversity of people's behavior. It attends to the temporal context and complex interaction of the element that make each situation remarkable" $(1995,6)$. Accordingly, the goal of the narrative mode of analysis is to configure "the data into a coherent whole" (Polkinghorne 1995, 15). Like Polkinghorne (1995), the aims of narrative research in this study were to uncover themes, relationships, and commonalties among refugees, as well as produce in-depth knowledge and particular insights into their unique experiences entering Sweden's labor market. In particular, the research was interested in gathering perspectives based on age, time of arrival, and gender. This was done to gain insight from the varying perspectives on the utility of social capital. This was done to better understand what may impede refugees from developing useful relationships. Creating a narrative from the data requires assembling the events, actions, and other data to form a coherent plot. For this research, the narrative weaves together the story of individual experiences and pulls from that story a discussion of how resources were accessed by refugees.

Schütze $(1977 ; 1983)$ proposed six steps for analyzing narratives. This process notably has a strong semblance to coding (Strauss \& Corbin 1990). First, the researcher should create a high-quality transcription of the verbal material. Second, the text must be separated into indexical and non-indexical material. Indexical material directly references 
"who did what, when where and why, while non-indexical statements go beyond the events and express values, judgements and any other form of generalized life wisdom" (Jovchelovitch and Bauer 2000, 10). Non-indexical statements can be categorized into two-types: descriptive and argumentative. Descriptive statements explain how experiences are felt and the values and opinions attached to them. Argumentation is reflective, returning to the events that took place and attaching them to concepts and theories. The third component asks the researcher to make use of all of the indexical information and analyze the ordering of events; Schütze referred to these outcomes as trajectories. In the fourth step, the non-indexical aspects of the text should be analyzed as "knowledge analysis." After carrying out this knowledge analysis, operative theories must be constructed that facilitate the understanding of the informant. Step five calls for the clustering and comparison of individual trajectories. In the final point, through case comparison (between groups, genders, and human capital), individual trajectories are put into context and similarities and differences of outcomes are discussed. In this research, the interviews were first conducted and then transcribed. Quotes are used throughout the analysis to show how refugees accessed resources in a transformed Sweden, but there no significant coding was applied. Rather, the narrative quotes were carefully selected to identify the order in which refugees accessed particular resources (i.e., "resource use" was situated within the broader context of their story).

While secondary sources were helpful in piecing together a macro-interpretation of how the institutional process of integration has matured, interviews were used to gather deeper, thicker details of how individuals actually experienced the process. Instead of sheer volume, similar to large $n$ studies, this research used the interviews as a way of 
gaining deeper insight into the actual experiences of refugees and to better understand the transformation of the practices and policies from the view of elite stakeholders (Swedish MPs and representatives at CSOs).

\section{Potential Limitations \& Criticism}

Similar to other qualitative research, the study's sample size is not large. While it is possible to look at the participants as representative of the refugee population and their particular ethnic communities, the study's results cannot be generalized (Hamel et al 1993). Nevertheless, this is not a major limitation; a large $n$ quantitative approach may offer greater generalizable claims, depending upon the type of data one seeks. Hence, this research will complement existing quantitative studies on labor market integration in Sweden. In particular, it offers a strong focus on the refugee community and the growing body of literature on their integration experiences. In simple terms, generalizability is the degree to which findings may be universalized to represent the entire population and not just the study group (Polit and Hungler 1991, 645). Nevertheless, qualitative studies are somewhat generalizable. For instance, by studying refugees from a particular country, we may be able to gain insights into how immigrants with similar backgrounds and circumstances also enter the labor market.

Using an historical institutionalist approach created some limitations. While the research looked at the evolution of refugee integration since the 1970s, the individuals chosen for interviews were limited to those who had arrived after the year 2000. For several reasons, interviewing individuals from earlier generations of refugees would not have been as useful. It is difficult to determine the accuracy of memories ranging back 
more than two decades. Interviewees of this sort might not have been able to offer as much clarity as desired. Hence, interviews of earlier generations were not likely to be as revealing as those from more recent groups of refugees.

Narrative analysis is often criticized for being too closely linked to history; while interesting, it does not provide causal explanations. In other words, it is viewed as a mere representation of reality and not, in and of itself, a form of social analysis (Somers 1994, 614-615). These criticisms, however, do not take into consideration the necessary understanding of how the social realities described in narratives translate into action (e.g., how resources are actually accessed by the refugee community). Narrative inquiry is well suited to addressing the intricacies of refugee experiences and the complex process through which they access the labor market, and in particular, their personal experiences and interactions with existing structures such as their social/ethnic communities and "native" Swedish society. Effectively, narrative analysis allows one to study the intersection between the personal and the political (Riessman 2005). As a complement to HI, it lends itself to get at a deeper analysis of the lived (labor market) integration experience.

\section{Conclusion}

The analytical framework and method described above provides a comprehensive approach to addressing the research questions set forth in this dissertation. For the exploration of refugee labor market integration, this study utilizes the case of Sweden. Embedded within the case study framing, HI, semi-structured interviews, and NA are also employed. While the research body was built on a platform of secondary data, it also 
includes semi-structured, in-depth interviews to gather the information necessary to analyze the outcomes for individual refugees. This project seeks to provide a thickly detailed interpretative analysis of the refugee experience, and more broadly to gather representative data that can be used to understand the situation in Sweden from both the elite level and the micro, individual refugee perspective. Through this methodological approach, this research sheds light on how the policies and overall mode of integration have changed over the past twenty-five years for the refugee community: namely how actors outside the state, and particularly those in civil society, participate in the process of economic integration in an ever-changing state-guided "Swedish" model. 


\section{Chapter 4. Refugee Integration: A Historical Analysis of Norms and Trends Impacting Refugee Integration in Sweden}

Using a historical institutional approach, this chapter analyzes the economic, political, and social transformations in Sweden since the 1970s. Operationally, the work situates integration policy according to three distinct historical junctures. The first is from 1970 to 1990, when the state was largely responsible for the integration of its refugees. The next stretches from 1990 to 2010, as the era of reform: when market liberalization took effect. The last, from 2010 to the present, is marked with the introduction of the etableringsreformen (establishment reform), the period of reform categorized by labor market integration.

Using available secondary source material (Statistics Sweden, the OECD, ILO, MPI, and research conducted by the Pew Research Center), this chapter offers a descriptive interpretative approach to the development of refugee integration in Sweden. As John Gerring has noted (2012, 722), “descriptive argument describes some aspect of the world ... it aims to answer questions about [a] phenomenon or set of phenomena. Descriptive arguments are about what is/was." For example, over the past four decades, descriptive arguments have been used to answer questions such as: What are some aspects that have shaped and impacted refugee integration policy in Sweden? As a matter of course, this work constructs a descriptive foundation for more contemporary empirical research analyzed in chapters 5 and 6 concerning both meso-level issues (e.g., the role of civil society), and micro-level aspects (such as the perspective of the refugee). Organizationally, the chapter is split into three parts. First, it puts forth the norms of 
Sweden's contemporary social democracy, as led by Sveriges Socialdemokratiska Arbetarepartiet (the Swedish Social Democratic Workers' Party, or SAP). This section highlights the unique ideological aims of folkhemmet (the concept of the people's home), folkbildning (informal adult education), and studieförbunden (study associations). To conceptualize the evolution of Sweden's refugee integration policy and to shed light on how civil society has evolved in the refugee integration process, a historical overview of folkhemmet's normative foundation is useful. Namely, informal adult education and study associations (direct byproducts of Sweden's social democratic development and folkhemmet) seem to now play a central, yet rather unexplored role in the refugee integration experience. Understanding the historical development of Sweden's social democracy, the ideological aims of folkhemmet and the evolution of its integration policy is necessary for exploring the contemporary process of refugee labor market integration in a more capitalist oriented welfare state. Subsequently, the chapter is divided into six sections. The first section gives a historical overview of the evolution of the SAP. Attached to the SAP, section two outlines the historical importance of informal education. Sections three, four and five provide a descriptive overview of each juncture discussing a description of the economic, political, and demographic particularities of each period. Section six looks at present challenges, specifically those attached to educational attainment and unemployment.

In sum, the goal of this chapter is to cultivate an in-depth historical understanding of the political, economic, and societal evolutionary facets surrounding the labor market integration of refugees in Sweden. As Tilton (1990) explained, "no adequate account of modern Swedish politics can neglect the ideological dimension" (Tilton 1990, vi). 


\section{Generating Norms: Establishment of the SAP, Folkhemmet and Equality and}

\section{Openness for All}

This section describes the framework of Sweden's social democracy. Structurally, it is divided into two main segments. First offered is a brief historical overview of what social democracy means in the Swedish context. Second is an exploration of the concept of folkhemmet (the people's home) and how its normative principles extend to current refugee integration policy.

\section{1a. The SAP: Sweden's Social Democracy}

In political theory, social democracy is a multi-faceted ideological platform that takes into consideration the welfare needs of its people. Often, it is associated with varying degrees of universal social insurance for all citizens, or in the case of Sweden, its residents. ${ }^{16}$ In Scandinavia, universal welfare extends to all. At its core, social democracy strives to quell the social injustice associated with purely capitalistic systems of governance. The roots of Sweden's approach are historically rooted in the foundation of the SAP.

A historical background is particularly useful for this topic. The SAP emerged at the end of the nineteenth century. The party elected its first representative to Riksdag (i.e., Parliament) in 1896. Later, under Prime Minister Hjalmar Branting, the SAP came into power. From 1932 until 1976, with the election of the Thorbjörn Fälldin (or Centre

\footnotetext{
${ }^{16}$ For a concise overview of different types European welfare regimes in a comparative context, see Berman (2009); for a similar discussion in a purely Swedish context, see Sainsbury (2006). For a concise overview of Esping-Andersen's famed work Welfare, see Arts and Gelissen (2009).
} 
Party), the SAP oversaw Swedish politics, a run of four decades (except for 101 days in 1936, when the Farmers' League gained control of the position of Prime Minister). From the 1930s onward, the SAP's "dominance at the polls depend[ed] heavily upon its close ties with the powerful blue-collar trade union confederation, LO" (Tilton 1990, 2). To foster the support of its members and remain politically significant, the LO has sought to provide all individuals with schooling (a position supported by Sweden's press and institutions), and actively interact with its members on a regular basis (Linton 1985). Put another way, the LO has aggressively engaged with and encouraged the education of its members. The SAP would remain in power until the mid-1970s.

After "a brief interlude of bourgeois coalition governments, the [SAP] returned to power in 1982 and handily won the elections of 1985 and 1988" (Pontusson 1992, 305). Up until the end of the 1980s, Sweden remained largely unaffected by any global conservative or neoliberal trends (Pontusson 1992). It was not until the end of the 1980s that major political and economic transformations began to take place. As late as the beginning of 1989, Sweden's social democratic political party appeared to be as strong as it had ever been; no other administration had ever had its level of success (Tilton 1990). By the end of the 1980s, however, a housing bubble was emerging. Due to rising housing costs, easy access to credit, and a reduction in competitiveness (Englund 1999), Sweden found itself on a path to reform. Carl Bildt, head of the centrist Moderate Party, handedly won the election in 1991. With "37.6 percent of the national vote, [the SAP] did worse than they had done in any election since 1928 (from 1932 through 1988, the Social Democrats' share of the national vote never fell below 41 percent)" (Pontusson 1992, 305). The loss in 1991 marked for the first time since 1928 that the leader of the 
conservative-led coalition ascended to Prime Minister. The newly-elected government implemented widespread reform. The conservative coalition ruled from October 1991 to October 1994, after which time the SAP returned, holding office until 2006. In the fall of 2006, the Moderates resumed as the leading party, holding control until 2014. Since then, the SAP has retained power. In order to regain voter confidence, the SAP has become more right-of-center than at any previous time (Kuisma \& Ryner 2012).

In sum, since the 1930s, Sweden has been heavily influenced and governed by the Social Democratic Party. However, by the end of the 1980s and as globalization gained pace, Sweden began to move toward market reform. During that time and into the current day, the LO has remained strong. For instance, in the 1990s, the LO represented over two million workers - roughly 90 percent of the blue-collar workforce - and close to 50 percent of the entire labor force in Sweden (Tilton 1990). While the Moderate Party now plays a greater role and the Sweden Democrats, Sweden's relatively new far-right party, have become more popular, Sweden is still the foremost representative of social democracy in Europe. One explanation for its resiliency is folkhemmet, Social Democracy's social project that emphasizes the family, good homes, and a stable community (Rojas 2005). To highlight its significance, the next section discusses folkhemmet.

\section{The Role of Folk: A Home for All}

Folkhemmet (the people's home) is one of the most significant elements of the SAP's ideological framework. It is a philosophy whereby the state provides for the wellbeing of 
its people. Albin's classic January 1928 statement on the concept espouses its core components:

On special and indeed on everyday occasions, we often speak of society - the state, the municipality - as our common home, the people's home (folkhemmet), the civic home ... The foundations of the home are community and the sense of belonging together. The good home knows no privileged and disadvantaged, no favorites and no stepchildren. None there looks down on any other, none tries to gain an advantage at the expense of others, the strong [do] not oppress and plunder the weak. In the good home, equality, consideration, cooperation, helpfulness prevail. Applied to the great home of the people and citizenry, this would signify the breaking down of all social and economic barriers which now divide citizens into privileged and disadvantaged, rulers and dependents, rich and poor, propertied and impoverished, exploiters and exploited (Hansson 1982, pp. 227-234).

His words mark the beginning of a new social experiment and are an embodiment of the Swedish norms we know today: "from class to people, from confrontation to consensus, from revolutionary class struggle to folkhemmet" (Rojas 2005, 22). With his speech to the 1932 Party Congress, Ernst Wigforss ensured this ideological and economic transition away from concentrating on the means of production and instead on its outcome. "The ideal image of the home and family, the community of close relations or of the small world, was elevated to a model for the whole structure of society" (Rojas 2005, 23).

Sweden's Social Democratic party created the world's most comprehensive welfare state (Tilton 1979; Lindbom 2001; Bergh 2004). The political compromise between the Farmers Party and the SAP spurred on by the Great Depression produced a new ideological dimension that persists today. Illustrative examples include folkbildning (informal adult education) in the form of studieföbund (study associations), and study circles (smaller informal meetings organized by study associations). Within the existing literature, in relation to refugee labor market integration, the role of informal adult 
education has not been extensively analyzed. When discussing its wider political implications, its effects are often left noticeably untouched (Larsson \& Nordvall 2010). Below is a discussion of the role of informal adult education that highlights this unique aspect of Swedish civil society and lays a groundwork for future research into this practice's role in refugee integration.

\section{2a. Study Circles: Cultivating Interest and Solidarity}

As informal adult education seems to be a key component to refugee integration, hence an overview of its origin is needed. For analytical purposes, this creates situational framing and provides greater nuance for thinking about its utility in an increasingly diverse population, in highly-advanced, yet regulated welfare states. Put differently, understanding the evolution of informal adult education in the Swedish system is vital to understanding its role in the current Swedish integration framework (e.g., what its resources are and its utility under the present establishment scheme).

Folkbildning was first popularized by Oscar Olsson at the turn of the $20^{\text {th }}$ century. Olsson created the first study circle as a part of the International Order of Good Templars. Since 1912, the state has funded folkbildning. Uniquely, while it is sponsored by public funds, it is run separately from the state; hence, the informal educational sector is by and large a part of civil society. The effectiveness of this informal learning is directly tied to political developments in the $20^{\text {th }}$ century. By the late 1920 s and early 1930s, the utility of study circles to educate and empower farmers and the working class was evident. The rise of the Farmers Party and their influence on Swedish politics (such as with the 1932 Compromise) provides clear evidence of this. 
Sweden's tradition of study circles was formed "outside of the state— by social movements that in the start conflicted with the dominant culture and power structures" (Larsson 2001, 200; Blid 1989). Objectively, a study circle eliminates hierarchy and privilege, and promotes democracy. Larsson's (2001) research furthered the notion of democracy as a process of education. He offered seven key points:

1.) Equal participation;

2.) Horizontal relations;

3.) Deliberation;

4.) Knowledge that informs a standpoint;

5.) The recognition of diverse identities;

6.) Internal democratic decision-making; and

7.) Actions to form a society (201)

The facilitation of learning and access to information is fundamental to democratic practice, as well as the integration of immigrants.

In the past, study circles were the only education available to older individuals, and they allowed for social ties to be developed between groups. Studieförbund is an area in the public sphere (Habermas 1964) whereby individuals form a group to study a topic of their preference (with a few exceptions, such as with groups seeking to incite hate speech), without any outside influence or critique from the state. Larsson $(2001,203)$ highlighted four common rules. First, there is no formal examination process. Second, participation is completely voluntary. Third, each study circle is expected to include between five and 10 persons and must have a leader, often a participant or expert. Fourth, the circle usually meets once a week for three hours, for 10 to 15 sessions. They can be 
valuable to Swedish residents, as well as newcomers looking to gain friends (social capital) or simply develop new knowledge (cultural or for technical). While study circles have been accessed by native Swedes, there is still no systematic application for refugees. A gap in communication between their utility, the public employment service run integration program and other actors in civil society persists.

Irrespective of the incongruity in Sweden's integration platform, it is known that study circles play a large role in the formation of Sweden's democracy. Several other studies have examined the utility of informal learning networks and their ability to foster common interests, as well as their educational benefits for Swedes (Blid 1989; Larsson \& Bron 2001; Larsson \& Nordvall 2010); however, few have specifically addressed refugees. For example, study groups may be particularly useful for newly-arriving women. Notably, Larsson (2001) emphasized a visibly higher level of participation among women Dewey argued in Democracy and Education (2004) that to engage isolated groups, we must work towards cultivating common interests. It is through the formation of these horizontal relations that citizens can build their social capital (Valtonen 2012) and cultivate weak ties (Granovetter 1973; Portes 1998). Instead, they bring about commitment at the grass-roots level, from its citizen base. Folkhemmet and study circles continue to prove useful to the wellbeing of Sweden's social democracy. Given their known efficacy in educating and uniting native Swedes, we should expect that they will continue to become a greater part of the refugee integration platform.

The political developments discussed above foster two issues fundamental to an analysis of the sociopolitical and economic developments in Sweden. First, much of today's ideals are rooted in the early philosophical foundations of the SAP, particularly 
the idea of equality. Second, folkhemmet continues to play a prominent normative role in how Sweden views asylum-seekers and its refugees. For instance, even with the high level of refugees reported through 2010, Svallfors (2011), in his analysis of the Swedish Welfare State Surveys, found support for the claim that the welfare state remains strong. And during the 2015 Refugee Crisis, Sweden remained the most open European hoststate and the only member to offer full-rights and access to employment to newly confirmed refugees (this has however, since changed). Notwithstanding, moving forward its foundational principles of maintaining full-employment, equality of opportunity, and support of an extremely generous welfare state may be difficult to sustain (Steinmo 2002; Rothstein 2014; Schall 2016). Yet despite several transformations, the apparatus of its expansive welfare state remains intact, for now.

In sum, any analysis of how Sweden's approach to integrating refugees into the labor market and how its policy concerning this process has advanced over time must first take into consideration the development of its socially democratic norms. Understanding the normative directives and general evolution of the SAP - namely, the aim of establishing equality for all - gives insight into the psychosocial makeup of Sweden's integration policy. To provide greater context and further information on how these ideals have been challenged by the effects of globalization, the next section divides the reception of asylum-seekers into three policy junctures: 1970 to 1990,1990 to 2010 , and 2010 to the present.

To explore its evolution in greater nuance and detail, these following sections chronologically presents the socioeconomic and political characteristics of each of three junctures. The first ran from 1970 to 1990, wherein Sweden experienced a relatively low 
number of refugees and efficient labor market integration led by the state. The second juncture, from 1990 to 2010, is considered the era of reform. This juncture is characterized by market liberalization and increased crisis levels of asylum-seekers. Finally, the third juncture marks the beginning of the most recent era of integration policy reformation: etableringsreformen. It is typified by an emphasis on labor market integration. In terms of organization, each section discusses aspects specific to a particular group of refugees (e.g., size of group and type of employment, etc.), existing policies, and the greater economic environment (Sweden's opportunity structure, as well as the global financial regime).

\section{1970-1990: The Birth of Integration in the Swedish Welfare State}

Toward the end of WWII, Sweden began to accept refugees. In 1942, it began by admitting small numbers of Norwegians fleeing Nazis. Shortly thereafter came Estonians and other Baltic citizens, and finally Danish Jews. "As Sweden began to build its social democratic state after the war, the ready acceptance of refugees became a symbol of the national commitment to moral principle" (Traub 2016). Central to this was the aim to provide refuges with the same extensive social benefits that Swedes received themselves (e.g., housing, health care, high-quality education, maternal leave, and unemployment insurance). In the aftermath of World War II, there were between 11 and 20 million displaced persons falling into this category globally. In Sweden, the demand for labor could not be met by domestic manpower. Hence throughout the 1950s and 1960s, labor was imported from Finland, Italy, Yugoslavia, Greece, Turkey, and Germany. By the mid-1960s, however, the Labor Union began to worry about the future effects of labor- 
based migrants. Symbolic of their concerns, in 1972 - the same year the Ugandan-Asians (Ugandans of South Asian descent expelled by Idi Amin) began arriving - the Swedish Labor Organization (LO) recommended ceasing the importation of labor. The Social Democratic government, with its historic ties to trade unions, complied with this suggestion (Westin \& Dingu-Kyrklund 1997).

Before the 1970s, immigrants to Sweden typically came as labor migrants. Like many other Western European countries, after the war, Sweden sought workers; thus, the vast majority of émigrés heading to Sweden were those in search of work (UNHCR Research Report 2012/2013; Bevelander 2009). As export industries began to flourish in the early 1950s, companies began to recruit foreign labor. In 1954, the Nordic region formed a common labor market, sparking mass migration from Finland to Sweden. In the 1950s and 1960s, 550,000 Finns migrated to Sweden (Bijvoet 2002; Westin 2006). Notably, there are two important takeaways from Sweden's early postwar era. First, the nation never initiated a guest worker plan. Instead, they operated under the assumption that those arriving in Sweden to work would stay and become citizens. Accordingly, they were given permanent residency. Second, the government and the LO agreed that cheap labor was not the goal of this program. Hence, it was agreed that all coming to Sweden would be given equal access to rights and social insurance. In addition, prior to the 1970s, the majority of all immigrants coming to Sweden were typically from Finland and Germany and had prearranged employment. As many believed integration would happen organically, no formal integration policy existed at this time.

By the end of the 1960s, regulated immigration was introduced. From that point forward, anyone wanting to come to Sweden would have to prove they had an offer of 
employment and appropriate housing. "Labor immigration continued through the 1960s but decreased when, in 1967, the migration rules were changed, sparked by criticism from LO. It became more difficult for non-Nordic residents to receive residence permits" (Eklund 2003, 8). Prior to granting a labor permit, Sweden's migration board (Migrationsverket), newly formed on July 1, 1969, would perform a labor market assessment. If the assessment determined there were unemployed local individuals with the skills needed to perform the job, then no permit would be issued. Earlier in 1967, the approach to labor migration had been drastically reformulated. By the time of the 1973 oil crisis, many Western European countries had also begun to curb the recruitment of foreign labor. In 1972, Sweden officially ended labor migration from non-Nordic countries (Bucken-Button 2009).

Pushback from the LO came twenty years after the end of the World War II. Even at this early point, the effects of globalization were beginning to be felt. For any astute observer, this was shocking because:

In the early 1970s Sweden was one of the most economically and technologically advanced countries of the world, second only to the USA. It was a well-developed welfare state striving to reduce economic and social inequalities. The Swedish model was admired internationally since it seemed to combine the best of the twocompeting economic and political systems, a system of state planning within a market economy, and liberal democracy housing a well-developed corporate structure in which major interest organizations had considerable stake in political power (Westin 2002, 10).

It was becoming clear that in this context, Sweden would need to initiate new policies more attuned to a more globalized reality.

Before the instillation of Sweden's integration policy, all newcomers were granted equality through a list of basic rights. Many thought that no other additional 
formalized measures would be needed (Cnossen 1964; Oberg 1974; Schiff 1974). Rather, immigrants would organically enter their new societies, without any strict requirements such as supplementary vocational classes or language acquisition. This was largely the case because historically, labor migrants coming to Sweden had arrived with appropriate skill sets and relatively similar cultural and even linguistic backgrounds (most notably, surrounding Nordic Member States and Germany, Brochmann \& Hagelund 2012). In the 1970s, when Sweden first formed an integration policy, unemployment rates hovered around 2 percent (Ginsburg \& Rosenthal 2002,2). Solidarity and equality where the catchwords of the day. Put differently, it was an easier time to be generous. However, as newcomers began to shift from labor migrants to refugees, bringing their family members along through a mechanism of family reunification, Sweden entered a new phase of a more formal approach to integration.

As a result of the increased levels of asylum-seekers, Sweden developed a new stance toward its integration policy. The foundation rested on three fundamental tenants: equality (i.e., new arrivals were to be guaranteed the same rights as the native population), freedom of choice (all new arrivals could choose whether or not to adopt the local culture), and cooperation. The latter highlights the need to build social bridges and links (Valenta \& Bunar 2010, 468, original cite; Eastmond 1998; Doraï 2003). In addition to these three tenets, the new policy called for tolerance. This meant that integration measures were not substantiated on policies of assimilation, but rather on a view of multiculturalism. Notably, the 1970s marked the beginning of Sweden bringing non-EU refugees into Sweden. It is important to note that in the 1970s, the number of refugees remained relatively low. There was a broad low-skilled labor market sector which 
employed Swedes and new immigrants. There was not a big rift between natives and immigrants (Aldén \& Hammerstadt 2014). Regardless of their education, merits or skills, the National Board of Labor provided refugees with jobs in an industry. Turners and machine operators were other jobs in demand, as is illustrated in Westin's (2002) study of Ugandan-Asian refugees (Ugandan exiles of South Asian decent) in Sweden.

With the inception of roughly 800 , and subsequent family reunification totaling approximately 1000 Ugandan-Asians, Sweden received its first wave of non-European refugees. Initial newcomers were placed in camps for medical checkups and basic language training. Subsequently, they were bustled off to various towns. Within a few months, almost all able-bodied men and quite a few women were employed working on assembly lines. Westin (2002) traced the individual migratory careers of Asian-Ugandans in Sweden, primarily in the municipality of Mariestad, where much of the community eventually resettled. Every newly arriving Ugandan-Asian entered the labor market in the same way. "Regardless of people's qualifications and experiences from Uganda, the Swedish labor market authorities treated the Asians as though they were only unskilled laborers" (Westin 2002, 7). In answering the question of how these refugees managed to successfully integrate into Sweden, Westin pointed to the factor of time. He noted that Ugandan-Asians comprised the first non-European refugee group to be accepted in Sweden. Those who arrived in later stages typically remained in low-skill factory work employment.

Comparatively, Chilean immigrants who began arriving no more than a year after the Ugandan-Asians, had a much more difficult time integrating (Mella 1990). Mella (1990) noted that the Chileans were often only willing to settle in major cities and 
because many of those arriving were young academic hopefuls that thought the Pinochet regime would not last long, they were often unwilling to settle for these types of jobs. Lundberg (1989) similarly highlighted the relative freedom of university studies which allowed them to participate in resistance politics while in exile. Between 1973 and 1989, Sweden took in a total of 18,000 Chilean exiles. While some Chileans did successfully integrate into Swedish society, large numbers returned to Chile (Klinthäll 2007). Comparably, the Ugandan-Asians did not believe they could return in the foreseeable future. This lack of hope, enabled them to settle more efficiently, despite being less educated than the Chilean group. While the Chileans preferred to remain in larger, urban settings, Ugandan-Asian refugees, were willing and preferred to relocate to smaller towns. Westin posits, that it was this willingness to move to medium-sized industrial settings afforded them more opportunities. In smaller communities, refugees could more efficiently learn and become familiar with the inner workings of Swedish society, and access the local structural configurations. Also, timing was in their favor.

When they began to arrive in the early 1970s, there was a high demand for unskilled labor. They did not have to go through any long-term period of unemployment, as many of the later generations of refugees did. Also, steep language requirements associated with more recent policy and lengthy labor market training programs did not supersede the primary objective of employment itself. Irrespective of any dissatisfaction with low-skill factory work, this type of rural and factory based employment is typically understood as a point of entry (Westin 2002, 8). The 1970s marked the beginning of the common era of asylum in Sweden. During the two decades leading up to the 1990, Sweden received comparatively few refugees. In addition to those from Uganda, Other 
groups who came in the 1970s included individuals from the Middle East. These were primarily Christian Orthodox Syrians and Kurds from eastern Turkey, Iran, and Iraq. Due to changing conditions, both local and global, Sweden's integration policy would continue to evolve in the 1980s.

Beginning in September of 1980, with the eruption of the Iran-Iraq war and the subsequent destabilization of the region, many began to flee the Middle East. In the 1980s, 7,000 people from Iraq and 27,000 people from Iran received residence permits to live in Sweden as refugees. Due to crises throughout the Mideast, Sweden began to receive even larger waves of Iranians and Iraqis. By the mid-1980s, the number of asylum-seekers from Iran, Iraq, Lebanon, Syria, Turkey, and Eritrea was on the rise throughout Western Europe. Notably, however, by the late 1980s, many began to have their applications for refugee status rejected. This was because the Swedish Immigration Board (the predecessor of the Swedish Migration Board) had begun to find that many of those arriving were not actually fleeing persecution.

In accordance with the Social Services Act (1980), registered aliens received access to the same social welfare benefits as Swedish citizens. Moreover, state policy during this time dictated that each refugee go through a certain series of programs provided by the state. These were intended to lead to eventual employment. In addition, during the 1980s, Sweden integration policy is characterized by its "Whole Sweden" program. Instead of refugees having a say in where they would live, refugees were placed throughout the entirety of Sweden (Ekberg 2004). In theory, this seemed like a productive way of dispersing newly-arrived groups throughout the country. Unfortunately, the outcomes were not as hoped. Many refugees were placed far away 
from industrial areas, and thus found themselves isolated from the native population. Ergo, the probability of bridging with local communities was limited and jobs typically offered to newly arriving refugees were visibly reduced.

Regardless of mandated municipalities, throughout much of the 1980s, Sweden's economy remained visibly healthy. Unemployment rested at around 2 percent. By the end of the decade, it had dropped to nearly 1.5 percent (data provided by Eurostat). However, Backström noted that "wage formation functioned badly, fiscal policy was unduly weak, and this was gradually compounded by structural problems" $(1997,131)$. An eventual crisis was looming. In 1985, with a move toward credit deregulation, monetary conditions became more expansionary. Easier access to credit led to a rise in personal debt. From 1985 to 1990, the GDP ratio for private sector debt grew from 85 percent to 135 percent. Also during this time, housing prices increased by a total of 125 percent. In effect, a speculative bubble was created (Backström 1997, 132). In addition to the expansionary shift towards easy credit, inflation throughout the latter-half of the 1980s led to an erosion of its competitiveness and an overvalued currency. Ultimately, this led to a reduction in Sweden's exports. These factors combined with ever-increasing housing prices and decreasing competition brought about an eventual crisis.

Throughout the 1970s and 1980s, Sweden saw its tax burden increase from an average European level to the world's highest. All provisions within the public sector expanded and controls on the labor market contracted. For example, one such shrinkage occurred through the introduction of collective employee investments funds. This "transfer[ed] ownership in all listed companies to ... union-controlled funds" (Fölster \& Kreicbergs 2014, 3). Throughout the 1980s, real income stagnated and private sector job 
creation came to a visible halt. Additionally, from 1970 to 1990, Sweden's GDP per capita among OECD countries fell from $4^{\text {th }}$ to $14^{\text {th }}$. Unrest and uncertainty overtook the public discourse. By the end of the 1980s, "there can be little doubt that economic issues were the primary concern of voters" (Pontusson 1992, 306). The growing bubble, decrease in household purchasing power, reduction in overall competitiveness, and augmented impact of globalization (soon to reach its full force in the 1990s) increased the pressure for reform. It was in this environment that in the $1980 \mathrm{~s}$, the government orchestrated the integration of its latest refugees.

By the end of the decade, the situation was much different. A state-driven model began to gesture towards more market-oriented practices. Public consensus began to demand higher levels of competitiveness. Thus, there was political pressure to begin moving toward a more privatized network. The new model relinquished previously stateowned and operated industries to private firms to increase competition. While Sweden began this transformation in the 1980s, it was not until the 1990s (with the onset of the financial crisis) that the overall direction of its economic model could be seen. Indeed, such a drastic move toward privatization and increased flexibility of its labor market, as well as the rise of uncertainty for native Swedes, has continually affected the evolution of its labor market and undoubtedly altered what is available, how hiring practices are carried out and ultimately how refugees become employed.

\section{1990 to 2010: The Era of Reform}

The 1990s saw reform of the "Swedish model" (Blomqvist 2004). As noted above, for roughly seven decades, the controlling party in Sweden was most frequently the SAP. 
This changed with the election of Carl Bildt in 1991. At the same time, the eruption of war in the Balkans produced the largest wave of refugees ever to arrive in Sweden. The country received 100,000 Bosnians during the 1990s, as well as 3,600 Kosovo Albanians. ${ }^{17}$ In 1992 alone, more than 84,000 persons sought protection in Sweden. Per Statistics Sweden, between 1989 and 1993, Sweden received a total of 208,700 asylumseekers, of which 115,900 (56 percent) came from the Former Republic of Yugoslavia and 43,000 (21 percent) were from the Middle East. At this time virtually all applications were approved (Westin 2006).

With this large intake of refugees, Sweden began to face new challenges to its well-intentioned goal of full employment. At the beginning of the 1990s, the unemployment rate skyrocketed. "Between 1990 and 1993, unemployment increased from 1.6 percent to 8.2 percent ... For five successive years in the mid-1990s, official unemployment was stuck around 8 percent" (Holmlund 2003, 1). Sweden's opportunity structure had now drastically changed. "In part due to increased automation and efficiency, industrial-sector employment [declined] since the 1970s, while jobs in the service sector ... increased" (Fredlund-Blomst 2014). Throughout the 1990s, due to globalization and market reform, Sweden became an increasingly more private, marketoriented economy (Blomqvist 2004; Bergh \& Erlingsson 2009). Requiring refugees to find other paths to employment than those traditionally provided by the state. In addition to the rise in unemployment, the country also began to face new challenges with regards to uniting its communities.

\footnotetext{
${ }^{17}$ Numerical data were provided by Sweden's Government Website on Immigration and Emigration.
} 
One of the primary goals of integration policy reformulation in the 1990 s was to stymie segregation. Soininen remarked:

To counteract the exclusion of immigrants from the labor market and increasing segregation in society, 'integration' [was] identified as the solution. As a result of the parliamentary review of immigrant policy in the 1990s, a new integration policy was introduced and the immigrant minister was renamed the integration minister (Soininen 1999, 692).

Shortly following the large influx of refugees (as shown in the figure below), it became clear that Sweden's reception mechanisms were to be put to the test. Prior to the 1990s, the integration policy in place was not comprehensive. In 1994, at the peak of the crisis in the Balkans, 40,994 asylum-seekers from the former FRYM arrived in Sweden.

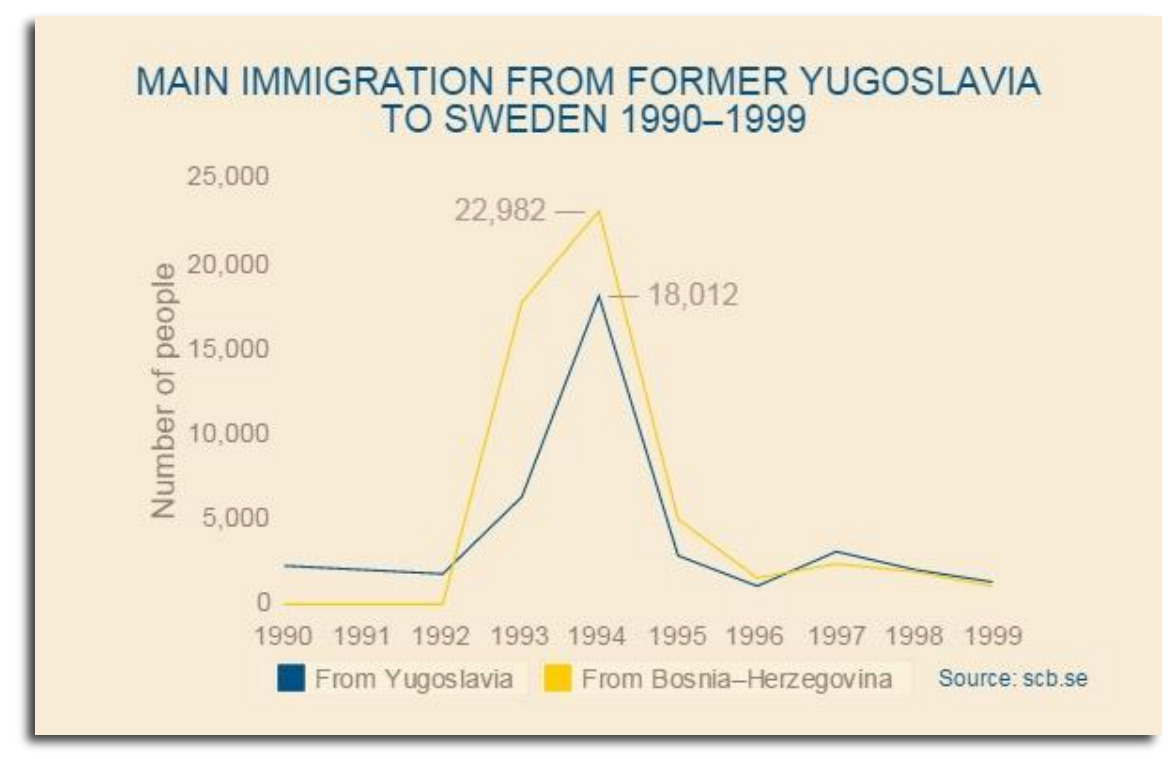

Figure 2Main Immigration from Former Yugoslavia to Sweden 1990-1999

As a mode of processing, at the beginning of the conflict, refugees from Bosnia and, later, Kosovo, were collectively granted "temporary protection." This was true throughout Scandinavia. This system of temporary protection, however, had some major downfalls. For instance, once the protection period ended, refugees were expected to return to their native country or apply for asylum on an individual basis (Koser \& Black 
1999; Brekke 2001; Berg 2002). Newcomers were not encouraged to learn the language or devote themselves to learning the skills and cultural knowhow needed to properly integrate into their adopted country. Thus, making them less competitive in the increasingly liberalized labor market.

While Sainsbury (2006) noted that temporary residency was eventually offered to some refugees, provisional permits remained in place for some from Kosovo and Albania. The decision to create the category of temporary residency remains contentious, because receiving nations cannot forecast the length of ongoing conflicts. Consequentially, immigrants unable to register as permanent residents are not entitled to universal social insurance benefits (Prop 1993/94, 94), nor may they feel encouraged to take steps necessary to integrate (e.g., acquire country specific skills and for relationships with native residents). Notwithstanding, at this time the management of refugees was split into two separate groups.

The first [were] those from Bosnia and Herzegovina (over 66,000 persons) who were granted permanent residence permits on humanitarian grounds under Chapter 2, Section 4, sub-section one, paragraph 2 of the Aliens Act (1989:589), as a result of the Government's guiding decisions in Cases Reg. 11 and Reg. 13 on 21 June 1993. The second group [were] over 5,000 Bosnian refugees with Croatian passports who, on 5 May 1995, were granted a time-limited residence permit under Chapter 2, Section 4a, of the amended Aliens Act pursuant to Act 1994:138. 3 (Dacyl 1999, 173).

Non-Croat Bosnians were granted permanent residency, while those from what was perceived as a more stable zone within the conflict were only granted temporary residency (Koser \& Black 1999, 533). On 10 October 1992, visa requirements for Bosnians seeking to live in Sweden were lifted (a choice that has since been rescinded). 
Because of the drastic increase in applications for asylum, the immigration board decided to stop screening asylum applications made by Bosnians.

Sweden eventually moved to offering permanent residency; however, this stipulation was not always clear and may have been viewed as contradictory. In Chapter 2, Section 4, sub-section one, paragraph 4 of the Aliens Act $(1989,529)^{18}$, any individual may obtain permanent residency on humanitarian grounds. However, this is contradicted in Chapter 3 Section 1, paragraph 3 of the Aliens Act, which states that asylum does not apply to situations of external aggression, occupation, or civil war. In order to receive asylum, the threat must be positioned directly toward the individual. In other words, the persecution must be individualized and come from the state, or the state must fail to protect its inhabitants from the threat. However, because of the exceptional threat posed against Bosnians, and particularly Bosniaks, the government felt its residents should be granted permanent residency.

To facilitate the process of implementation, in 1993 the Immigration Board administered 270 reception centers capable of housing some 90,000 asylum-seekers and refugees. Approximately 42,000 of these persons were from Bosnia and Herzegovina, granted permanent residency because it was determined that under no foreseeable circumstances would they be allowed to return to their home countries. It is worth noting, however, that even in cases in which a refugee was not granted permanent residency, they were still allowed to find employment. Under Chapter 2, Section 4a of the Alien's Act, no aliens with either permanent or time-limited residency status were required to obtain 
any additional permit for work. Moreover, contained within Chapter 4, Section 3a of the Alien Ordinance $(1989,547)$, which was amended by Ordinance 1992, a protectionseeker receiving a special certificate indicating that the decision pertaining to their residency would not be made for four months was permitted to work with no additional permits. Notably, if the individual earned his or her own wages, the daily allowance granted by the Immigration Board for food, accommodations, and so forth was reduced. Measures such as these were enacted throughout the duration of the conflict in the Balkans. Albeit, as noted above, for those without permanent residency, one may suspect the likelihood of them self-motivating to find employment to be far less probable than those with refugee status.

In 1996, another bill, 1996/97, 25, emerged (in 2013, a similar motion was also directed toward refugees from Syria). The bill proposed several important amendments to the Aliens Act, which were accepted by Parliament in December of 1996. As argued by Dacyl (1999), the most important amendment in shaping a separate protection category was Chapter 3, Section 3, which conceptualizes aliens who need protection as follows: a) one who has a well-founded fear of being sentenced to death or subject to torture, b) due to internal or external armed conflict or threat of an environmental disaster, or c) sexual orientation and a well-founded fear of prosecution. Thus, the de facto refugee in Sweden was understood to be a person who has fled for reasons similar to, but more expansive than, the requirements set by the 1951 Geneva Convention on the Status of Refugees. ${ }^{19}$

\footnotetext{
${ }^{19}$ The core principal of the UNHCR 1951 Convention is non-refoulment. It "asserts that a refugee should not be returned to a country where they face serious threats to their life or freedom."

http://www.unhcr.org/uk/1951-refugee-convention.html. "A refugee, per the Convention, is a person who is unable or unwilling to return to their country of origin owing to a well-founded fear of being persecuted for
} 
The magnitude of the Yugoslav crisis resulted in long delays in decision-making and a need for further assessment to standing policy. In hindsight, this is seemingly a natural evolution in Sweden's integration policy. To recall, its policy had not advanced much beyond its initial normative agenda set into place in 1975. While the failed Whole Sweden Policy was an attempt to rethink integration in terms of employment on one hand and acculturation on the other (e.g., the goal was to put them in situations where they were supposed to engage with locals), not much had been instantiated in terms of emergency reception and long-term integration for large groups of refugees.

As a result, policymakers and researchers concluded that new mechanisms needed to be put into place during times of peace, rather than waiting for a crisis. One example was "a simplification and easing [of] the interpretation [of] the Aliens Act ... in particular, to consider amendments in the Aliens Act in order to adjust it to handling an extremely high influx of maybe tens of thousands of protecting-seeking aliens from regions of armed conflict or crisis" (Dir. 1992, 51; Dacyl 1999, 156). Along with a reformulation of their approach to reception, Sweden additionally had to formulate how to begin the process of integration. As a result, throughout the 1990s, the role of integration remained widely viewed as a duty of the state. It truly began to take shape as a more comprehensive and intelligible approach to refugee integration.

With regards to the intake process, the state was (and remains) the primary actor. To this day, each asylum-seeker awaiting the processing of their application is given the same services. Sweden offers each new arrival housing, immediate medical attention,

Reasons of race, religion, nationality, membership of a particular social group, or political opinion" (UNHCR Convention and Protocol Relating to the Status of Refugees 1967, 3). 
food, and a small daily stipend for incidentals (approximately $\$ 8.60$ USD per day for singles and \$7.40 USD for cohabitants, per person). Additional provisions are also made available for those with children, as well as those in need of winter wear, eye glasses, or necessities for infants. The daily allowance has not changed since 1 July 1994 (Anderson \& Nilsson 2011, 177). Because of the immense number of refugees arriving, Sweden has had to devise new methods of facilitating their integration. For example, under the Reception of Asylum-Seekers Act 1994, sections 4 to 7, if a refugee is not able to find employment, then the Swedish Immigration Board is required to provide them with other activities (language training, skills development courses, and culture-related classes). According to Chapter 13, section 6 of the School Act 1985, 1,100 municipalities are responsible for arranging instruction in Swedish as a foreign language (Svenskunderisning för invandrare, SFI). Irrespective of the policies in place, however, integration - especially in terms of finding employment - is typically a painstakingly long process marked by several hurdles that range from acquiring the proper skillsets to overcoming discrimination (Carlsson \& Rooth 2007).

As highlighted by Soininen (1999), by the end of the 1990s, the new Yugoslavian wave of immigrants caused an increase in housing segregation and unemployment that prompted a transition to more social programs directed at promoting integration. To rectify this, the government proposed groundwork for a new integration policy (Governmental Proposal 1997/98, 16) and moved its stance from a multicultural approach to one more representative of cultural pluralism (another way of saying tolerance). This is when the host society accepts the unique cultural qualities of smaller, incoming groups. As policymakers and actors became more aware of the challenges refugees faced, they 
began to think proactively about how best to resettle the refugee population. Since that time, the crux of its integration agenda has been employment and establishing autonomy for its newcomers.

Considering the fundamental shifts in the market and the size of the wave of newcomers Sweden needed to absorb, an important question to ask is: How well did some groups integrate? For example, in a longitudinal study conducted by Växjö University (Ekberg 2004, in ed. Södersten 2004) of Bosnians who arrived in Sweden in 1993 and 1994, researchers found that integration varied significantly depending on where the particular Bosnian relocated. As stated above, approximately 48,000 Bosnians arrived in Sweden in 1993 and 1994. The group was distributed among approximately 250 of the 289 municipalities in the country. To reduce the scope, the researchers in that study selected four municipalities: Gnosjö, Gislaved, Vaggeryd, and Värnamo, all in western Småland. The combined population of the four municipalities was roughly 100,000. Compared to the outcome in Malmö municipality (home to roughly 250,000 inhabitants), it was found that 75 percent of Bosnian men aged 20 to 59 found employment in the small business district, which is based on small-scale industry (Södersten 2004, 204). This is about the same rate of employment that was seen for native-born Swedes in this region. Bosnian women also achieved successful integration. In Malmö, on the other hand, after roughly the same amount of time, Bosnian men achieved an employment rate of less than 15 percent. For women, the situation was far worse. While rates of employment in general improved in 1998 and 1999, the situation remained dire for those in Malmö. In more recent work, Bevelander and Lundh (2007) found similar outcomes for refugees, and in a study carried out by Frykman (2012), who 
examined the personal experiences of Bosnian refugees arriving in the early 1990s, suggests that individual employment paths could not be determined by levels of education, age, or gender, but rather by the structural composition of the labor market in rural/urban settings. Thus, an analysis of labor market integration policies is required.

In addition to the increased number of refugees arriving, in the early 1990s Sweden was also struck by a financial crisis. For the SAP, this was a tipping point. With the nation's surge in unemployment and reduction in purchasing power, faith in the SAP was weakened. Nevertheless, its expansive welfare state survived. However, due to globalization and the state of its own internal issues, Sweden's economy continued to shift toward greater liberalization. At the end of the decade, as Sweden resituated in response to the crisis in the Balkans and its own economic missteps, it faced another humanitarian challenge in the Middle East: the war in Iraq.

\section{4a. 2003: The Invasion of Iraq}

By the end of the 1990s, Sweden officially became a hub for refugees. While many might argue that Sweden has long been characterized as a nation of immigrants, it was not until the 1990s that it distinguished itself as one of the leading hosts of refugees (per population) in Europe. Up to the beginning of 2000, Sweden received culturally diverse refugees from Asia, the Middle East, South America, Africa, and Europe. Into the new millennium, individuals from these regions continued to come to Sweden under the country's policy of family reunification. Notwithstanding the previous arrivals, at the beginning of 2000, the world was met with another challenge. The America-led campaign in Iraq (sparked by the incident on September 11, 2001), ensuing war, and eventual 
destabilization of Iraq. Since then the largest group of individuals arriving in Sweden aside from Finns - has been Iraqis.

Since the Iran-Iraq war, refugees from this area have found new homes in Sweden. However, due to the escalation of the war effort by foreign fighters, the impact of the conflict grew significantly. By some estimates (Internal Displacement Monitoring Centre and UNHCR), the total number of displaced individuals from these three wars (Iran/Iraq War, Dessert Storm and the US led campaign in 2003) included roughly 2.8 million individuals from Iraq. ${ }^{20}$ Many of these were Kurds (though this is not welldocumented, since this information is not detailed in their passports).

Due to general discrimination and a pervasive language barrier, many Iraqi residents found it difficult to find their way into the native labor market (Triandafyllidou \& Gropas 2007). As noted above, the first Iraqis coming to Sweden in the 1980s and 1990s had limited resources, but entered a less-competitive and more regulated labor market. Following the US-led invasion of Iraq, the Iraqi refugee population increased significantly. Unlike their predecessors, this second wave of Iraqis were met by an existing community. In 2014, there are roughly a reported 132,000 Iraqi-born refugees in Sweden (data retrieved from Statistics Sweden). While some have interpreted this as positive, others feared that this would lead to lower levels of socialization and bridging across communities (Zhou 1997; Sidanius et al. 2004; Andersson 2007).

In 2008, Riksdag reaffirmed that the goals for Sweden's integration policy were "equal rights and obligations and opportunities for all, regardless of ethnic or cultural

\footnotetext{
20 "Little New Displacement but Around 2.8 Million Iraqis Remain Internally Displaced," Internal Displacement Monitoring Center, March 4, 2010, accessed January 15, 2017. http://www.internaldisplacement.org/assets/library/Middle-East/Iraq/pdf/Iraq-March-2010.pdf
} 
background" (Regeringen 2009; Regeringen 2010a, 5). At that time, the government also announced seven key priorities:

1.) Foster an effective system for reception and introduction

2.) Help bring more refugees into the labor market and create more opportunity for entrepreneurs;

3.) Create equal schooling opportunities

4.) Help new arrivals (especially adults) develop better Swedish language capabilities;

5.) Implement resolute anti-discrimination goals

6.) Reduce social exclusion among groups

7.) Develop a common set of values in a society characterized by increased diversity (Arbetsmarknadsdepartementet 2011, 5).

Sweden is largely in line with the rest of the EU in their focus on increasing the social, cultural, economic and political participation of non-EU migrants (European Commission 2011,3). Moreover, Sweden has placed a heightened emphasis on areas of education and employment.

In addition, the 2008 policy also readdressed the issue of housing segregation. It stressed that foreign-born Swedes and their children would be likely to end up in lifelong exclusion (Regeringen 2010a, 15-16), and that areas largely populated by refugees "report higher unemployment, lower average income and lower grades in lower secondary school, which impedes access to upper secondary school" (UNHCR 2013, 11). Arguably, increased levels of education and, correspondingly, employment (since in an ideal setting, education leads to employment) improve refugees' integration into 
mainstream society (Envall 2012, 316). The Swedish government recognized that it would require a vast amount of time for immigrants to become integrated and the first few years of their arrival were critical to their eventual assimilation into Sweden's social fabric. Consequently, the government's initiative expanded with the assumption that the longer an individual resides in Sweden, the more likely it will be for them to integrate (Envall 2012, 314-315). Yet despite the newly drafted amendments to their refugee integration policy, in the beginning of the 2000s, unemployment rates for refugees remained staggeringly high. To remedy this issue, the main thrust of the country's integration effort shifted from the municipal level to that of the state. In 2010, Sweden redirected the responsibility of economic integration away from local authorities, to the arbetsformedlingen (the public employment service). This was done to systematize and structure the employment process.

\section{2010 to the Present: Retableringreformen}

In December of 2010, Sweden unveiled its Etableringsreformen (or establishment reform policy). This strategy is one of the most important shifts in Sweden's integration policy and is directly focused on refugees. The main directive is to apply a labor market perspective to refugees from their first day in the country (Regeringen 2012b, 18, 28). Within this directive, Sweden emphasizes education and employment; the government assumes that better results in these areas will lead to improved employment and integration overall (Envall 2012, 316). The decision to reformulate the approach was based on an effort to speed up the process of labor market integration, because at the time it was perceived as too slow and ineffectual (Swedish Government Bill 2009/10, 60). In 
addition, the role of integration was moved from the municipal level to the state (Swedish Public Employment Service). At its inception, the directive strove to place greater emphasis on and better monitor each refugee to determine how they fared finding employment. Presumably, from 2010-on, the integration process should have become more forthright. In other words, this shift should have made it more easy and likely for refugees to settle, find employment, and become autonomous.

Monitoring is currently carried out by the Swedish Public Employment Service (PES). This entity is responsible for managing introduction activities at the local level for refugees aged 20 to 64 (Arbetsmarnadsdeparementet 2011, 4). Arbetsförmedlingen (PES) mission is to contribute to a well-functions labor market for job-seekers and for employers. In addition, the central goal is to promote a swift and efficient introduction of immigrants into the labor market. Primarily, they are responsible for public employment placement, yet they also work to improve the way the labor market operates. Presently, one of its greatest challenges is to help permanently raise long-term employment of Sweden's refugee population. The organization is comprised of 280 local employment offices throughout the country.

Since 2011, the Ministry of Employment has held the primary responsibility for coordinating integration policies at the national level. The Ministry oversees "a number of areas - assisting newly arrived refugees to establish themselves in the labor market and society in general, anti-discrimination measures, urban development, issues relating to Swedish citizenship and financial support to municipalities for their reception of refugees" (UNHCR 2012/2013, 11-12; Regeringskansliet 2012; Arbetsmarknadsdepartementet 2011, 4-5). The public employment service approach to 
integration is, however, not always effective (OECD Report 2014). Put differently, it may be necessary, but not always sufficient for tackling refugee integration. For instance, many employers refrain from listing their employment opportunities with the PES. One reason for choosing not to list is that employers often become inundated with applications. Instead, they often choose to use existing networks (friends, family, alumni networks, etc.). While human capital (e.g., employable skills and education) is important, in a more flexible and capitalist oriented system, relationships (social capital) may matter as much, if not considerably more.

Regardless of this reform process, municipalities continue to play a role in the reception of refugees. At the local level, they are responsible for meeting their most urgent, immediate practical needs, including housing, adult education, and youth schooling, among others. Local municipalities are also responsible for budgeting for language training (SFI). These costs are supported by Sweden's central government, who subsidizes SFI, civic orientation, interpreters, and special introductory activities provided in school. Under the current legislation, the reception and placement of refugees is coordinated on a voluntary basis. However, in recent years this mode of redistribution has been criticized. Relying on municipalities to voluntarily receive refugees, especially since asylum-seekers are allowed to choose where they live, has created a disproportionate stress on a handful of areas (e.g., Malmö, Angered and Södertälje etc.). For instance, due to a lack of resources, at the height of the refugee influx, the state had to rely on private actors to provide housing. Problematically, many of these shelters were not up to 
standard. Moreover, they were often placed in inaccessible areas, far from cities, native Swedes, industry and employment. ${ }^{21}$

Since 2000, refugees from non-EU countries have not integrated well. Sweden is now the most segregated country in the EU. According to the Migration Policy Institute:22

In 2008, 60 percent of native Swedes lived in areas where the majority of the population was also Swedish, and 20 percent lived in areas that were virtually 100 percent Swedish. In contrast, 20 percent of Sweden's foreign born lived in areas where more than 40 percent of the population was also foreign born. Demographic differences among regions, and particularly between the north and the south of the country, are also important.

The formation of these ethnic enclaves may be evidence of what Putnam (2007) has referred to as "hunkering down." Integrating into a new culture is a lengthy and challenging process. Instead of making the effort to find ones' way into the adoptive society, it may be easier to reside within one's ethnic community, even if that limits opportunity and choice. For individuals associated with larger preexisting groups (such as the Iraqi community), the apparent benefits of hunkering down may be even greater. Because of the network effect, such segregation may increase employment chances as refugees hear from family and friends about new opportunities that come about, though further research is needed.

Similar to the Bosnian crisis in the early 1990s, in 2013, Swedish authorities (the Swedish Migration Board) gave all incoming Syrian refugees permanent residency. ${ }^{23}$

\footnotetext{
${ }^{21}$ David Crouch. "Swedish Private Housing Sector Accused of Profiting from Refugees." The Guardian. https://www.theguardian.com/world/2015/oct/18/swedish-private-housing-sector-refugees.
}

${ }^{22}$ Sofie Fredlund-Blomst. "Accessing Immigrant Integration in Sweden after the May 2013 Riots." MPI. January 16, 2014. http://www.migrationpolicy.org/article/assessing-immigrant-integration-sweden-aftermay-2013-riots. 
When the decision was made, there were approximately 8,000 Syrians in Sweden with temporary residency. From 2012 to 2013, 14,700 asylum-seekers arrived in the country. In 2015, nearly 163,000 applied for asylum. Within that group, 51,000 came from Syria, 41,000 from Afghanistan, and 20,000 from Iraq; thousands of others arrived from Eritrea, Somalia, and Iran (data provided by the Swedish Migration Agency). Since 2016, refugees from Afghanistan have surpassed Syrians as the largest ethnic group seeking new lives in Sweden. Today, around 18.3 percent of Sweden's total population is foreign born, making it the most diverse state in the OECD (data provided by the Pew Research Center Report). ${ }^{24}$ Over the past two decades, public spending has decreased. It "has fallen from its peak of 67 percent of the GDP in 1993 to 53 percent (in 2014): as a percentage of GDP, overall taxes have gone down from 51.4 percent in 2000 to 44.3 percent in 2012" (Ekman 2014). Despite the reductions, Sweden has attempted to retain the philosophy of folkhemmet - equality of opportunity and universal welfare for all residents.

Today, working class immigrants and refugees typically live in housing estates along the periphery of the city. These developments were constructed in the 1960s and 1970s (Westin 2002, 5). The overall quality is relatively good; however, the neighborhoods are characterized by poor infrastructure, e.g., "run-down schools, lack of jobs, unsatisfactory public transport, high unemployment rates, high crime rates and widespread social welfare dependency" (Westin 2002, 5). Today, these areas are

\footnotetext{
23 “Sweden Offers Residency to All Syrian Refugees,” The Local Sweden. 3 September 2013. http://www.thelocal.se/20130903/50030.

${ }^{24}$ Phillip Connor and Jens Manuel Krogstad. "Immigrant Share of Population Jumps in some European Countries," Pew. 15 July 2015, accessed 8 December 2016. http://www.pewresearch.org/facttank/2016/06/15/immigrant-share-of-population-jumps-in-some-european-countries/
} 
characterized as immigrant ghettos (Andersson 2007). Each of the three largest Swedish cities (Stockholm, Gothenburg, and Malmo) have surrounding areas with high numbers of immigrants, high levels of unemployment, and low educational achievement (Hedetoft 2006; Larsson 2015). In a 2014 statement, Sweden's Former Minister for Integration, Mr. Ullenhag, emphasized the country's duty to offer refuge to those in need. He explained, "we're a small and rich country; we should take our share of responsibility in the world. And we think that if people who come here get jobs and become part of Swedish society, there is a lot of support for the idea that people should be able to continue coming to Sweden" (Ekman 2014). However, Sweden's open policy toward refugees, which first came about in the 1970s, has made it difficult to meet the needs of new arrivals. As a result, the country's approach to asylum-seekers has become more cautious. Notably, at the beginning of 2016, Sweden reinstated border controls. This was the first time the country had implemented a border check between it and its neighbor, Denmark. Even with this new measure in place, many still share Ullenhag's vision and perceive the new controls as a move in the wrong direction.

Today, refugees do not need to wait for their asylum request to be approved before they can seek employment. Any refugee who has applied for asylum can legally be employed by any Swedish enterprise. However, certain rights have now changed. Any refugee who applied for refugee status on or before 24 November 2015 would be granted permanent residency. Accordingly, they would be allowed to immediately apply for family reunification. Alternatively, refugees arriving after that cut-off date are now placed on a three-year probationary scheme. A key alteration, signed into legislation 21 June 2016, is that refugees are now no longer allowed to apply for family reunification 
until they can verify that they can support them. ${ }^{25}$ In addition, other changes have been made concerning certain rights for refugees. For instance, they can no longer claim the full amount of paid leave ( 480 days per child under the age of 8 ). Now they can only claim parental leave for children under one. ${ }^{26}$ These policy changes will greatly increase the pressure on newly arriving asylum seekers, and may incur several negative consequences concerning their integration. Nevertheless, Sweden's welfare state is still arguably the most expansive in the world. All residents within Sweden are afforded universal healthcare, education, and protection against unemployment. Even with these changes, the system remains both unique in its aims and highly desirable. Thus, even with its more cautious approach, we should assume Sweden will remain a very desirable location for many refugees.

Because of the long-standing political sway of the SAP and influence of the LO, employment has historically been provided by the state (this employment scheme largely ended by the 1991). While others seek different avenues, the status quo remains for refugees to continue to rely on placement by Sweden's employment office, the arbetsforminlingen. Throughout the job search process, refugees are required to attend a series of courses and practicums called internships. Through these, they learn specific skills ranging from the technical (such as with computers) to the less complicated (such as cleaning services). Regardless of the selected avenue, all refugees must attend a set of courses. These typically last anywhere from six months to one year. For sustenance, each

\footnotetext{
25 "Government Presents Migration Restrictions." Radio Sweden, http://sverigesradio.se/sida/artikel.aspx?programid=2054\&artikel=6367175, accessed May 14, 2017

${ }^{26}$ E.H. "How Immigration is Changing the Swedish Welfare State," Economist, www.economist.com/blogs/economist-explains/2017/06/economist-explains-20? fsrc=scn/fb/te/bl/ed/ accessed June 24, 2017.
} 
refugee is given 5,000 SEK (approximately \$546USD per month) and housing. From language acquisition to finding a practicum, and eventually to stable employment, the process of economic integration in Sweden is lengthy.

\section{Challenges: Educational Attainment \& Unemployment}

Many natives have expressed fear of over-reliance on general welfare by refugees (Hansen \& Lofstrom 2003; Dahlstedt \& Neergaard 2015). This fear may be overstated, but as the education level and unemployment figures display, Sweden faces several challenges to adequately integrating its refugee population. Education levels among most refugees remains low, though it is needed in a high-information society such as Sweden. "Almost one third of immigrants hold, at most, a lower secondary education. This is twice the share among the native-born. What is more, over the decade preceding the current humanitarian crisis, the share of refugees arriving in Sweden with a low level of education has been increasing" (OECD 2016, 19). Another report from the OECD noted that most refugees come from countries with failing education systems. For example, Afghanistan has a literacy rate of 38.2 percent (male 52 percent and female 24.2 percent respectively; data provided by CIA World Factbook). Consequently, many lack even the most basic qualifications and skills. Even more challenging is that those with tertiary qualifications often acquired them in a context very different from their newly-adopted country, raising concerns about the transferability of their credentials (OECD Report March 2015). The educational disparity between foreign and native-born individuals is among the largest in the OECD (ibid). These individuals require intensive remedial education. Sweden's department of Municipal Adult Education (MAE) offers courses to 
adults in such situations. The Public Employment Service (PES) assists in coordinating (through both public and private providers) labor market training courses. Additional ad hoc projects are often created for those lacking basic functional literacy. "'Knowledge Boost', for example, provides local authorities with grants to run general and vocational adult education courses.

Along with educational difficulties, high levels of unemployment persist. As a consequence, the Sweden Democrats have politicized immigration to gain support for their proposed programs. In a September 2016 Reuters report, Jimmie Åkesson (Leader of the SD) expected to garner 20 to 25 percent of the national vote in the 2018 elections. That would put them on equal footing with the ruling SAP. ${ }^{27}$ Considering the issues of education, employment, and populism, Ekman (2014) posed a question similar to the one driving this research and that of other scholars (Goodhart 2004; Joppke 2007; Eger 2009): “can $[a]$ modern welfare state be reconciled with rapidly increasing diversity at a time of rapidly dwindling job prospects?" (2014, Online Edition). Job scarcity, especially in the low-skilled sectors into which refugees typically fall, may become very difficult for Sweden to address. Despite the etableringsplan, high levels of unemployment persist, and segregation is becoming even more of an issue. Yet even though Sweden's stance toward asylum has become more restrained, its agenda remains steady. The challenges of such rapid increases in refugees demand more research on how refugees access the resources provided by the state and civil society.

\footnotetext{
${ }^{27}$ Simon Johnson and Johan Sennero, “Sweden's Far Right Eye 20-25 Percent Support, to Seek Government Role," Reuters. September 14, 2016. http://www.reuters.com/article/us-sweden-politicsfarright-idUSKCN11K20Z
} 


\section{Conclusion: Asylum, Social Democracy and its Challenges}

In 2015 , the UNHCR reported ${ }^{28}$ that there were roughly 65.3 million displaced persons (one of every 113) worldwide. Because of the long reign of the SAP, the country's social democracy, its expansive welfare state, the rise of the socio-ideological framing of folkbildning and folkhemmet and high number of refugees, Sweden provides a unique landscape for studying the labor market integration of immigrants. Until 1970, migration to Sweden was characteristically labor-oriented and European. However, after a slowdown and virtual rejection of labor migrants, the country began to receive its first refugees. Due to Sweden's economic structure, in the 1970s such refugees were frequently placed in industry, and most often in factories. Since the height of its welfare state, however, different circumstances for different groups have resulted in dissimilar levels of integration. Groups such as the Bosnians, despite coming to Sweden at a time of economic crisis and vapid liberalization, fared surprisingly well, whereas more recent groups since the end of the 1990s have spent considerably more time unemployed (Lundborg 2013). Undoubtedly, additional research is needed to provide alternative explanations for the different rates of success other than those provided through policy or economic analysis .

Swedish integration policy was first developed in response to the reduced need for labor migration and a transition toward refugee reception, demarcated by the arrival of Ugandan-Asians, followed shortly thereafter by refugees from Chile. Scholars have differed on the reasons for their varying levels of success integrating into Swedish

\footnotetext{
${ }^{28}$ Adrian Edwards. "Global Forced Displacement Hits Record High.” The UN Refugee Agency (UNHCR). http://www.unhcr.org/news/latest/2016/6/5763b65a4/global-forced-displacement-hits-record-high.html.
} 
society. One explanation was based on their respective outlooks for the future. UgandanAsians found the situation in Uganda to be futile and a return to their home country impossible, while Chileans believed that reconciliation with their home nation was on the horizon. Comparatively, refugees from Uganda found employment much more easily than did the Chileans. Because of the differences among the groups arriving in the 1970s, Swedish policymakers eventually formalized the nation's integration policy. No longer would the mode of integration be organic. Like the normative agenda of folkhemmmet that was expressed in Sweden's social democratic platform, this formal integration policy was firm in its intent that all refugees would receive equal access to services in the welfare state. To date, this outlook remains intact. However, increased levels of globalization and other market factors have forced the policy to evolve. In the 1980s, Sweden received more refugees and faced internal fiscal issues. The Iran-Iraq war brought a large wave of immigrants, and family reunification of individuals from the Middle East, Asia, South America, and Europe continued this trend. Moreover, a transformation in its opportunity structure resulted in differentiation of its employment paradigm. Moving to a more service-based economy reduced access to the types of employment typically frequented by marginalized groups. Due to economic instability and the increase in asylum-seekers, the 1990s spawned an era of reform.

One characteristic of the Swedish model is its ability to continually evolve. Considerable changes have occurred in Sweden's integration policy since the 1970s, when it was first codified. Over the last 45 years, the Swedish government has had to react to two principle developments: 1) the size of the refugee population, and 2) the state of the economy. Thus, it has regularly struggled with its level of preparedness. Its lack of 
readiness is visible in two ways. First, in the 1990s and today, at the peak of the refugee influx into Sweden, the state did not have adequate resources to evaluate and process asylum applications. Second, its labor market struggled with integrating such a large number of refugees in such a short period of time. Given the level of unemployment in foreign-born Swedes, especially in the last 15 years, it is well within reason to suggest that the likelihood of refugees meeting Sweden's vaunted labor market requirements (e.g., Swedish-specific skills and education) seems improbable. Strictly speaking, it appears that the labor market no longer has the capacity to absorb newcomers it once had in the 1970s and 1980s.

Indeed, a formal integration policy has existed in Sweden since 1975. Yet it was not until the 1990s that Sweden's official plan truly began to take shape. One explanation for this is the series of events including the transformative rise in personal household debt, subsequent financial crisis in 1991, and consequent political alterations that largely led to market reform: greater liberalization and labor market flexibility. While employment has been one of the central aims of Sweden's refugee integration policy since 2010, it has more recently become the primary focus of the program. Most notably, the introduction of etableringsreformen has placed greater emphasis on overhauling the process by which refugees achieve labor market integration. Yet the process remains complex, and for some, impenetrable. Visibly, the state can no longer manage integration on its own, which as highlighted by the Ugandan case, was almost entirely responsible for their employment. The welfare state remains strong, but several normative principles are being challenged. The rise of the far-right Swedish Democrats, closing of the border with Denmark, revocation of permanent residency, and limiting certain rights such as 
parental leave are together a telling of a shift away from Sweden's historically normative agenda.

Nevertheless, there are several lessons of the past that can be instructive today. Informal adult education and study circles should be central to the integration process. To date, few studies have been conducted on their usefulness to refugees. However, evidence has shown that if refugees have access to programs and activities in the informal educational sector (e.g., they know what is available to them), communities unify around similar interests and educational events. Hence, such programs are likely to assist with both language acquisition and relationship building, two quintessential aspects of integration in any setting. In the next chapter, this is explored in greater detail.

Even though the informal sector could serve to complement the services offered by PES (by facilitating alternative education choices, social networking, and other programs related to the wellbeing of refugees, such as counseling services), it does not eschew some of the very real challenges that Sweden (and the rest of Europe) faces: namely, pronounced unemployment and a growing welfare dependency among foreignborn residents. These are only two of the struggles faced by a considerable portion of the refugee population, especially those with less than a secondary-education who are attempting to enter an acutely liberal, culturally incompatible economy. Given these considerable challenges, many onlookers (such as those on the far political Right) have wondered whether diversity and the social democratic, universal to integrating a given group of refugees to be a viable plan (Castles 1995; Rothstein 2014; Schall 2016).

To explore this process in greater depth and better understand how refugee labor market integration takes place, I collected and analyzed first-person data cultivated via 
semi-structured interviews. The following chapters provide insight into the role of civil society and the personal, lived experiences of refugees. To answer the question of how civil society has evolved to assists refugees, Chapter Five discusses the different types of local, non-state organizations, largely byproducts of Sweden's informal adult education scheme, and native, ethnic, and faith-based affiliations, and the positions they hold in this process. This chapter also considers the types of resources they provide and the challenges they face when working with refugees. Chapter Six uses first-person narratives from an ethnically diverse group of high-skilled refugees, to provide nuance with regards to how immigrants access the labor market, as well as insight into the challenges they face. Notably, both chapters address issues of information access, communication among organizational groups and refugees, and the challenges that accompany the accumulation of social capital. This research assumes that for Sweden and in general, other European host societies to meet the challenges posed by globalization (increased competition and the refugee crisis, to name two), civil society will need to become a more prominent actor in bringing marginalized groups into the labor market and forming social relationships among newcomers, existing organizations, and the native host population. These accomplishments are crucial for incorporating refugees into this highly-advanced, quasi-capitalist, European welfare state. 


\section{Chapter 5. Labor Market Integration: Civil Society and Social Democratic Central Planning}

Civil society in Sweden has long been considered a central aspect of everyday life. Solidarity and the focus on the "collective" are bi-products of Sweden's social democratic platform. While the role of civil society organizations (CSOs) has been thoroughly researched (Griffiths et al. 2006; Hort 2014; Trägårdh 2007;), no studies have yet examined their role in refugee labor market integration. Greater research into how CSOs help refugees navigate their way into the labor market is fundamentally important to Sweden's economy. Due to the centrality of its state, and prior economic circumstances (evidenced in chapter 4), refugee labor market integration has long been almost entirely facilitated by the state. Given the surge of refugees coming to Sweden since the 1990s and the liberalization of its economy, programs for integration, which have now evolved to the etableringsplan ${ }^{29}$ (the flagship of its refugee labor market integration program), require non-state outside assistance to help it meet their goals.

The purpose of this chapter is to discuss the role of civil society in facilitating refugee labor market access in Sweden. The previous chapter presented a historicalinstitutionalist framework of the expansion of Sweden's integration project, in order to highlight how refugee labor market integration has changed over time and as an explanation of the fieldwork conducted for this research. Given the nature of the historical assumptions made in Sweden to date, my data cultivation and subsequent analysis began with information on the events occurring at the end of the 1990s. While a

29 Etableringsplan came into effect on 1 December 2010. While it takes into consideration other integration issues, labor market integration is its central role. 
brief comparison between historical junctures is made below, the goal of this chapter is to focus on what resources CSOs provide (e.g., available programs from the different types of organizations present), and how they contribute to manufacturing social capital, and their subsequent role in the labor market integration of Sweden's refugees.

The following chapter is divided in seven sections. The first gives an overview of how participants for this study were selected. The second describes how civil society's role has changed since the 1990s. The next three sections determine what types of resources CSOs provide to refugees and operationalize the role of civil society in the integration process. Specifically, section three covers the role of native (Swedish) CSOs, section four considers the participatory capabilities of ethnic organizations (attached to förbund - associations and förenings — organizations), and section five examines the role of faith-based organizations (FBO). Following an overview and analysis of specific individuals who provided the first-person data used in previous sections, section six examines the challenges civil society faces in this process, their utility in the acquisition of social capital, and capabilities with regards to disseminating information. Moving to the future, section seven describes how certain representatives of civil society view their role going forward, and in particular how new legislation may affect refugee integration. Finally, the chapter concludes with a summary of how each sector interacts with refugee communities, an overview of some of the biggest challenges faced by this research, and several recommendations for reconsidering the utility of civil society in the refugee integration process.

Because of the recent crisis (both in terms of the size of the arriving groups and the lack of a unified EU policy in response to the crisis exemplified bythe blowback from 
the Visegrad Four's rejection of the EU's distribution proposal) and the substantial obstacles to evaluating and meeting the needs of Sweden's refugees, an investigation into the role of CSOs is both timely and salient. As a response to Sweden's increase in immigrants and shift in its labor market towards greater liberalization, this chapter asks the following questions: how has the role of CSOs evolved since the 1990s? To what extent does civil society participate in refugee integration? What are the challenges CSOs

perceive in becoming a space for refugees to seek advice, training, and other forms of assistance, and how do they affect their efforts? Based on fieldwork consisting of 25 indepth, semi-structured interviews with civil society representatives, this chapter sheds light on the participatory capabilities and challenges of civil society in the refugee labor market integration process in Sweden.

\section{Selecting and Accessing CSOs: The Welfare State, Civil Society, and Refugee Labor Market Integration}

Though civil society is associated with an amalgam of potential actors and associations, this analysis focused on CSOs, which for organizational purposes were further divided into ethnic associations, native Swedish CSOs, international organizations, and faithbased groups. Associations and organizations were purposefully selected according to their participants (e.g., Iraqi, Syrian, Somali, Afghani, etc.), and other local organizations were chosen because they either worked directly or, to an extent, indirectly (in an advisory role) with refugees. After the initial contact and interviews, snowballing techniques were employed to access additional participants working with other organizations and associations. 
Several key findings from the literature (noted in chapter 2) will be analyzed below, including claims such as:

1.) A strong welfare state may have negative impacts.

a.) Because it may increase the prevalence of discrimination.

b.) Because of tighter regulations and how refugees are viewed by their host societies, labor market integration is less likely to occur.

2.) Having more substantial access to social rights may not directly translate to a higher quality of life.

a.) As per the living conditions survey, immigrants may not have access to the same opportunities as natives.

Much of the research directly linked to the role of CSOs in the process of labor market access for refugees remains sparse (Trägårdh 2007). Thus, this chapter contributes to the greater body of research examining their role in refugee integration in an increasingly liberalized and economically flexible social democratic platform.

\section{The Changing Role of Civil Society and the Types of Organizations in Sweden}

CSOs were divided and selected to provide insight into how varying actors work with refugees throughout the process of labor market integration. This helps not only to assist in answering what resources are available to refugees, as each presented different opportunities to the refugee community, but also highlights some of the obstacles faced by each type of organization. In addition, the division allows us to better understand how the varying levels of civil society communicate. While civil society's role in the economic integration process has not been uniquely defined, by looking to specific 
organizations/associations and their projects we may begin to conceptualize its role in a more systematic way. Notably, in this research, more Swedish/native organizations are discussed. The reason for this is that native organizations were found to yield a greater variation of projects (labor market training and community outreach), and seemed better and more consistently funded than ethnic associations.

Before a proper understanding of the evolution of CSO participation and refugee integration can be achieved, we must first investigate how civil society has transformed since the 1990s. An exploration of this issue is included below, along with a discussion of each type of association and examples of their respective roles.

\section{2a. How has the role of Civil Society changed since the 1990s?}

Sweden is known for high levels of civic and associational participation (Vogel 2003). One might imagine that this would lead to an equal level of systematic participation from civil society (e.g., volunteer-dependent organizations and refugee integration). However, due to the centralized political, social and economic structure of Sweden, integration has long been a process run by the state. While civil society has indeed played a role, its position has been subdued since the 1990s:

I remember the refugees from Bosnia and Kosovo ... this time we have more refugees than the time with Bosnia and Kosovo. What I remember is that there were buses from Bosnia and Kosovo to Sweden, so it was easier to come to Sweden than it is now; they did not have [to] travel for three or five months to get to Sweden. What I have heard is the Red Cross helped a lot, but I do not recall much chatter about [CSOs]. I think it was easier in the 1990s. In that way, the politicians stood for a more open asylum process. I think the whole society was saying we really need to help these people who cannot stay in Bosnia and Kosovo (Refugees Welcome Representative). 
The mode by which refugees arrived in Sweden seemed to make the transition more manageable. Because of the proximity of the crisis and the transformations taking place had not yet become fully visible nor understood (the liberalization of its economy, the substantial rise in its foreign-born population, and the rise of non-EU refugees), CSOs during the 1990s had virtually no formalized role in refugee integration. "Civil society's role was for social integration. All things concerning labor market integration were left to the state. Today, it is very much the same. CSOs could be doing so much more" (Frederik Malm, Labor MP).

As has been represented in much of the literature concerning the Scandinavian welfare state, the Swedish government has been and continues to be the primary actor in the integration process, as expressed by this CSO representative:

It used to actually work. If you arrived 30 years ago, you would be referred to a job. Today, we try to create pathways. What do you call it? To bridge. It is important to get people out of [PES] and into stable work. It is not working perfectly, of course, but it is a method to work within the Swedish context. This is a really good way of thinking; this is how Sweden works. (Priyanka, Sensus)

While Public Employment Service (PES) is the main platform by which refugees currently find employment, civil society is becoming an essential participant in this process. One indicator reflecting this change is visible in the how funding has improved.

In the last two decades, very little funding has been allocated to refugee integration; today, however, funding schemes are adapting to the pressure. With the recent surge of asylum seekers since 2011, primarily due to the conflict in Syria but also as a result of mass migration from Afghanistan and Eritrea, greater funding and other forms of state support have been given to refugee CSOs. This is visible in the increased investment from the state. Priyanka explained, "just this year, we were given over 100 million kroner (14.5 million USD) to provide asylum seekers with Swedish, Swedish 
cultural classes, and other courses that increase local participation." Because of this increase in funding, "my job is to work with the asylum seekers" by orchestrating a series of activities at various levels (Priyanka, Sensus). Native CSOs are now working for the integration process at all stages:

We work with the Swedish Church. They have a lot of study circles that meet in these remote places in Skåne to teach the asylum seekers different things (e.g., knowledge about Swedish society and language). We are trying to support these groups and the organizers there to get books [and other supportive materials]. Our approach is [to ask] 'what do you want?' and 'what do you need?' Therefore, we are not telling them what's best, but rather listening to what each specific community desires. (Priyanka, Sensus)

This approach hopes to cultivate a sense of autonomy among refugees, helping them to feel as if they have a say in their future, even though for several reasons, self-motivation remains difficult.

Engaging in these types of projects and working closely with those in the refugee camps continues to be a challenge because refugees are not required to settle in specific locations. While many do settle in refugee camps, unlike previous policy, refugees can elect to live and settle wherever they choose to do so. For many, this means moving to heavily segregated communities for reasons such as comfort and accessibility is more amenable than moving to refugee camps. Aptly put:

We are trying to do our best in a very difficult situation. For instance, in a city like Malmö we try to coordinate activities. We have tried to reach out to like twoto-three hundred people who found housing and placement on their own. We do not know what they are doing. We assume they are with family members and so forth, but we really do not know. (Priyanka, Sensus)

In addition to not knowing where or what some of the refugees are or what they are doing throughout the city, motivating individuals in the camps is an exceedingly difficult process. Working with new arrivals is difficult. For various reasons (certainly not all 
accounted for here), motivating refugees from their point of arrival to becoming gainfully employed may be extremely difficult and lengthy. For instance, we may reasonably presume that some may not be in the right state of mind to begin the arduous process of integration, not to mention in the right frame of mind to secure a paying job. In other words, we should not discount and underestimate the potential level of trauma and distress experienced by those seeking protection. Nevertheless, Sensus continues to push to help facilitate the integration process for newcomers.

One reason for the rise of civil society, is the different dynamics of the current wave of refugees. Certainly, asylum-seekers face a variety of challenges. Moreover, their arrival experiences vary significantly. For instance, those coming from the Balkans in the 1990s undertook a relatively short journey to Sweden; typically, they arrived by bus. Upon entrance, they were brought to state-run reception centers. The processes of applying for asylum and the subsequent societal integration began immediately thereafter. What's more, these refugees came from mainland Europe. This is not to denounce the dissimilarities between Swedish and Yugoslavian cultures, but it is noteworthy that these groups were culturally more similar than the most recent refugees. To meet these needs, new resources and capabilities are needed, such as greater emphasis on civic courses to increase human capital, which may or may not be part of one's establishment plan.

At the height of the most recent crisis, from mid-September to mid-October 2015, with large numbers of asylum seekers coming from Syria and Afghanistan:

Only civil society people came. For one month, most of the asylum-seekers came at night, after $21 \mathrm{~h}$ or $22 \mathrm{~h}$. At one time, we had one thousand people arriving at once. We handed them water, fruit and whatever people would bring. A lot of 
people brought baked goods. The last train would come at like $0 \mathrm{~h}$ or $1 \mathrm{~h}$. After $1 \mathrm{~h}$ we did not know where to take them. But Kontrapunkt helped gather mattresses and helped bring people to the local Turkish Mosque, where they could stay for a couple of days (Representative Refugees Welcome Sweden).

Many of those arriving in large groups to the Malmö Central Station had been traveling for months. Given what the international community knows about human smuggling and the distance between Sweden and the Middle East/North Africa, the journey for these most recent refugees was long and arduous. When many asylum-seekers arrived, the mechanisms in place, while well-intentioned, were not sufficient to meet their needs. The state was not able to accommodate those in need as it had in previous crises. It took time for the state, as well as for larger private organizations like the Red Cross to assess the situation and mobilize additional resources.

Today, CSOs are involved in the reception process; however, due to the orientation of integration practices, and certainly the sheer size of the challenge, CSOs also work with refugees on finding employment. While the role of CSOs and their official position in relation to the refugee project seems clear, their relationship actually remains complex and understudied. Quintessential to this complication: "civil society is not as strong as it should be when it comes to integration. Many organizations and foundations and churches ... have only very recently received a bigger role" (Malm, Labor MP). To explore more directly how local organizations aid refugees, below I discuss each type of organization addressed in this research, beginning with native Swedish groups. 


\section{The Role of Native Actors: Relationship Building \& Education}

As highlighted in the previous chapter, folkbildning (adult education) has historically played an intricate role in Sweden. Moving beyond traditional, informal adult education, it now is a very active and visible non-state actor working with refugees. This section begins by discussing the umbrella approach inherent to the Swedish system and proceeds to narrow its focus to the discussion of smaller, local-level, native CSOs. To bring clarity to two complex issues in the evolving relationship between the state and civil society, this section applies a hierarchal mode of analysis (from larger umbrella networks to local, native CSO's carrying out programs which are a part of the larger network). This is done to provide insight into what local organizations working with refugees, provide the local communities, how these organizations interact, as well as to discuss the rising utility of "flash" organizations, and their role in the integration process.

\section{3a. From the Top-Down: Folkbildining and networking among Native CSOs}

In Sweden, study circles are central to everyday life (Uddman 2014). They provide those who are interested with access to local activities and informational groups, where they can seek assistance with difficult matters and interact and participate with others in the community who are interested in the same activity. To examine how this takes place, this research examines Sensus, a native "studieförbund" directly focusing on refugee integration, among other activities. Sensus has "four [core] purposes: to promote democracy, to increase the level of empowerment, to increase the level of influence over your own life, primarily through learning ... and last, to increase the participation in cultural activities" (Priyanka, Sensus). The goal is to help bring state-run operations 
together with local activities in the community (and as a consequence, bring together actors from different communities). In other words, Sensus cultivates relationships between the state and local municipalities. Larger studieförbund's like Sensus, act as a one of the primary intermediaries between the central government and smaller CSOs. The benefits are twofold. First, by pooling their resources e.g., contacts with local CSO's they are able to provide grass root level insights into policy generation concerning the challenges in each community. Second, through larger network these organizations help procure funding and provide a platform to other CSOs. It is through this top-down approach that local organizations, operating in both their own interest and the interest of the state, help local communities and the refugees hoping to become a part of them.

In this model, there is a direct relationship between länsstyrelsen (the county administrative board) and local groups and organizations (e.g., Rådrum and Yallasofielund discussed below, among others) seeking to assist with state-directed motives (such as those of PES):

What Lännsstyrelserna does is provide other activities [apart from PES]. They contact [representatives] from different associations to forge relationships. For example, we had one person here, Sandra, who likes to play chess. The chess club was interested in increasing chess among some young people and were very interested in learning Arabic. They applied for funding for him to work, especially with the kids, which was approved. As part of their integration program, [he attends the group] twice a week.

This is one of many stories of how civil society works together with the state to help refugees navigate their new lives in Sweden. Civil society seemingly cultivates relationships (social capital) between refugees and CSOs (native, ethnic, faith based or otherwise) as well as coordinates the aims of the central government (which provides the majority of its funding) with those of grass root, local activists. 


\section{3b. Local Community Organizations}

At the crux lies Sensus's goal of forming bridges between local refugee communities and local Swedes. Similar organizations are also working towards doing just that. Hut Skåne (HS), through its project Rådrum, works to promote refugee integration.

HS has been around since 1998, which initially became as a forum to create meeting places to discuss environmental issues, is now tied to both education and integration. Reflective of these aims, Rådrum, a program modeled after Britain’s Citizen's Advice Bureau $(\mathrm{CAB})^{30}$, is not an organization per se, but rather a type of ongoing project:

It works with a consortium of participants. [It] started as a partner between these organizations, both with the development and these daily organizations. The public, the organizations, were important in the beginning with their knowledge and expertise. When we talk about Rådrum as one of the key actors in civil society, [we mean that it works] to provide a space for organizations to connect. The boundaries and the aim [are] pretty clear. ... it is like an ideal förening; it has some organizational structure, but it is still not a full organization. (Magnus, Hut Skåne)

Magnus continued, stating that at its core:

The aim of Rådrum is to strengthen and empower individuals. [Operationally,] Rådrum's essence is to advise and educate its volunteers to become advisors. [Advisors] work on a voluntary basis. They have a meeting room where you can come and ask any question ... There is a lot of information from local authorities and the central government, and ... they offer a similar service, but not everyone wants to speak in such a formal setting. [What Rådrum offers] is much more welcoming. It serves as a space where individuals can come on their own and ask questions [of] people who are passionate about [serving as a community liaison]. [What we offer] is a meeting space where you can get free, confidential and unbiased advice.

Rådrum is place where anyone (not only refugees) can come and seek advice, and gain contacts with Swedes and other advisors working with the program. These points of

\footnotetext{
${ }^{30}$ Britain's Citizen's Advice Bureau is an organization that works to provide guidance for the challenges people face as well as work to improve policies and practices affecting the lives of many throughout the U.K. The consultation practice is free, confidential, independent and impartial.
} 
access help refugees in that they can ask any questions or request assistance with any issue they may be having. Notwithstanding, the project is still growing and has not been in practice for long. The project was initiated in 2013; its first physical location opened in May of 2014.

A key feature of civil society is that it provides local access points for refugees. Beyond the immediate integration processes (registration, resettlement, and PES), civil society (both formal organizations and informal associations) assists refugees in navigating local communities (e.g., the local opportunity structure or labor market). Many cultivate projects that assist refugees in becoming labor market-ready. These include anything from courses in supplemental skills (e.g., cleaning, cooking and learning skills associated with paying jobs) to social activities (e.g., language cafes). These organizations range from FBOs to local ethnic or Swedish groups, to larger international administrations such as the Red Cross, Amnesty International, and Caritas, etc.

Along with Sensus and Rådrum, which seek primarily to inform policy, bridge communities and provide refugees with pertinent information of what is available to them, other native Swedish initiatives focus specifically on education and language. Along with SFI, folkhogskola (folk high schools, or FH) help facilitate training in the Swedish language and culture. While they do receive their funding from the state, programs such as these are separate from the municipality. These are programs put together by independent actors who are then awarded contracts by the central government to facilitate language learning. Many programs specialize in one form of learning. For instance, some will focus more intently on low-educated refugees (such as the one discussed below), where others may work more closely with high-skilled refugees and 
other types migrants (e.g., labor migrants). Notably, these programs supplement state run SFI. To make sure these programs carry out their proposed educational programs, immigrants must show evidence that they are improving their language skills and actively participating in the program. A measure in place to ensure this is taking place (though the rigor of this measure is questionable), consists in representatives of these programs signing off that said individual was attending their course which is accordingly reported back to their handler at PES.

For efficiency's sake, refugees are placed into courses according to their previous educational attainment. Classes for those with high school educations are often conducted during the evenings, as participants are expected to attend extensive training during the day. For those with little education, SFI courses are carried out during the daytime. One school administrator stated:

We have focused [on] people who have [little formal] education. Sometimes it is very hard. One problem is they will not show up and then argue with us to tell local authorities that they were in class. We have to give them this verification. We cannot say they were here if they were not here. (Elisabet, Hylliepark Folkshögskola)

For schools such as Hyllie Park Folkshögskola, working with refugees who have had very little formal education can be difficult.

Organizationally, schools are usually divided into three types of classes. Individuals are placed in a particular course based on their previous educational experience. Elisabet explained:

The first path is for people with very little to no education. Level two is for people up to maybe high school. And three is for those with an academic (tertiary) background. Three is only available at nighttime. Two out of three of our learners (we have 450) are in study group one. We maybe have 10 percent of the whole 
city of Malmo. We are known in Sweden and in Malmö for taking the people with low education.

Because the majority of the students consist of those with very little education who also often are not fluent English speakers, the majority of the classes are conducted in the native language of the students being taught. Notwithstanding, the rate of completion for refugees remains low. Despite these efforts, many students leave before they complete the coursework and receive an internship.

It is either because they have had a child or they have found some form of work. If you have very low education, it is harder, of course. But it depends on what you are ready to do and how old you are, and what you come with. It is very individual. (Elisabet, Hyllie Park)

Compounding the difficulty one experiences upon arrival (which also varies by each individual case), other reasons affect how far refugees progress in the integration program. Low-skilled refugees are especially "at risk," as they may not have as much to gain from more formal integration programs as those with high-skills. Nevertheless, one recurrent issue raised by both high and low skilled migrants was the amount of time required to complete language training. Because of this, many students stop attending courses long before completion.

Language training is, nevertheless, only a part of the integration process. To help refugees find pathways to employment, other native organizations work to train refugees with skills appropriate to the available opportunities. Yalla Trappen and Yalla Sofielund are other local Swedish initiatives that provide opportunities for work and social entrepreneurship, with the central goal of finding employment for refugees. The program 
is based largely on the Yalla approach (also referred to as the Yalla Staircase ${ }^{31}$ ). Adopting the Yalla Staircase from Yalla Trappen, Yalla Sofielund works to integrate social enterprises with women's cooperatives, and establish partnerships among property owners, businesses, housing associations, and village communities and associations. At the core of the program is the goal of bringing refugees and non-native Swedes, and in particular, women, closer to the labor market. Not only does this method provide an environment where participants can practice Swedish, but they may also receive referrals from employment agencies:

We have commercial cleaning [which] comes with certain associations...come here [and] learn a new task. Different types of initiates, different types of projects. [Participant have] jumped from one project to another. [Some are] learning how to sew. [One] already knew how to sew [but] spent six to eight months [in the program] ... she knows so much about sewing, so now she is learning how to cook. (Louise, Yalla Sofielund)

Though just getting started (the program was launched in March of 2016), its utility is directly visible. Not only does the organization help refugees gain useful skills, it also assists them in establishing connections that will increase their future chances of employment and well-being in Sweden. Seemingly, the organization works to build social capital in two visible ways. First, it brings refugees and Swedes together as they majority of the programs are run by Swedish nationals. Second, it brings together refugees from different ethnic groups. What's more, programs such as Yall Sofielund, help empower the most marginalized women. Categorically speaking, these are women coming from states where woman's rights are substantially weaker than of those in the

\footnotetext{
${ }^{31}$ The Yalla method is designed to strengthen foreign-born women's position in the labor market through the introduction of work in workplaces based on democratic and solidarity principles. The Yalla staircase integrates social enterprises and women's co-ops run by nonprofit organizations in Rosengård. The staircase is based on three lines of business: café/catering, sewing and cleaning, and conference services.
} 
EU and Sweden (e.g., many were not allowed work outside of the home, and were often neglected any formal education). Building skillsets aka human capital is, however, just a part of the process. Looking at the process from a wider perspective, another aim should be to cultivate partners with access to paying jobs and to bridge refugees with native communities.

Like folkbildning, Rådrum and Yalla Sofielund, other organizations are working to help prepare refugees for their new lives in Sweden. Individuell Människohjälp (IM) strengthens the voices of those who are excluded because of racism and discrimination, or who might otherwise need assistance. Again, organizations like IM are necessary. While they may not be directly tied to "economic" integration per se, monitoring levels of discrimination and providing help to those who may have been discriminated against is essential. After all, how can any newcomer become settled, not to mention employed if they feel uneasy? Most recently, much of this organization's work has focused on children.

Focusing on the wellbeing of children has proven a useful approach to engaging with and cultivating interest among communities. Not only does this group alleviate some of the stress associated with refugees' new lives, it also brings parents together to work for the sake of the children. A recurrent concern raised by those in civil society and refugees alike is the lack of localized social meeting arrangements where all can gather together and engage with one another. Despite the clear benefit of projects run by IM, like many other programs funding is precarious. To secure funding, "we work with Idéburet Offentligt Partnerskap (Leading With Public Partnership, IOP); we write agreements. But these are typically not long-term. So, we rely almost entirely on 
volunteers. As you can imagine, this is difficult to sustain" (Kornelia, IM). As Priyanka eluded to above, only recently has increased funding begun to flow into these civil organizations. Planning for long-term activism seems to continue to be a struggle for many organizations working with refugees.

Finally, to highlight the expansiveness of native organizations, the final part of this section points to so-called "flash" organization. Today, there are several other reasons for this limited level of non-state participation. One indication for civil society's reluctance to assist is the dip in overall participation and shift from a more formalized setting to digital/flash platforms that are more anomic in nature:

I think a few years ago (maybe five years ago), there [was] a crisis in civil society because there were lower levels of participation. You had small groups like on Facebook; there was sort of a flash civil society. When asylum seekers began to arrive, it was very difficult for the Red Cross and some of the established associations [to respond], because they had already planned their activities for the fall...We needed a lot of training ... its shows the threshold for getting involved with organizations was too high for people who just want[ed] to do something. I don't think everything needs to be long term. The backbone of civil society in Sweden [is] the ones [helping] now ... old ladies (and pensioners in general) are the backbone of civil society in Sweden, but now a lot of flash associations are helping. (Priyanka, Sensus)

While formal participation has seen a reduction, many are working at their own pace and in their own capacity to assist refugees. Irrespective of more formalized initiatives, flash movements suggest that embedded within Swedish civil society is a sense of altruism and civic duty. The visibility of flash movements also suggests more formal associations are nowadays eschewed by citizens. Flash movements come together virtually overnight, and disappear almost as fast. Refugees Welcome - Malmö is a hybrid of these movements. While they have a presence today (though seemingly rather limited), they were most active at the height of the crisis, in the Fall of 2015. Presently, they work closely with the 
camps themselves. Organizations like Refugees Welcome Malmö sprung up to try to alleviate some of the pressures associated with isolation and resettlement. Indeed, their role is more pronounced in the early stages of the pursuit of a new life in Sweden.

From above, it can be seen that native/local Swedish organizations offer refugees a multitude of resources. Of those mentioned, Swedish CSOs provide asylum seekers with:

1.) Education (both language and skills training-human capital)

2.) Try to help alleviate some of the stress associated with the immigration process and the potential resulting isolation.

3.) Attempt to build social capital among those with labor market contacts and ulterior members in society (those from different ethnic groups as well as with Swedes).

These resources range from immediate needs at reception and fundamental information and education useful for refugees awaiting a decision on their status, to points of interaction throughout the community where individuals can seek out information concerning anything in Sweden and attain further skills training to prepare them for their employment search. Like those of Hjerm (2005), these findings suggest that acquiring the proper social contacts (appropriate social capital) will provide refugees with greater access to employment than will more formal programs run by state organizations. Moreover, it appears that following the interests of the refugee themselves, rather than delegating tasks, is the most productive approach to providing aid. However, it takes substantial resources and time to train new people and weave together contacts from PES and private associations. 


\section{Ethnic Associations: Bonded Support within Ethnic Enclaves (Iraqi, Assyrian, Somali, Afghan)}

Using selected participants, the previous section provided an overview of how some native associations work with refugees. As noted earlier, these received greater overall attention as they were more accessible, and because they receive more funding (especially of more recent). Notwithstanding, as we know many newcomers seek out familiarity via friends, loved-ones or cultural comforts (e.g., religious tradition, food or comfort from those experiencing similar struggles), so this section answers the question to what extent ethnic organizations work with refugees.

For newcomers, ethnic associations may be central to stabilizing their lives. By and large, these associations provide local meeting spaces to gather, hold forums, join in projects, and address topics facing the community. While many are broad-based, focusing on the needs of an entire community, they may also be narrow and address only particular issues such as women's activism or specific religious needs. It is in this realm that we find hybrid förening or FBOs, such as the Afghan's Women's Empowerment Program (AWEP).

The Afghan Women's Empowerment Program (AWEP) works to facilitate improvement in the living conditions of Afghan women. Some of its core functions include advocacy and educating Afghan women on their rights:

We try to have different programs (for example, exhibitions) so they can show that ... they are here and they can help ... with something specific with Swedish society. We are here if they need us. We collect different information from organizations. The most important thing is for us to share our own experience, the experience of the people who have lived here and been in the society and been in the Swedish and the Afghan cultures. It is one of the most important things for us when we work with refugees in Sweden. Some organizations are more well managed than others. (Helalia, AWEP Representative) 
AWEP is just one example of many ethnic organizations working with refugees and while it does serve the local Afghan women's community in Gotheburg, its reach seems to be rather narrow. Ergo, its aim is almost exclusively to work with at risk Afghan women. Notably, as Helalia suggested, for a multitude of reasons, inter-organizational cooperation may not always be possible. Unlike with native run organizations that seemingly work tirelessly to create a network of support, it seemed the opposite for ethnic organizations. There appears to be very little contact between ethnic organizations. However, some suggested they would like to find ways to do so.

The local Iraqi förening in Malmö is very accessible to those it is trying to help. It has open hours most every day, and it is located just north of the city center:

This association has many members, a large number of members, and they are active in different cultural affairs but also with the refugees and the integration. [First,] we invite Swedish people to come to the förening and speak with members about the culture, about poetry, about life, about the work, so you can find work in [Sweden]. [We also organize] some studies and these types of things. We invite everyone; it is open to all. I would say briefly these activities, cultural or otherwise, bring about social connections. [...] Our community is not just here; all our information and events also go to the members through telephone and Facebook, in Swedish and in Arabic.

The Iraqi förening acts as a salon. People are free to come and speak about whatever they like. By inviting prominent writers, politicians, and artists (among others), the association builds social networks. These networks provide access to employment in their own right, especially through making connections among refugees and Swedes, as well as help refugees become more a part of the local social fabric, enhancing their sense of community. 
Among others I spoke with, the Assyrian organizations also provided much to the local Syrian community in Sweden. The Assyrian organization in Sodertalje is the largest ethnic organization in Sweden. Notwithstanding, it operates primarily in the Stockholm area, so they are having difficulties accessing local Assyrians in the South:

The federation started in 1977; some years prior to that some others had sprung up. And then they decided to get it all together. Helsingborg recently has fallen apart. They [lost] the need to fund a local association. Very few Assyrians in Malmö. The biggest community is in Stockholm. If you put together all the activities, it amounts to [a lot]. [We offer] language classes, dancing, lectures, seminars, weekend courses, summer camps, and we publish a magazine throughout the year. With every diaspora community, it is a huge challenge; the easy thing to do is to just go with the flow. As a nation that is threatened with extinction, our culture is perhaps extra important to preserve. (Afram, Assyrian Community)

Like the Iraqi förening, the Assyrian network helps the local Syrian community build cultural awareness, while at the same time allowing those within the community to become more aware of their rights and the opportunities available to them in Sweden. However, unlike the Iraqi community, despite working with Swedish networks, the Assyrian network did not appear to be reaching out to other ethnic organizations and operated almost exclusively in the Stockholm area.

We should expect a natural gravitation toward ethnic organizations, as ethnic enclaves do provide a sense of solace for newcomers. However, within the web of organizations, there seems to be a clear disconnect within the network of ethnic organizations themselves as well as with other Swedish run CSOs. As noted, more wellfunded Swedish run organizations are continuously working to improve communication and cooperation between these networks. At the same time however, it appears they may not have great relationships with ethnic organizations (some of these challenges are 
addressed in section 4). Moreover, in terms of interconnectedness, it also appears ethnic organizations do not themselves have a lot of interaction between one another. Indeed, ethnic organizations provide much needed immediate social capital. In other words, given their circumstances, there is plenty of room for bonding to take place. But, as highlighted by several other studies (Browning 2009; Portes 2007; Ryan 2011), this may not be the right type social capital as too great of a reliance one's own community may be stalling refugees from penetrating the Swedish labor market.

\section{The Role of the Swedish Church and other non-Formal Faith-Based Organizations}

The previous section highlighted the utility of ethnic organizations. These organizations

primarily provided refugees local points of contact whereby refugees can interact with others within their own ethnic enclave and to a certain extent, with others from outside. Albeit, one of the key findings is the latter is rarely the outcome. In addition to these organizations, other faith based organizations are actively involved in the integration process. Their role is examined below.

Aside from the Swedish Church, which works most closely with the state and other IGO's (the Red Cross, Amnesty International among others), as they have the permission to work within refugee camps, non-traditional faith-based organizations are becoming more active in the integration process. To an extent, we may think of these as being similar to ethnic organizations because they often serve a particular community. FBOs (apart from the Swedish Church), have become more active. Swedish FBOs have emerged as influential actors in assisting refugees. These organizations work directly 
with asylum seekers and the public at large to support their education and formation of community connections. Sallahuddin, from the Islamic Academy, explained:

When they had a lot of refugees coming, we ... took in a lot of refugees, almost 200 to 300 every night. Kontra Punkt, the Turkish Mosque, among others, came and helped ... Also, when the Islamic holiday came in that time last year, we gave the children some gifts. The Swedish Church was in there and actively working [because] they already have established connections and so forth where the Islamic community [does] not. It will take some time, but we must continue to work for this.

While the Svenska Kyrkan (the Swedish national church) applies a more comprehensive agenda (insofar as it works directly with refugee camps), others are more specialized and often serve specific communities. Smaller FBOs help refugees appear to not only assist during the reception phase, but also thereafter. In addition to cultivating relationships with for the religious community they represent, they may also work to assist in bringing together refugees with the local Swedish population.

To alleviate some of the misunderstandings circulating about Islam, organizations such as Islam Akademin (IA) hosts roundtables, meets with individuals, and holds information sessions to prevent extremism and educate the public. The Islam Academy is an educational institute that teaches about traditional Islamic education; it also provides outreach to the local community and industries in Malmö. It engages in five key activities related to education and the spiritual, social events, nature, sports, and culture. Moreover, it works to educate against violent extremism. The Academy works in close cooperation with Manpower, a temporary employment agency. Moreover, IA:

Also [acts in] cooperation with the chamber of commerce, just trying to do something with local small businesses, local small growth, restaurant owners, import/export businesses. Not from [the] beginning. They already exist but they cannot develop it. There was one restaurant that did well and grew really fast, but 
then it became very [disorganized]. They did not have the competence to take it to that stage. Bringing in speed dating helped create connections. (Sallahudin)

IA is unique in that its aims are multi-tiered. They not only reach out to the native Swedish population, but also to refugees. Through education, the organization helps alleviate some of the misunderstandings encircling the Islamic faith, and brings together individuals from different communities (e.g., the public, private, native, and non-native sectors). While most FBOs except for the Jehovah Witnesses are reported to work with refugees, IA is a prime example of how religion, education, and public discourse can work in tandem to bring together people from all communities; this improves the level of discourse typically provided by local and international news outlets, and forms relationships among communities that may serve to bolster employment opportunities. Its resources are hence two-fold. First, they provide education and insight to very real issues in the community. Second, it helps build social capital between refugees and local business, especially in the Muslim community.

While this is indeed a small sample of the acting FBOs in Sweden, it does appear that FBOs may act more like local Swedish CSOs, insofar as they build bridges of communication between CSOs, themselves, ethnic organizations and the state, than unitary ethnic organizations. Given the unique position of FBOs (especially Muslim organizations) in that they are in close contact with refugees and have individuals who are both fluent in sending nation languages and Swedish, they may be particularly strong actors in creating social capital in Sweden and Europe relies upon as the crises evolves.

Despite the benefits available from each type of CSO (e.g., assisting refugees at time of reception, language and skills training and the production of social capital both in 
ethnic communities and in between communities), unemployment remains high. CSOs, are visibly a much more relied upon actor in the refugee integration. However, several challenges persist. While this section gave an overview of what different types of CSOs may offer refugees during their integration process, the following section sheds light on some of the challenges facing refugees, as described from the perspective of representatives of civil society.

\section{Availability and Access: Challenges of Participation in Civil Society}

The previous sections gave insight into how different actors assist refugees in their integration process. Essential to this analysis however, is the need to look more closely at the challenges preventing them from doing so. Moving beyond the overview of visible actors working with refugees, this section puts forth some of the challenges expressed during the interviews.

Drawing from the questions posed during the interview process, the following section gives a perspective on the challenges faced and utility offered by civil society with regards to the process of labor market integration. The section provides insights into how the role of civil society in relation to this process has evolved and the resources they now provide, particularly in terms of the allocation of information. Finally, the section discusses how civil society representatives view their role going forward.

\section{6a. Perceptions and Discrimination}

The process from reception to employment is complex and complicated with political and social challenges. This affects how and the extent to which CSOs can interact with newly 
arriving asylum seekers and refugees still in camps. One such issue is discrimination and the need to provide for the safety of new arrivals. For their protection, much of the information concerning the locations of refugee camps must be kept confidential:

Camps under migrationsverket are kept secret. No one is permitted to know where they are. And because of the most recent fire [(in Munkedal)], they will all stay a secret. It is, therefore, up to the person in the camp to uncover information. At one camp that I know of in Simrishamn, they have a language board in Afghani and Arabic that informs of local språk cafes and other activities to go to. One example was a public garden. I do not know how it is for other camps ... We do know where some of them are because we were given permission. But we do not have access to them. (Refugees Welcome Representative)

Refugees in camps are isolated. Due to safety concerns ${ }^{32}$, in Sweden, their locations are kept secret and it is difficult for CSOs to access that information, even if they are looking to assist the individuals inside.

Along with safety concerns, members of civil society noted other forms of discrimination. For instance, finding work is a challenge. This is more pronounced in some communities than in others. For Somalis, the future remains bleak. "It has gotten better but not substantially. There is a whole kind of negativity attached to being a Somali. In Sweden, there is an entire generation of refugees who grew up with no education or order" (Amina). Coming from a place like Somalia, with hardly any infrastructure or rule of law and only inconsistent educational practices, how feasible is integration into a structure with austere requirements, high levels of regulation, and very few low-skilled positions? Entrepreneurship offers one route, but opening a business in

\footnotetext{
${ }^{32}$ Concerns over the safety of refugees emanated from a string of threats and a large fire being set to a refugee settlement. Swedish policy prevents virtually anyone other than the Swedish church from working directly at refugee camps.
} 
Sweden is not as simple as merely setting up a shop and opening the door. As Amina queried, how is one to:

Explain to new migrants that they need to pay VAT? They grew up in a system with virtually zero accountability. For instance, if they start a business in Somalia, they may pay taxes here and there but there are very few restrictions for starting a business. [In addition to paying taxes, once you start a business here] you lose all your benefits. If you are living on welfare and getting any help, as soon as you register that also disappears.

Instead of going through the Swedish process, they do not pursue the traditional route.

Many in the Somali community find alternative avenues:

What happens is they talk to friends. They come together and instead of seeking out an organization or state institution, they borrow and exchange funds in and amongst themselves. Authorities cannot follow the trail. There are plenty of scandals, because of regulatory pressures. (Amina)

In addition to pressures from the high level of taxation, there are few natural places for refugees to interact with those who may be able to offer assistance.

The primary goal of PES (the state-run directorate of employment training and integration-arbetsförmedlingen) is to help refugees formulate a plan, consisting primarily of supplemental education courses. These classes are intended to make refugees market-ready. To provide access to local opportunities, PES helps refugees find internships. However, these often do not yield long-term, stable forms of income:

A lot more chances need to be created. There should be more interaction between natives and refugees. Of course, the refugee needs the proper training and skillsets, but we know that people have the required skills and training and still do not get the job ... [they] need to have more acceptance towards social entrepreneurship so that they can work for a living. If you have an entrepreneurial person, they should be motivated and encouraged [to do] that. Right now, you get punished. (Amina, Somali Business Center).

As Amina suggested, there are several difficulties facing the refugee community and that certainly, these may vary by group. For Somalis, these difficulties are more pronounced. 
Even for those with high levels of education and knowledge of Swedish, the general perception of the Somali community may stall access to gainful employment. Along with other challenges, hidden discrimination may make cultivating social capital for highly marginalized communities especially difficult:

Refugees do not even know how to make contacts and social networks. [This is especially] difficult in the business world. Everything is about contacts. When you don't have these social connections you are not getting these [professional] connections. [We] need to create new networks and pathways. Civil society needs to be more of a facilitator, to get the commercial sector connected and acquire a lot of contacts from not only the local Swedish community but also the local Muslim community that has been here for decades. Good contacts will be good at bringing these things together and will make it easier for refugees to meet local employers. (Amina, Somali Business Center)

While civil society may be able to foster social capital, following Amina's insight, it appears more needs to be done. There seems to be a disconnect between what CSOs offer refugees and what they can access. To overcome some of these lapses, more effort should concentrate on encouraging relationships between local business owners, civil society and refugees.

There are some signs that things are changing. Irrespective of the difficulties in finding publicly subsidized employment:

There has been a shift to private companies. [The Swedish economy] has a demand for a lot of knowledge and has many different areas of ... expertise. The private companies have a role; they have put a lot of production in other countries. It is colored by this phenomenon. Over the last two years, there have been more opportunities in construction and cleaning. Tax reductions in Sweden ... for normal people [have] led to [the creation of] more jobs. For instance, new markets for home cleaning [have] emerged. More people have been able to afford help. (David, Arbetsförmedlingen)

While some new low-skilled jobs are emerging in Sweden's economy, the majority continue to be those requiring tertiary education and advanced skillsets. 
Despite these trends, Amina's observations regarding the Somali community and her experiences as an asylum seeker in the 1990s have afforded her first-hand knowledge of the challenges facing refugees. She and her organization, the Somali Business Center, work with immigrants, local industry, and the government to cultivate networks among newly-arriving Somalis and the local social structure. Impeding the growth of these relationships, she expressed a belief that discrimination is widespread and severe, and that regardless of the resources available (e.g., jobs and networking potential), such discrimination may keep refugees from accessing jobs. As was evidenced in Bursell (2012), discrimination can be based on something as superficial as one's name. In support of these findings, the head representative of Red Cross Malmö, who was also a former head mistress at a local high school expressed the challenges of identity and discrimination:

First, I think it is being labeled a refugee. Most never even get an interview. But there is more to it than that. [For instance], we have one volunteer, he is high[ly] educated. He is not a refugee. He came because his wife is employed by one of the big companies. He had been working as a high-level marketer in Iran. I cannot say how many applications he has sent out, but it's a lot. He has not received a single interview. He speaks fluent English, but he can [also] make himself understood in different languages from [the Middle East], and now speaks quite good Swedish. He is now employed in a trainee program at another NGO. It is work, but it has nothing to do with his competence. I think the Swedish labor market is [close-minded], and they look for the people who are like themselves. As far as I can see, Denmark is worse, but Sweden's labor market is moving into their direction. My point is, from what I have seen, if they are named Muhammad or something like that, they have so much difficulty entering a [highly skilled position]. (Representative from the Red Cross, and former Head Mistress of Malmö High) 
If it is the case that Swedes are becoming more closed-off to others, and less in support of refugees, which a new poll in Aftonbladet $^{33}$ suggests, then irrespective of possessing tertiary education and language skills, breaking down the barriers to the Swedish workforce may remain invariably difficult.

Discrimination, lack of central meeting places, and networking contacts with businesses are all challenges refugees face. Embedded within each is the effect they have on how refugees access information, one of the primary resources provided by CSOs. In terms of solutions, "we talk a lot about social inclusion, but if we expect the new Swedes to get into Swedish society, we [native Swedes] must let them in. We talk talk talk and we have all these values, but how do we actually engage in them" (Red Cross Representative)?

\section{6b. Accessing information}

The previous section gave insight into potential challenges related to the issue of discrimination. The following looks more closely at the challenge of how information is accessed. In particular, how high-skilled refugees navigate the labor market from the perspective of CSO representatives.

From the perspective of the Malmö Iraqi Association, Iraqi refugees who receive tertiary education have a higher chance at successfully entering the workforce; however, many others remain in isolation.

I think one part of [the] Iraqi people in Sweden have integrated in a good a way. They, their sons and daughters, have found a job and they will live better and

\footnotetext{
33 “Fewer Swedes Want to Help Refugees," Aftonbladet, September 6, 2016, accessed May 18, 2017. http://www.aftonbladet.se/nyheter/article23452855.ab??eav=7f4973978511c4ec2a3f0e78594e2b432d5d35 $\underline{\mathrm{c} 3}$.
} 
better here. But this is one part of Iraqi people. [The other part] is difficult to integrate and they live isolated and it will not be good there for them. Maybe they will go back to Iraq. Maybe 10 to 15 [percent] will go back to Iraq, especially those who came here last year. They had a dream that they will get an apartment and money and everything will be good but the situation is not like that. (Ivan, Iraqi förening Representative)

Ivan suggested that remaining solely within one's ethnic enclave may prove deleterious to refugees (Warman 2007; Danzer \& Yaman 2013). While the local associations will help many settle when they first arrive, in the long term they will have to work toward obtaining an education and becoming more active with the local Swedish population.

Along with these challenges, a persistent obstacle is accessing information. Especially for those with high levels of education and work experience requiring verification, taking the proper steps to prove one's qualifications is often difficult:

It is a problem. It is not easily accessible ... it is not easy enough. Often, the people that they meet, they have letters or some decision from the government. They do not understand it. One project where they meet, they also see this. They often say that they are the first Swedish person that they have met. (Kornelia, IM)

In a recent article in The Local ${ }^{34}$ (Sweden), one refugee explained that his only way into the labor market was via those he met at SFI. Korta vagen, an expedited process available to refugees with high levels of education, was unknown to him. Granted, he eventually stumbled upon the opportunity, but the information about the program was not readily available.

For CSOs, gaining access to refugee communities is certainly part their particular challenge. Immigrants may gain information from a variety of different individuals (e.g.,

\footnotetext{
34 "Syrian Refugees Speed into Top Jobs in Sweden," The Local, June 14, 2015, accessed May 21, 2017. https://www.thelocal.se/20150614/syrian-refugees-take-sweden-fast-track,
} 
from those directly linked to the labor market or from others met through social activities). While these points of access do exist, some have suggested that refugees:

Do not know [what] services exist. They remain fairly unknown, in part, due to funding we still do not have that capacity to get the word out. We have Facebook, a webpage for Rådrum, and other modes of dispersion such as municipal social guides, which can help with local municipal expertise, but it is not enough and it is not targeting refugees themselves. (Magnus, Rådrum)

Providing local refugee communities with information on and access to the resources available to them is difficult. Magnus suggested that the biggest difficulty for non-state actors is an issue of funding. He believes that adequate funding would help in two specific ways. First, Rådrum and other organizations with similar goals would be able to hire people to reach out directly to refugees in need. Secondly, they would be able to hire translators. While it may not be possible to hire enough people with the specific language abilities required, it would be possible to bring on more people with the primary goal of outreach, and then outsource translators where needed.

Amina has also found it difficult to lead asylum seekers to proactively access Rådrum's and other similar services (e.g., language exchanges and other labor market training programs such as those offered by the Somali Business Center). Not only does the organization offer direct counseling, it is also tied to the Somali Umbrella Organization, which is made up of twenty smaller groups, all with a single goal. More specifically, the Somali Business Center uses individualized meetings and programs to help refugees with job placement. In addition, the Center organizes seminars and workshops on how to find jobs. At these workshops, motivational speakers and people who have successfully transitioned to life in Sweden are invited to talk. Yet despite all 
their efforts and their knowledge of the Somali language and culture, it is still difficult to access the local community and fully assist them with integration.

Civil society is, in part, secondary to the process of resettlement. Its utility, however, becomes more pronounced as refugees overcome the initial hurdles and begin their search for employment. Regardless of the potential of civil society, language remains one of the foremost challenges throughout. While cultivating common spaces for refugees to integrate with Swedes is a persistent issue, refugees must first have the language skills necessary:

People who do not have Swedish or [at least] English [are unable to interact with] the companies who have a lack of will to employ [people] who do not have these languages ... they regard the Swedish or the European education with a lot of respect. It is tough to come from other places and have your education validated. It looks different from different places. It is not always right to compare. It doesn't necessarily say that much to learn to take to a job which you may not have had before. (Magnus, Rådrum)

Given structural issues, such as an apparent lack of flexibility among several companies, for civil society to be truly effective, refugees must have some language capabilities. Notwithstanding, civil society aids the state by providing a number of supplemental activities, which should lead to refugees to having better access to what is available to them. The overall capabilities of civil society, however, remain under-utilized. In other words, it may not be the case that civil society is underperforming, but rather, it is extremely difficult to gain access to refugee communities. This is especially the case for those who arrive and move directly into ethnic enclaves. Seemingly low levels of interaction, may also be attached to the consistent lack of funding. In this regard, CSOs rely almost entirely on volunteers; albeit, they also require some permanent, full-time staffers to coordinate and implement activities. Indeed, volunteers may operate with a 
greater personal desire to help refugees reach their full potential. But without consistent funding, encouraging individuals to remain consistently active in these schemes is difficult. If the precarious nature of employment is dissuading many from staying on board with local CSOs, then we should suspect a lull in consistency of the programs themselves. Moreover, given that it appears communication is one of the greatest challenges facing all types of CSOs, creating a more viable employment platform, at the very least, is essential to improving the legitimacy of civil society in refugee integration.

New policies should take into consideration the utility of CSOs and provide greater consistency across the funding scheme. Aside from direct policy measures, more needs to be done to encourage engagement at the local level between Swedes and refugees, as a means of stymieing discrimination, helping educate new arrivals, acculturate refugees lacking essential Swedish-specific qualities and increase public discourse to carve viable paths of communication with the refugee communities themselves. This means sending actors into refugee communities and actively recruiting and empowering individuals to proactively spread information, participate with CSOs and inform other members of what is available to them. Two of the largest challenges facing refugees are empowerment and communication (at both the meso and the micro level). Put aptly by Louise (a Yalla Sofielund Manager):

When I go home at the end of the day, I hang out with Swedish people. I would not say we are necessarily [a] segregated [society], but we lack a common reference point. When you go home, everyone in your closest circle of friends has common interests and points of interaction. But I would love to have more nonSwedes in my circle of friends. I wish there were more natural ways to spend time together. This is difficult, though, and lacking Swedish on their part makes it more difficult to integrate and harder to [find] common ground. All I can say is overall, there is so much the state needs to learn from civil society. The state has had good intentions but they have not necessarily worked out. The state is more 
sort of all-encompassing. Civil society is more in tune, guided, and informed. People come from all over the world. This needs to be taken into greater consideration.

The state provides a wider, legalistic scope for how refugees should be integrated, however, much more can be learned and utilized by the third-sector. As Louise poignantly identifies, cultivating social capital is necessary. Unfortunately, Sweden and other host countries face the dilemma of not only providing refugees with the necessary skills (especially language), but also the challenge of motivating native populations to interact with newcomers and refugees, more generally. Nevertheless, challenges to civil society are not necessarily their own doing. CSOs have continued to play a more systematic role in this process, however its capabilities continue to rest on measures provided by the state. Over the last sixteen years and most certainly over the last five (2010-2015), policy concerning refugees remained relatively consistent. With current transformations, CSO's face additional challenges of reifying their utility. Begging the question (highlighted below), if refugees are dissuaded by policy developments from integrating, how should we expect civil societies role to be carried out and advance in this process?

\section{New Legislation: Effects for Refugee Communities}

To gain perspective on additional challenges facing the efficacy of CSOs in the refugee integration process, this last section takes into consideration a recent piece of legislation revoking the automatic right to family reunification and permanent residency. No longer are asylum seekers given refugee status on a permanent basis. Instead, all new refugees 
are placed on a three-year probationary plan. One repercussion of this change is that before refugees can apply for family reunification, they must prove they are gainfully employed:

I do not know what they are doing. It is so bad; it is just going to further force people to enter society. They are not going to be able to reunite with family. This is going to prevent people from going to University. We should be able to provide for these people and encourage them to pursue what they want to. I think we have slim chances of helping with this new law. (Magnus, Rådrum)

Magnus suggests, placing limitations on refugees will more than likely pressure them to not pursue programs that might help assess their situations and when possible, recertify in their previous fields (and thus reach their full potential). There are two key foreseeable problems. First, Sweden will struggle to attract those with high levels of education and highly desirable skills; those who do come to Sweden are unlikely to take the time to become recertified. Second, refugees will be deterred from establishing long-term connections, greatly affecting the cultivation of relationships (social capital) and exchange of information between groups. The increase of self-doubt, dissatisfaction, and sense of being an outsider or second-class citizen will arguably be greater for the highly educated and trained:

Instead of applying pressure to refugees, a representative of the Red Cross articulated that she would like to see more state-level reform. For instance:

In the future, I hope that we [are in] contact with more camps. Or the better thing is more camps close so that [refugees] can find their way into society. We hope to help just with integration instead, because we still have camps ... the best thing is to close the camps and help them find a home and get them a job so they can manage [on] their own, but we do not know how long it will take. 
After asking several representatives of different organizations in Sweden, I concluded that the general sentiment was the shift in policy was not a good idea, but that rather, it was counterproductive to the aim of settling refugees. Priyanka expressed:

It is a long-term investment. [If the chance for a future in Sweden seems slim], refugees may ask "why should I learn Swedish? I will try to get a Swedish passport and then leave and go somewhere else.' Right now, it is so hostile here. You are not giving people incentives. Families view this differently; [they want] to invest their lives here because of their children. For people who do not have children, they do not feel that they have a future here.

Losing sight of the long-term agenda of creating stability and autonomy for the refugee population creates many hurdles. These hurdles will be deleterious to the potential benefits of civil society, in that they will fundamentally stymie a newcomer's willingness to learn Swedish and participate in local activities and organizations designed to help them integrate. This will likely promote a sense of alienation and decrease the importance of investing in their new lives in the adoptive state. Most of all, it will likely reduce the importance of forming relationships with those outside of their communities and make any long-term agendas to stay in Sweden futile. Though the outcomes of this new policy are unknown, many do fear that increasing barriers and restrictions will lead to insurmountable disenfranchisement.

To sum up, this new legislation has placed the refugee population in an even greater state of uncertainty. "To change the rules in the middle of the game, it is not ethical. Keeping people hanging on such a line will remove the motivation" (Sallahuddin). No permanent residency or the ability to bring your family with you shifts the long-term outlook of those who came to Sweden to start over. 


\section{Conclusion}

Through the analysis of my in-depth, semi-structured interviews with representatives from civil society, it appears that CSOs, especially, ethnic and faith-based organizations (other than the Swedish Church), are underutilized and not yet fully trusted by the state. Despite this being the case, it also seems that their role in the integration process is becoming more systematized and supported, especially for native, non-religious, nonethnic associations. These findings suggest that increasing refugees' access to all available resources remains difficult. While the state is at the helm of the integration process, CSOs assist not only in reception, but also during the later stages. CSOs should not be regarded as competing with the state, but rather as complimentary. On a local level, they provide insight into how the process is carried out, where it may or may not be visible to the state, and areas that need improvement. One example is in the provision of increased access to cross-cultural engagement within communities, and the offering of additional educational and cultural programs. Indeed, ethnic associations provide an insular, localized community for refugees. However, accessing organizations provided by local Swedish authorities requires greater effort.

My findings suggest that some of the challenges facing civil society include funding, community accessibility, information dissemination, discrimination, cooperation with the PES, förbunds (study circles/activities), and förenings (primarily ethnic organizations). The role of larger international organizations is clear. Mainly, they assist in the reception process and while asylum seekers reside in camps. Flash movements such as Refugees Welcome, Kontra Punkt, and other local actors assist during times of crisis, but their effect can be fleeting. Kontra Punkt, however, has transitioned into a 
permanent actor. As refugee labor market integration persists as a challenge and a need, local CSOs must continue to adapt to meet areas where gaps persist. Rådrum and Yalla Sofielund are just getting started, but given the progress they have made thus far and the increasing number of participants they attract, I expect that they will continue to become more active in the labor market integration process.

Many within civil society hope that their roles will becoming more formalized and relied upon as a means of helping refugees gain access to others in the community and cultivate networks. It seems clear that civil society is playing a larger role than it has in the past. Several new programs now exist that help to ease labor market integration measures. However, their full effect and utility are yet to be seen. While refugees are finding their way into more and more training programs, it is not clear that this will translate into stable employment. It would appear that having access to these programs will offer a point of access for refugees to begin cultivating labor market skills, but at this point, the end result remains unclear. What is becoming clearer is that the state can no longer carry out integration on its own as it once had. The pressures of globalization (e.g., the rise of international competition and the rise of its foreign-born refugee population), mixed with the transformations in the Swedish society and economy (e.g., educational requirements and greater liberalization of its market), leave a lot of questions unanswered.

Civil society continues to be a mixture of different types of associations with various goals. One major challenge remaining for NGOs concerns the stability of CSOs. The lack of consistency makes it difficult to plan and hire for the future. Hence, most organizations working with refugees rely heavily on volunteers. For instance, flash 
organizations rely almost entirely on social media and rapid respondents to help assist during times of crisis (e.g., fall 2015). These organizations are noticeably effective in attracting individuals to help when other more traditional entities (e.g., Red Cross \& Amnesty International) are slow in meeting the immediate circumstances. Despite their utility, these groups often disappear or are no longer needed as they were during reception. However, as noted, there are some exceptions-Kontrapunkt. Ethnic organizations play a role as a point of contact. However, based on my interviews, these are not consistent either. While they may act as a means of establishing relationships, they may not be directly associated with access to the labor market. Yalla Sofielund, IM, and similar projects working to directly engage with refugees are most promising. Not only do they offer asylum seekers a way of venturing outside their ethnic enclaves, they help to train refugees in skills that may at some point be marketable. These programs are especially useful for women. While these organizations do prove useful for training refugees, there still appears to be a gap between CSOs and building meaningful relationships with local firms. Given the shift within Sweden's economic orientation, we should expect private industry to employ a significant percentage of refugees. Based on these findings, CSOs do accompany labor-market training programs run by PES (the state). However, as highlighted by Amina and to an extent Sallahuddin, there is a marked disconnect between cross-communication between the private and the civil sector and realizable hiring practices. As suggested by Amina, the practice of hiring refugees is likely viewed as corporate social responsibility, rather than a realistic hire practice on its own. Admittedly, this research did not engage wholeheartedly with private enterprise, as it would have required selecting upon the dependent variable. But based on evidence 
revealed through the semi-structure interviewing, these findings suggest, entering the private sector for refugees, seems unlikely, albeit needs greater research. Beyond relationship building between CSOs and the private sector, one other clear remaining challenge is cultivating greater contact between native organizations, which are more systematic, pluralistic in their aims and much more well-funded, with ethnic organizations. It appears, fostering these connections (either through legislative measures or via grassroots activism) would greatly increase the procurement of social capital between natives and refugees. In theory, this should greatly increase chances of future, long-term employment in the Swedish and European labor market.

Other, larger international organizations like the Red Cross remain actively involved in the integration process. While they may not be directly associated with labor market access, they do provide refugees with information. One of their approaches is through internships. Outreach programs with the Red Cross have also successfully recruited volunteers who are themselves refugees. This appears to be extremely effective. Not only does it empower refugees who may be looking to gain social contacts, it also allows them to interact with native Swedes to discuss their stories and difficulties, which should help to achieve a more nuanced relational perspective to their plight.

Some of the relevant literature has argued that state-assisted integration is not as effective as other interventions (Valenta and Bunar 2010). Mestheneos and Ioannidi (2002) claimed that highly-developed welfare states may succumb to discrimination against marginalized populations. However, the extent to which discrimination exists within the Swedish system requires much more research. Like Koopmans (2010) and Hjerm (2005), my findings indicate that not only are refugees having a hard time finding 
work in Sweden, they also do not have access to the same opportunity structure. This may come down to an issue of relationships and networks, but if these findings remain consistent, we may eventually be forced to assume that more developed welfare states have an inverse effect on integration. We will then need to reconsider how access to social rights — access to welfare (Sainsbury 2006) —affects local attitudes and employment opportunities.

In sum, the state has traditionally been, and continues to be the primary facilitator of refugee integration in Sweden. After the numerous interviews I conducted with civil society members, my findings suggest that CSOs play a much larger role than they have previously. Due to the most recent migration of asylum seekers beginning in 2011, civil society's approach is now much more systematic and relied upon. As more and more refugees filter through etableringsplan and awareness among groups blossoms, I expect that CSOs will only continue to become a more central figure in the labor market integration process. Nevertheless, some fear that "soon the halo will fade and [refugees] will just become 'immigrants.' Together with the rest of us who are non-Caucasian, it is almost like a 'second-class citizen"” (Priyanaka, Sensus). A shift in sentiment from regarding a person or a group in need to that of an "immigrant" could have significant effects that are not fully understood or known at this point. 


\section{Chapter 6. Employment Challenges: Individual Experiences with Labor Market Access for High-Skilled Refugees in Sweden (2000 to 2016)}

Over the last four decades, Sweden has undergone several changes (e.g., extensive privatization, increased support for its far right political party and a sharp increase in the size of its foreign-born population). In 2015, an estimated 163,000 refugees arrived in Sweden. By 2016, Sweden's foreign born population reached 18 percent of its population, making it the most diverse EU member state. Coincidentally, it is also one of the most segregated states in the OECD (Farchy \& Liebig 2014; Gustafsson et al. 2017). As highlighted in Chapter 3, the current refugee population is facing an entirely different economic and political structure than it has in the past. The platform for integration has shifted from being purely state-driven and relying on low-skilled industry, to a more pluralistic and cooperative approach between the state and civil society that requires high-skilled workers and service-oriented training. Due to the liberalization of Sweden's economy and more flexible work organization (Blomqvist 2004; Rosholm et al. 2006; Jonung et al. 2009), the high number of newcomers, and Sweden's societal organization, finding long-term gainful employment has become more and more difficult.

This chapter explores those challenges from a refugee perspective, and is divided into four sections. The first gives a brief overview of the aims of this chapter (e.g., this chapter offers an interpretive examination of the labor market integration process and highlights the challenges associated from the perspective of the refugee). The second presents how data was collected and subsequently analyzed. To give relational perspective from what we know about the Swedish model of integration, section three discusses many of the structural challenges and obstacles faced by refugees. Drawing 
from 45 interviews conducted throughout Sweden (Skåne, Småland, Gothenburg, and Stockholm), section four describes the experiences of several purposefully selected highly qualified refugees. To better understand potential factors enabling and impeding refugees from accessing employment, section 4 is operationalized by age, gender, time of arrival (2000-2010 and after), and degree of entrepreneurship. While ethnicity was used to select as diverse of a pool of candidates as possible, it was not rigorously analyzed here. As noted in previous chapters, these groups were selected because they represented two critical points of analysis. 1.) Each group was at one point the largest arriving group; 2.) They each classify different sociopolitical and economic points in the evolution of refugee policy in Sweden. Hence, irrespective of one's ethnic background, this research was interested in shedding light on how age, gender and time of arrival may affect labor market outcomes for high-skilled refugees.

The last section summarizes how these participant perspectives provided insight into how refugees gain access to the available resources and the extent to which refugees may bridge out of their ethnic communities (e.g., how social capital is manufactured). Lastly, it provides an outline of some of the difficulties which they and others in their respective communities, experienced throughout their integration experience.

While the previous chapter discussed the role of civil society from an institutional welfare perspective, this chapter relies on scholarly work related to economic sociology and social capital theory (Granovetter 1973; Portes 1998; Sanders \& Nee 1996; Wells 2011; Ryan 2011) to provide a micro-level viewpoint of the lived experiences of refugees themselves. While some broader ideas regarding Sweden's political and social structure are highlighted, these serve only as context for what the participants explained regarding 
how they interact within Sweden's government framework (e.g., its policies and regulatory agenda). This also serves to highlight how refugees form connections with native Swedes, as well as the obstacles that high-skilled refugees face in the labor market.

\section{Labor Market Integration and Refugees}

This chapter examines the challenges described by refugees that serve as obstacles to them entering the labor market. Analyzing these challenges allows addressing the effectiveness of current policy and the bureaucratic structure already in place, as well as how officials might begin rethinking ways of meeting refugees' needs. The process of integration requires a systematic approach, yet policy makers and researchers should exercise caution when making sweeping generalizations, and must differentiate between what is needed (via the state, local communities, and CSOs) and what is desired by refugee communities (such as the availability of certain types of employment). Based on current unemployment figures for refugees, it is clear that there is a discrepancy between what Sweden (in its state-based integration platform) views as best practice, and what refugees think they need to navigate the labor market. This research provides more indepth knowledge regarding how refugees access the resources available to them.

Aside from tangible capital (in-kind, as well as direct cash transference), this chapter is interested in highlighting the unique importance of information and how it is acquired (e.g., the pathways by which refugees obtain available information about what services and opportunities exist). In other words, along with state-run and civil society programs discussed previously, this chapter is interested in how information is accessed and the role of social capital in doing so. More specifically, it examines how bridging 
occurs between refugees (their respective ethnic communities) and native communities takes place and how the cultivation of new relationships or inability to do so, plays in employment. At the core of this research is the assumption for refugees to establish longterm stability, they must become autonomous; gainful employment is a key aspect of that autonomy and the right kinds of social capital should enable them to do so. While Sweden represents an exceptional case (the depth and accessibility to its social safety net programs for all residents and the sheer number of refugees it has taken in), this challenge is not unique to Sweden; it continues (and will continue) to be a matter for all EU members. Given the ongoing crises in the Middle East and North Africa, many refugees will be permanently resettling in Sweden as well as throughout Europe in the years to come.

Sweden has received non-EU refugees since the 1970s. Over the last four decades, asylum-seekers have continued to enter at ever-increasing rates. As a result, Sweden's political, economic, and social landscapes have changed. While it remains the socially democratic vanguard of Europe, its economy has become increasingly liberal and dependent upon highly skilled workers (Blomström et al. 2002; Schioppa 2009). Comparing skilled labor markets across thirty-countries, the 2016 Hays Global Skills Index, ${ }^{35}$ places Sweden as the country with the greatest labor market stress levels (based on seven key indicators: labor market participation, labor market flexibility, talent mismatch, overall wage pressure, wage pressure in high-skill industries, wage in highskill occupations and education flexibility the index highlights issues facing businesses). The European Centre for the Development of Vocational Training (CEDEFOP) has

\footnotetext{
${ }^{35}$ Hays Global Skills Index/ http://www.hays-index.com/countries/sweden/, accessed May 1, 2017.
} 
forecast that by 2025, 51 percent of the employment in Sweden will require a high level of skill (up from 38.5 percent in 2013) ${ }^{36}$ Such jobs consist of highly specialized services in the engineering, education, and medical fields, and other services requiring tertiary education. Yet most refugees arrive without a high level of education. A 2015 OECD Sweden policy brief stated that:

Many refugees come from countries with failing education systems and lack even basic qualifications and skills; others with tertiary qualifications often acquired these skills in a very different context, raising issues about the transferability of their credentials. ${ }^{37}$

Educating refugees and verifying their credentials are clear challenges among the wide variety of difficulties Sweden faces.

Given what we know about the current state of Sweden (the structure of its labor force, the high-rates of unemployment for its refugees, and the precarious nature of its rightward political surge), the goal of this chapter is to broaden our understanding of how high-skilled refugees become employed or struggle to do so, in a heavily regulated, yet privatized and competitive European labor market. The next section outlines the chapter's approach in acquiring participants, the limitations therein and outlines the interview process.

\section{Method and Material: Selecting and Interviewing Participants}

To address the question of how high-skilled refugees access available resources, shed light on the difficulties they experience throughout this process in the Swedish system,

\footnotetext{
36 "Sweden: Skills forecasts up to 2025." CEDEFOP http://www.cedefop.europa.eu/en/publications-andresources/country-reports/sweden-skills-forecasts-2025, accessed January 28, 2017.

37 "Sweden Policy Brief." $O E C D$ https://www.oecd.org/policy-briefs/sweden-promoting-labour-marketintegration-among-migrant-population.pdf, accessed January 28, 2017.
} 
and uncover the extent to which social bridging takes place this research applied qualitative approach, relying almost exclusively on semi-structured interviews focusing on refugees' employment-related experiences; these interviews were conducted from February to October of 2016. To make the sample as diverse as possible, the body of interviewees was comprised of 45 individuals from four primary non-EU countries and of which sent the largest number of asylum seekers to Sweden since 2000: Afghanistan, Iraq, Syria, and Somalia. Through snowballing, meaning direct referrals from initial respondents, other respondents were identified, and interviews were carried out with individuals from the Democratic Republic of the Congo and Eritrea as well. Notably, the interview processes strove to gain insights from both genders. A near-equal balance was achieved between male and female participants; however, there were slightly more women interviewed than men.

The goal of the fieldwork was to use in-depth interviews acquired through purposive and snowballing techniques in order to obtain narratives that would provide a proxy to some of the struggles refugees were experiencing as they attempted to enter Sweden's labor market. These data bring individual nuances that add to the depth of the greater body of literature on labor market integration and refugees in Sweden and Europe. Such details highlight the complexity surrounding this process, and can be used to identify barriers to accessing employment. The material included here consists of narratives that cannot be regarded as empirical data documenting external phenomena, but rather as data documenting people's perceptions and the related subjective bearing of their unique situations (Liversage 2009, 36-37). Through the use of narratives, this work complements the growing body of literature concerning the economic integration of 
refugees (Scott 1999; Rooth 1999; Bevelander \& Lundh 2007; Bevelander et al. 2009; Connor 2010).

While this research initially set out to acquire an equal number of low-and highskilled refugees, all of the participants eventually used in this analysis were considered high-skilled. Each had at least some post-secondary education. Due to language barriers, gaining access to low-skilled refugees was often not feasible. Yet these interviews evidence that even relatively high-skilled refugees have problems adapting to the Swedish labor market. Moreover, because the central research question concerns employment, the experiences of individuals at the very beginning of their integration period, while academically interesting, were outside of this research's central theme. Purposeful selection and snowballing techniques were used to acquire and select participants. Selection was based on gender, age, country of origin, and level of education. While primarily this research is concerned with employment, I did not use type of employment (public, private, or informal) as one of my indicators. While I agree that selecting by employment could yield more direct results, I refrained from using it as a dependent variable because it would have reduced my range of observation.

The selection of participants was surprisingly time-consuming. Initially, I sought out individuals through everyday interactions (e.g., chance meetings at cafes, local events, welcome proceedings held by refugees, gatherings at Malmö Folkets Park, public announcements on the board at the Malmö central library, etc.). Many of the contacts acquired through this approach were, however, outside of the observation period of this research, as they had arrived much earlier (in the 1980s and 1990s). From these conversations, I did gain significant insight into the structure of the refugee community 
and places I should go to find likely candidates (e.g., ethnic associations), as well as additional contact names, since many of the refugees I initially spoke with served as volunteers assisting newcomers.

Shifting my approach, I visited local ethnic associations (a specific type of förening) in Skåne, Småland, Gothenburg, and Stockholm. Förening are organizations independent from (though funded by) the state, that are not always, but often associated with a particular ethnic community. In Sweden, there is a unique relationship between the state and local activism. As long as an organization does not promulgate extreme doctrine or ideology (e.g., hate speech and extremism), it is left to operate as it sees fit. Some of the groups I visited with were more established than others; for instance, the Assyrian network was the most well-established in all of Sweden. This proved to be slightly problematic. Seeking out less well-established associations was far more difficult and often yielded little benefit for the additional effort. For instance, finding an Iraqi association was only possible after much trial and error. While the majority of my research took place in Malmö (since I was a visiting researcher based at Lund University, ten minutes' northeast of Malmö), I had to travel throughout Sweden to engage with communities that did not have significant populations in Malmö or Skåne (the southernmost county in Sweden), so as to account for differences in urban and rural settings. Accessing other groups (such as the Afghan Film Festival headquarters in Stockholm, the Afghan Women's Empowerment Program in Gothenburg, and the Assyrian network in Södertalje) required extensive travel around Sweden.

To learn more about the complexities embedded in finding employment as a refugee, I posed open-ended, semi-structured questions to my interviewees. They 
included: where did you receive the majority of your resources? (i.e. from the state, civil society, or social networks). How often do you interact with the native Swedish populations? (i.e. individuals born in Sweden). What has been your biggest challenge as you begin your new life? What type of employment have you and others your community obtained and is it long-term? And what are your aspirations for the future? Open-ended questions worked well for this research design. They gave the participants time to think deeply and discuss issues they faced, and allowed them to reflect upon their present situation, imagine potential solutions, and offer advice to those experiencing similar difficulties.

\section{Challenges Embedded in Sweden's Labor Market: A Backdrop to Individual Experience}

For refugees, finding stable employment is typically a long and arduous, if not indefinite, process. To acquire employment, any individual in any circumstance should have the appropriate skillset required for the opportunity. In advanced, service-oriented, postindustrial Western countries like Sweden, the demands are many. Often, employment requires a tertiary education, language capabilities, and an understanding of cultural norms, factors that can best be summed up as human capital.

Acquisition of the host country's language and culture is especially important for newcomers. Learning the language provides refugees with a pathway to useful, local information outside of their immediate communities, where the majority of their daily social interactions are likely to be carried out in their native language. Before reducing the scope of this analysis to specific individuals and taking a closer look at social capital 
in terms of interpersonal interactions and relationships, the following section outlines structural obstacles (specifically, segregation, the challenge of reception (e.g., its capacity to work with refugees and issues of housing), increased flexibility in its labor market and the types of jobs that exist and the challenge of learning Swedish to the standard of the Establishment Plan - typically requiring two years of study). Contextually (via an overview of the state approach), the following subsection also raises questions about Sweden's regulations.

\section{3a. Structural obstacles}

A clear debate centers on Sweden's regulatory structure. Its institutional model builds upon the Rehn-Meidner system: low inflation and unemployment rates, high economic growth, and an equitable distribution of income (1951). "In a model like Sweden's ... ambitious social objectives have to be squared with the need for a competitive and strong private sector" (Fischer 2006). A universal welfare system as expansive as Sweden's requires a high level of participation in the labor market. With its shift toward more liberal market practices (Bergh 2014), decreased availability of low-skilled employment, and high rate of taxation, placing refugees in sustainable, long-term employment is a challenge.

From the international perspective, it is not hard to see that there has been a decline in Swedish exceptionalism (Rothstein 2014). Highlighting this claim, Pierre $(2016,5)$ detailed:

Sweden's performance on several key welfare measures is down; among comparable countries Sweden now ranks twelfth in terms of poverty rate (Eurostat Online Database 2013); tenth in NEET rate (Neither in Education nor 
Employment); sixth in Gini coefficient (Eurostat online database); ninth in life expectancy (World Bank 2012), and fifth in preventing infant mortality (World Bank 2012).

When looking specifically at inequality in relation to employment, we find only 51 percent of non-European migrants in Sweden have a job and median household incomes are 36 percent lower than for native-born Swedes (in 1991 they were only 21 percent lower). Mark Dahlberg of Uppsala University also points to a reduction in the level of support to redistribute coming particularly from high income earners (e.g., those working in Sweden's private equity industry which is only second to Britain's in Europe) and a growing cultural clash. Namely, the growing tension between those from countries where men and women are segregated and criticizing the prophet Muhammad is considered a serious offence, with Scandinavian liberal values, which prize sexual equality and freedom of speech. ${ }^{38}$ Along with these declines and potential cultural challenges, Sweden also faces the growing issue of segregation. While not implicit, these transformations especially the latter - impact the refugee population's opportunity structure.

One explanation for this high level of segregation is that it is an unintended consequence of the Million Program (Miljonprogram), a housing program implemented by the Social Democrats in 1964 and again in 1974. The goal was to build one million new homes in one decade, in order to meet the demands of Sweden's growing population. Initially, working-class Swedes lived in these areas. However, in part due to government housing policies that place new immigrants in available housing, areas around

\footnotetext{
38 "Immigrants: Ins and Outs." Economist Special Report http://www.economist.com/news/specialreport/21570836-immigration-and-growing-inequality-are-making-nordics-less-homogeneous-ins-and, accessed April 29, 2017.
} 
Stockholm, Gothenburg, and Malmö have become known as betonförorter, or concrete suburbs, and immigrant ghettos (Fredlund Blomst 2014).

Segregated communities in their own right are not problematic. For instance, living in an immigrant/refugee enclave could offer a means of social and emotional support to new arrivals. Some have even suggested its positive effect on employment (Edin et al 2003; Xie \& Gough 2011). However, this research assumes, if such areas are not transitional (for instance, if generations of immigrants find that there is no place else for them in their host country), then such enclaves may negatively affect their residents, such as by increasing their marginalization in terms of education and further stigmatizing them in the society at large (Sanders \& Nee 1987; Whiteley 2000; Lancee 2010). Moreover, governments are less interested in allocating funding in non-voting foreigner districts. It was these conditions that allowed for the rise of the Sweden Democrats, as the quote below by Sofie Fredlund-Blomst (2014) expresses:

Despite the government's recent policy interventions, the May riots reflect continued and deep discontentment among Sweden's immigrant populations. The discontent is fueled by the persistent difficulties that [refugees] face, including increasing inequality, high unemployment—especially amongst the youth, experiences of discrimination and nativist political backlash.

Beyond the placement and perceivable segregation for foreign born communities (primarily consisting of refugees), once an asylum application is approved, refugees must begin the integration process. The most significant policy directive changing Sweden's integration platform came into effect in December of 2010. Monitoring and facilitation services were moved from the local municipal authorities to arbetsförmedlingen, or the Public Employment Service (PES, in other words, the state). While, the primary integration measure in the Swedish model has always been employment, under the new 
plan's legislation, employment definitively became the core of its agenda. However, since the transition, unemployment figures suggest that securing employment remains challenging. Even after a decade, unemployment rests at 22.5 percent for those who arrive from outside the EU. ${ }^{39}$ While there are several potential explanations for these pronounced levels of unemployment, this research found evidence for three: available resources to process reception, internal segregation, and a lack of Sweden-specific capital (i.e., an ability to speak the language).

\section{3b. Processing Reception: Expectations and Outcomes}

Given the challenge of segregation and present levels of unemployment for foreign born Swedes, what are some of the other visible obstacles in the integration process (e.g., the states' capacity to receive refugees, placement and housing)? First, it is likely that the new policy never imagined it would need to accommodate so many people at once. It "was a plan for 34,000 people. It has had major capacity problems. Many have complained, but many have not been taking [this issue] into consideration" (Frederik Malm MP, Labor Party). The state and civil organizations needed time to amend their plans and adjust to the new set of needs and challenges. The policy put into place in 2010, while a useful starting point for promoting labor market access, did not include sufficient mechanisms for a sizeable emergency influx of individuals in need. The lack of sufficient emergency personnel has persisted since the 1990s (Dacyl 1999). Processing asylum requests, assessing refugees' qualifications, and facilitating integration has ceased

\footnotetext{
39 "Refugees in Sweden: Seeking asylum — and jobs." The Economist http://www.economist.com/news/finance-economics/21709511-too-few-refugees-not-too-many-areworking-europe-refugees-sweden-are, accessed January 22, 2017.
} 
to be a timely process. For instance, the average time to receive assignment of a first decision, a milestone that affords an individual access to more formalized learning platforms such as SFI and the ability to make a plan with the Swedish Public Employment Service (SPES), is 343 days (data provided by the Asylum Information Data Base-AIDA).

In addition to the challenge of registering refugees, other structural issues slowed the process of integration. Namely, refugees are not required by the state to resettle in specific municipalities. Requiring refugees to settle in specific municipalities (Whole Sweden) was a previous approach in the 1980s. As noted in chapter 4, this approach had very limited success, as there were few jobs and native-Swedes in targeted municipalities. In other words, refugees were left rather isolated. Today, while many arrive with no contacts and settle wherever they can (these are individuals living in refugee camps), many prefer to settle near friends and family. But this raises the peculiar challenge of knowing where they are and how they are progressing in their programs. This has resulted in a surge of refugees settling in the surroundings of Stockholm, Gothenburg and Malmö. Consequently, at the height of the most recent refugee influx (November of 2015), Sweden ran out of places to house refugees. ${ }^{40}$ This led to instances of corruption, with government housing contracts being handed out to private contractors. The result was that refugees were taken to less-regulated housing developments. Jad (a Syrian refugee who arrived in 2015) explained:

\footnotetext{
40 Griff Witte. "Sweden is Running out of Housing for Refugees, So It's Pitching Tents." Washington Post https://www.washingtonpost.com/news/worldviews/wp/2015/10/20/sweden-is-running-out-of-housing-forrefugees-So-its-pitching-tents/?utm term=.4149d082fe07, Accessed January 20, 2017.
} 
Here in Sweden we have so many problems with finding a place to live, to find a home. It is very difficult here in Sweden. It is a big problem, not just for me, but for so many people-Syrians and other foreigners. If you want a house, you must pay more, almost double. This is a problem. Even the Swedish people are suffering.

The quality and location of refugee housing are of great importance to both newlyarriving and settled refugees. Access to efficient modes of transportation and the sense of connection that comes from finding a home both affect outcomes associated with securing employment. Therefore, few refugees move to more rural, less-populated parts of the country. The necessity to live in a major city is problematic. First, the lack of available housing in larger cities drives housing prices up, which may then leave refugees more reliant on their own community as they will have to share housing. Second, if this is the case, the probability of bridging with local Swedes should also be reduced, as the majority of their time will be spent with others in their own ethnic community.

Even though Sweden's market is more liberal now than in previous years, the State continues to play a central role in reception and the acquisition of stable employment. Etableringsplan is currently considered among the most advanced refugeeintegration programs in Europe. The two-year program of education and labor market initiation to promote job preparedness is the flagship of Sweden's greater integration platform. However, "according to SPES itself, in the past 24 months only 30\% of refugees put through its integration program have found jobs or accessed education."41

In part, low levels of employment are associated with the types of jobs provided and the level of skill possessed by the refugee. High-tech and service-based industry

\footnotetext{
${ }^{41}$ Edwin Lane. "How Sweden tries to assimilate its influx of refugees." $B B C$ http://www.bbc.com/news/business-34261065, Accessed January 10, 2017.
} 
make up the majority of what is available. For high-skilled refugees who would be appropriate matches for these types of work, the two-year relocation program is often too long. For lower-skilled refugees, the unfortunate reality is that the low-skilled, lesstechnical sector of Sweden's economy makes up only 5 percent of the available jobs (data provided by the OECD). ${ }^{42}$ Low-levels of employment are likely resultant because of a combination of both, but mostly an issue of not being able to bring refugees up to the Swedish "standard." "In 2015, only 28 percent of low-educated foreign-born men and 19 percent of low-educated women were in employment one year after the program." ${ }^{43}$ After three years of successful completion (though, low-skilled refugees rarely complete the program), the employment rate remains half of what it is for those with more advanced skillsets. Because of the lack of low-skill employment options, refugees are pushed into a cycle of intermittent employment and a series of "labor readiness courses":

Basically, what they are doing is to get to people into internships. If you employ a person for six months, [the state has agreed that it will subsidize] the employer 80 percent of the taxes associated with the cost of hiring that person (Fredrik Malm, Liberal MP).

Internships vary, but for the most part they tend to be in cleaning or other undesirable vocations such as elderly care. The hope is that these internships will lead to jobs, though this is rarely the case. In a report published in September of 2016, the OECD and UNHCR (referenced in The Economist) found that many employers viewed recruiting refugees as a Corporate Social Responsibility (CSR) issue, rather than a business opportunity:

\footnotetext{
42 "Sweden in a strong position to integrate refugees, but support for the low skilled needs to be strengthened." $O E C D$ http://www.oecd.org/employment/sweden-in-a-strong-position-to-integraterefugees-but-support-for-the-low-skilled-needs-to-be-strengthened.htm, Accessed January 20, 2017.

${ }^{43}$ Ibid.
} 
Large employers made a big fuss about providing apprenticeships and mentoring schemes, but few offer jobs...obstacles employers cite include uncertainty about refugees' qualifications and their right to work, skeptical public opinion, and worries that language barriers will lead to lower productivity. ${ }^{44}$

Indeed, several structural difficulties persist. Some of which are the labor market itself, with little access to low-skilled labor, many employers regarding the employment of refugees as a CSR ploy and the length of the integration program itself. But, from the perspective of the refugee, one reported concern persisted throughout_learning Swedish.

\section{3c. Learning Swedish: A Tool to Access All Others}

Transitioning away from an overview of some of the structural challenges facing refugees (e.g., economic, demographic factors and the issue of internships vis-à-vis long term employment access), this section delves into specific aspects of Sweden's integration program. Svenska för ivandarare (SFI) is the cornerstone of Sweden's statesubsidized language program. SFI consists of three study paths (numbered 1, 2, and 3) and four classes (A, B, C, and D). A Dagens Nyheter report cited by Radio Sweden described how learning the Swedish language was the key to integration; it examined 2007 data from Statistics Sweden regarding refugees' language acquisition and wages. The report found that of the 13,464 refugees aged 18 to 57 who arrived in 2007, only $1 / 3$ completed the entire language program. This was found to have a direct impact on their future earnings. The reported also noted that only 36 percent of those who completed the SFI earned a monthly wage of more than 13,000 SEK (USD 1,460). Alternatively, 66

44 "Econ Refugee in Sweden: Seeking asylum —and jobs." The Economist http://www.economist.com/news/finance-economics/21709511-too-few-refugees-not-too-many-areworking-europe-refugees-sweden-are. Accessed January 22, 2017 
percent of refugees who completed the entire program earned more than 13,000 SEK per month. The difference in earnings for those with a secondary education is similar, with 49 percent of those who did not complete the program earning more than 13,000 SEK per month and 65 percent of those who completed the entire program earning the same. ${ }^{45}$ The reasons why participants did not complete the coursework included the amount of time required and the level of difficulty.

Age plays a role in one's ability to learn a new language. Consequently, younger refugees tend to be quicker in picking up the language of their host country than their older counterparts. Also, younger refugees can engage in language training at the same time as their other schooling. Both can work together to provide younger newcomers with a much-needed sense of structure. For example, Yasib, who is now 19, came from Afghanistan in 2012: "it took me five or six months. Usually, it is not that easy. It usually takes two or three years to learn Swedish." However, he explained that the language "is needed if you want to get into society." After being in Sweden for only four years, Yasib was hired for two different long-term, stable jobs. Currently, he works for a local sandwich shop and is studying to become a pilot.

Irrespective of the time it takes to acquire proficiency, one's subjective outlook plays a significant part in whether they will complete the necessary courses. For instance, Tony, aged 50, a Syrian who arrived in 2014, recognized that "the key to any society is the language. $[\mathrm{He}]$ hopes to find Swedish friends to go out with and invite them to go [do] things. But [for now he] must first have the language." Language invariably widens

\footnotetext{
45 "Finishing Swedish Classes Gives Refugees a Boost in the Job Market," Sverigeradio http://sverigesradio.se/sida/artikel.aspx?programid=2054\&artikel=6433133 accessed January 22, 2017.
} 
one's social network, thus increasing not only human, but also social capital. Like Tony, many within the refugee community expressed a desire to connect with native Swedes. While språk cafes/språk fika (language cafes) do exist, as highlighted in the previous chapter, there are few formal activities in place to bring communities together, and those that exist are still in their infancy. As a recommendation to allay some of these difficulties, more needs to be done at the institutional/organizational level to encourage interaction and relationship-building. As the example of Tony shows, newcomers do want to cultivate relationships with Swedes. Making it out of their community, learning about when and where language groups take place, and the level of participation from Swedes is seemingly insufficient.

Obtaining employment is a complex process, and multiple factors come into play. A central factor is the refugee's level of comfort with the more social aspects of Swedish society. Below, personal narratives provided by selected refugees are analyzed in an effort to understand how they view their position in Swedish society.

\section{Narratives and Social Capital: Individual Experiences Navigating Sweden's Labor Market}

The previous section shed light on some of the general barriers faced by refugees in Sweden. These ranged from issues related to systemic struggles such as the state's ability to process newcomers, internal segregation, lack of availability of housing and qualification evaluation, to other issues of cultural distance (such as the language barrier). Beyond these barriers, this research assumes that obtaining pertinent information via bridging (Kansas et al. 2009; Lancee \& Hartung 2012) rather than bonding within the 
immediate ethnic enclave, increases a refugee's probability of acquiring sustainable employment. To offer analytical depth to the study of refugees' market access, the next section draws from the narratives of selected highly-qualified refugees. My analysis of the narratives presented here is meant to explore how social capital embedded in their individual lived experiences, helps answer the extent to which bridging takes place, how this impacts employment outcomes and sheds light on how resources are accessed from the state and civil society throughout their experience.

\section{4a. Intercultural Contact: Experience Networks and Market Access}

From the participants' responses regarding the initial struggles they faced, the most prominent being language, it became apparent that there was a gap in how these refugees received pertinent information concerning their rights and the resources available to them. Aside from meeting with their handler (a PES case manager, for those who arrived after 2010), the participants were largely left to search for alternative employment avenues on their own. What peaked my interest was the social skill this demanded, and relationship formation processes among refugees and native Swedes. One major facet of economic integration, especially for marginalized populations such as refugees in heavily regulated, advanced economies, is social networking outside of their own immediate communities (i.e., weak-ties and bridging). Since Sweden's economy is highly advanced and liberal, ${ }^{46}$ I assumed that if refugees were to find long-term employment, they would need to build relationships with the native Swedish community. Forming new relationships outside of their immediate groups should provide refugees with useful local

\footnotetext{
${ }^{46}$ For greater detail concerning the liberalization of Sweden's economy, see Bergh (2007) and (...).
} 
information and increase the probably of employment. Even under optimal circumstances, however, cultivating relationships in a new country is difficult.

Establishing deep social connections in Sweden is difficult, even for native-born Swedes. Sweden fell to $42^{\text {nd }}$ (out of 67 countries) in the Internations Expat Insider 2016 (the survey accounted for factors such as quality of life, sociability, ease of settling, and cost of living). ${ }^{47}$ As explained by one local, "in Sweden we like to be together, alone" (Michelle, 30, Swedish native). While Sweden is very welcoming, many who came as students or economic migrants and continued to live there as expats expressed that it can be difficult to establish tight bonds with locals. Making contact with native Swedes increases one's understanding of the local market and helps with rapid navigation; thus, such connections would be essential to refugees seeking to make a path to employment. Aside from direct assistance, the greatest resource for any newcomer is information. Human capital such as mastery of the native language, experience with the culture, and education all matter. However, without the right contacts, gaining access to the local market may still be impossible. Hence, social capital is likely just as important if not more important than one's knowhow and formal education.

In this research project, participants were chosen by age, gender, country of origin, and year of arrival. The themes analyzed were drawn from the questions posed. Along with asking participants about their social networks and perceptions of Swedish culture, I queried the refugees on where they received the bulk of their information and what type of employment they and their friends and family had received. This line of

\footnotetext{
47 "The Best and Worst Places for Expats in 2016." InterNations https://www.internations.org/expatinsider/2016/the-best-and-worst-places-for-expats
} 
questioning was designed with the intention of learning more about the community and individual actors upon which they relied. What emerged from this line of questioning was the issue of cultural compatibility. Put differently, I endeavored to determine if these refugees were able to bridge outside of their native ethnic groups and connect with the Swedish population. Three themes emerged from the interviews: social capital, employment, and culture.

To analyze these themes, the analysis is divided by participant age and location of educational attainment. The first subsection below, describes the lived experiences of younger refugees (i.e., those in their early 20s) who arrived in Sweden before 2010 and received the majority of their education and skills training in Sweden. Given these individuals received most of their human capital in Sweden, the motivation of this groups was to explore how younger have fared in terms of employment as well as to better understand how younger refugees fair in their adoptive European society (e.g., how to they identify cultural and how have they struggled). The second subsection relies upon the narratives of older individuals who received all of their education and skills training outside of Sweden. Juxtaposing between a younger vis-à-vis an older participants allows for a comparative glance which assists in better understanding additional factors impeding or enabling employment. The final subsection examines the lived experiences of two recent refugees (arriving after 2012), both of whom are under 30 and received their majority of their human capital outside of Sweden. One received the majority of her education outside of Sweden, but has since attended university in Malmö. The other received all of his education outside of Sweden. Lastly, each group drew upon the narratives of both men and women at a near equal proportion. 
Dividing the analysis into three groups, each representing different static variables (e.g., age and where they received their education), provides greater analytical depth concerning what factors are seemingly most necessary or most impeding throughout the employment process. It also provides pertinent insight into the role of social capital (e.g., how/if it comes about, and some of the factors enabling some refugees to form social bonds where others may not). While this research is not generalizable, it does offer empirical robustness to the experiences of highly educated refugees within the context of Sweden and, tangentially, the greater European welfare state. Largely, the purpose of employing a more nuanced approach to the exploration of refugee labor market integration is to tease out personal factors, which may be used by proxy to determine what affects the labor market entrance rate of success in a highly flexible European welfare state.

\section{4b. Youth and Country Specific Human Capital}

To help provide insight into how the location of where one receives their education and skillsets and how age affects the likelihood becoming employed, this section uses the lived experiences of selected high-skilled refugees between 18 and 40 years-old. Their experience provided deep and personal insight into the difficulties they face, the extent to which they bridge with the Swedish community, how they accessed available goods and services and what type of employment they and those they know have obtained. Given the sensitivity of the topic, I first needed to establish a level of trust between myself and the participants. To break the ice, I began each interview by asking broad-based questions regarding their interests and general welfare. Before guiding the participant towards this 
research's central focus (economic integration), we spoke about their family, home culture, what it was like to be a non-native in Sweden, and other topics of interest such as current events and how they viewed the situation in their home country.

Saba and Helalia both came from Afghanistan in 2004. At the time of their arrival, they were 12 and 13, respectively. Their teenage years and early adulthood were spent in Sweden: Kalskrona and Gothenburg. Their parents left for Sweden two years prior to the sisters' arrival; once the parents were established, they sent for their daughters: "my mother and father first went to Germany and then Sweden. We did not have any relatives [in Sweden], but they did have some friends who helped them a lot before we came" (Saba, 23, Afghanistan). She went on to say that:

My father found a job very fast. He is [an orthopedic surgeon]. I think that is because they needed doctors with his kind of experience. He had to show that he was a good doctor in the beginning. After he studied the language, he was able to get a job at the hospital. It was quite hard for him in Afghanistan. He worked for eighteen years and in Sweden, he had to start over. I imagine it was very difficult. My mother is working with the municipality and she also helps run an Afghan women's empowerment NGO.

Their father was able to remain a doctor. However, this seems to be an anomaly. Many other medical doctors who came from Afghanistan at this time (the early 2000s), as explained by the sisters, had a very difficult time finding jobs. "There are some difficult requirements and many do not pass. One women was struggling for five to six years or maybe even more. It differs from person to person" (Helalia, 25, Afghanistan). Unlike the sisters' father, and much like today (post Establishment plan), doctors and other highly trained professionals often have a difficult time transitioning into the Swedish work force. As noted above, one explanation for this is the number of claims for asylum and the lack of readily-available resources allocated for the arriving asylum seekers. In 
addition, we may posit that an inability to obtain employment in their previous position or sector may be because an assortment of other issues, such as lacking the right information and contacts. Given their insight, it appears evaluating criteria and providing avenues for high-skilled refugees has persisted even during times of reduced numbers of arrivals. Regardless of the fastidious employment of their father, several difficulties have emerged for both.

The sisters explained that throughout their time in Sweden, their biggest hurdle has been the cultural differences between their host and home countries. Regarding relationships and networks, Saba explained that the Swedes:

are a bit a cold. [They] are kind of famous for that. Many of them who are honest would agree. For me, it is more obvious, because I come from a culture where it is totally different. I believe if I were in Norway, it would not be that different. For example, I believe they find it quite easy to be a part of the Swedish society.

Describing her network of friends, she continued:

I mean, I go to university, interact ... and attend lectures or have a lunch or a dinner [with friends]. My friends are Swedish and other nationalities. Some people find it easier to talk to Swedish people. What I have recognized, what I find funny but I usually do not talk about, is the difference in topics with my Afghan friends and those I talk about with Swedish people. What I know is I feel a huge difference between our interests and Swedish interests.

Saba's social network and her general outlook suggest a distance between the social processes of native and non-native members of Swedish society. This seems especially indisputable since Saba has lived in Sweden for most her formative years and the totality of her adult life. For Helalia, however, the situation is different:

You could say that everything has been a challenge. Mostly, the difference [is] in culture. For example, the way that they live their everyday life at home, at school, food, almost everything.

However, unlike Saba, Helalia does not feel as attached to the Afghan community. 
Almost all my friends are Swedish. To be honest, I do not have much contact with the Afghans here. When we came, we lived in a small town called Kalskrona. All our neighbors were Swedish and all our friends were Swedish. When I began my studies, I was the only one with a non-Swedish background. You could say, I feel Swedish. But I miss Afghanistan.

For Saba and Helalia, it appears fostering relationships with Swedes (bridging) has occurred rather seamlessly. Irrespective of their access to the native community, we should assume whether these relationships will be accessed or not remains entirely indeterminable as each is affected by a handful of unrevealed circumstances.

In terms of employment, she continued: "I have worked in elderly care. Once I finish my degree, I hope to become an architect." Saba explained that while the types of employment remained similar for her and her friends, there was an additional factor: coincidence.

I think that it is just a coincidence; a lot of them work in elderly care or cleaning and they do that as a part time job and a summer job, and I have another friend who works for a bank. I have a lot of friends who have worked many years in elderly homes. It is easy to get a job there.

Similar to the findings in Frykman (2012), chance or "coincidence" was referenced by some, at least in part, as a reason for their employment. Throughout my interviews, elderly care and cleaning were the two most reported types of employment. However, as alluded to by the two young women referenced above, often these jobs are temporary and viewed as a stepping stone, especially by those with at least some post-secondary education.

Yar had experiences similar to those of Saba and Helalia; however, his new life in Sweden began under rather different circumstances. Yar (29, Afghanistan), came to Sweden in 2000 as an unaccompanied minor. He attended high school in Sweden, and 
later went on to study mechanics. Presently, he works for Bilia (Volvo's manufacturer). When asked about his social network, he told me that all of his close friends are from Afghanistan. One explanation for this is that in his free time, he works with newlyarriving Afghans. He helps to translate and generally assist in any way he is needed. One could draw from this that he has a deep sense of connection to and responsibility for his ethnic community, much like that which was expressed by Saba. In 2008, his wife came over from Afghanistan, and she presently works as a nurse. While she was not educated in Sweden, she was able to navigate the process with Yar's help. He provided her with the information and support necessary to find gainful employment. What this shows is having access to the right type of information and social capital (relationship with a native or a refugee who has become a Swedish citizen), is indisputably beneficial for newly arriving refugees. From his perspective, however, the most essential tool was education. "Everyone I know that is educated, most of them in Sweden, work. My best friend works for skattverket [the Swedish Tax Agency]."

In contrast to the successful outcomes enjoyed by my participants, other studies (Nordin 2011, 2013; Tselios et al. 2015) have described the negative impact of refugees having a large share of their classmates being first-generation immigrants. These data suggest that location matters. Urban communities, with little interaction with native populations will have fewer opportunities. This was one of the primary issues throughout the 1980s Whole Sweden Program. Hence, we may also exercise caution in assuming education (in-state institutions or abroad) is more important than relationships. Though this remains undetermined. In the lives of Saba, Helalia and Yar, relationship building from a relatively young age and education took place simultaneously. However, one 
issue which remained unaddressed in these interviews was that education in non-Swedish communities may not be up to the Swedish standard. Upon graduation, these students will not be on equal footing as their Swedish counterparts. Like rural areas, refugees may who are educated in segregated neighborhoods may also become alienated from the Swedish workforce.

Cultural immersion provides access to language classes and cultural instruction to which they might otherwise not have access, and this is especially true for older refugees; however, it is of note that two of the three interviewees reported having closer contact with individuals from their ethnic community than with general Swedish society. This suggests, to some extent, for those educated in predominantly Swedish neighborhoods, bridging may be solely a volitional activity. Yet, the cultivation of significant crosscultural relationships seems to be left to be the individual. While the younger cohort was able to become employed, they expressed a sense of cultural distance (such as the language barrier and making building relationships) and concern for older refugees. Indeed, organic community established through tertiary modes of native education may be enough to bring younger refugees into the labor market, though this requires further research.

4c. The Plight of Older Refugees: Degree Qualifications/Equivalency Examinations/ and Employment

Moving beyond an analysis of younger refugees, the following uses older participants to highlight challenges and concerns for those trying to start over later in life. Looking at the 
situation from a rural and urban setting, this section selected participants from Sodertalje (a suburb outside of Stockholm) and from Växjö, a smaller municipality in Skåne.

In 2007, UNHCR reported that Iraqi citizens requested asylum in a total of 89 countries; almost half of those - 18,600 - were in Sweden. Sodertalje, a small suburb of Stockholm that is also referred to as Little Baghdad, reportedly took in more refugees than the United States and Canada combined ${ }^{48}$. Södertalje is also home to a large group of Assyrian Christians, also known as Syriacs. There are a reported 30,000 to 40,000 Syrians in Sweden. An estimated 18,000 live in Södertalje (Shah \& Foblets 2016, 183). In contrast to the general population, most of the Syrians I spoke with were doctors; many others were dentists. Unlike Helalia and Saba's father, several of the interviewees were not able to find employment; not one had found their way back to their chosen profession of medicine or dentistry.

The next participant serves as an example of an older, highly qualified refugee who arrived during the most recent crisis. Tony (52, Syria), who arrived in 2014, explained:

All my Syrian friends have the same problem. The problem [does not] only concern dentistry. It is not easy to find a job here in Sweden. You must first learn the language and then you must have a certificate to verify. For me, the main problem is adjusting my certificate. Those who came from European lands, people who are doctors from the EU, can work immediately. It is not a problem for them to start work here. But for us, from the Middle East, it is a big problem. They tell all of us to come and take a [recertification] class, but no one that I know of has passed. Imagine, 64 students and they all failed.

It seems that re-entering the medical field as a Middle Eastern refugee can be a painstakingly long process. To Tony and his immediate community, the process of

${ }^{48}$ Mary Jordan, "Iraqi Refugees Find Sweden's Door Closing," Washington Post, http://www.washingtonpost.com/wp-dyn/content/article/2008/04/09/AR2008040904319.html, accessed January 12, 2017. 
recertification appeared futile. Given the high requirements for becoming a medical practitioner, inherent structural challenges may be the greatest struggle for these types of refugees; however, from his perspective, those within the Syrian community needed to try harder to acculturate and meet native Swedes.

I have met people that have been here [for] 15 years [and] they have no Swedish. [They only speak] Arabic all the time with their friends. I think it is not okay; they need to be with the Swedish community more and more. We are not so young but we have a chance to start a new life and meet new people. For now it is hard to make real friends, but that will come with the language.

He therefore suggests, regardless of the steep hill ahead of them (studying long hours and meeting re-qualification standards), if those in his community were to make a stronger effort to cultivate social capital, then they would have a better chance of re-entering into their previous work as dentists.

Speaking on culture, though, he expressed that:

People here are cold. Nobody speaks to each other. They seem like they are not social. In Syria, you visit your neighbor. You invite them for dinner. If there are any problems, you help them. In Sweden, no one asks about anyone.

Like Saba and Helalia, Tony found significant culture difference. Bringing communities together is a reciprocal process. For those unable to learn the Swedish language, bridging to the labor pool and gaining additional tools (e.g., education, other forms of employment, and additional programs such as korta vägen, or the fast track) is unlikely. Despite Tony's outlook for doctors such as himself, he felt more optimistic about his wife's future:

She is a teacher. She studied economics and taught economics for the last 25 years. Now she is starting over. But here they have a lot of opportunities for teachers. They have something like 90,000 [positions] for teachers. [I believe] she has a chance to find work very fast. She must [finish] her language courses first and then [an internship], but I think she has a real chance at teaching again. 
Tony's experience suggests that those with highly technical skill sets (such as doctors) have a long road ahead of them. Depending on the industry, however, the pathway to employment could be significantly shorter. This also suggests that while many with substantial educations may have to take lower-level jobs, they continue to be deeply invested in returning to their former careers and lastly, that bridging, while not impossible, is a very difficult process in the Swedish context.

The next highly qualified participant I interviewed serves as an example of someone who arrived before etableringsplan; Abdi, a 60-year-old Somali who arrived in Sweden in 2007, was older than most of the other participants, and lived outside of one of Sweden's three large cities (Stockholm, Gothenburg, and Malmö). Before coming to Sweden, Abdi was a journalist and high school teacher. As a young man, he received his formal education in the hard sciences (specifically, chemistry). For the next 20 years, he taught sciences and was a political activist and journalist championing human rights. After receiving threats, he fled with his family from Mogadishu to Somaliland. In Somaliland, he continued to write, and in 2007 he was offered an invitation to fly to Stockholm to participate on a panel discussing human rights. While in Sweden, Somali journalists became targets, and Abdi has not returned home to Somalia since.

After he applied for asylum and began the immigration process, he met with several obstacles. Foremost was that he did not know how to go about having his qualifications verified.

There was nothing in place to have my qualifications verified quicker. They basically just keep you busy. I moved around a lot. First I was in Gothenburg and then I was sent to the middle of nowhere to sit and wait for the immigration office to decide on my case. After the decision was made, I sat down and made a 
contract of what I would like to accomplish. After that, I was sent to SFI and that was it. I never received a permanent job.

Like Tony, Abdi was also unable to have his qualifications quickly verified. Over the last nine years, Abdi has become fluent in Swedish, yet he continues to search for sustainable employment. In response to these hardships, Abdi told me: "I have always been a hard worker. I could not just sit around and wait for the state to take care of me."

To enter an industry of his own interest, he went to the local authority and asked to be placed in a school to teach science, even if it was unpaid. For one year, Abdi volunteered as a science teacher in a nearby high school. As is often the case with internships, once the year was completed, he was not brought on fulltime. He described the problem as follows:

It is more is difficult to [be] qualified than be unqualified. It is hard to make contacts with the Swedish population. Our communities have very little interaction. There is no common meeting place. In our enclaves, there are only a few Swedes. The system is not good at mixing the people. The integration process goes step-by-step. You start from one stage and you move to another stage and then you move and on and on until you stand on your own feet, but I am afraid this rarely happens, at least for Somalis.

In a 2012 report conducted by the Commission of the Future entitled "Somalis in the labor market: Does Sweden have something to learn?"49 researchers found that only 20 percent of Somali immigrants in Sweden had jobs. The problem with finding employment was not so much the process itself, but that the process was missing certain elements. In Abdi's eyes, the most important aspect not being considered was social integration. It is here that more should be done, and greater contact between refugees and the native population facilitated. Again, bridging with natives seems to be one of the most

\footnotetext{
${ }^{49}$ Carlsson et al. "Somalier på arbetsmarknaden—har Sverige något att lära?” Regeringskansliet http://www.regeringen.se/contentassets/55f58b2bc8fd4f66842e37f54c38fc51/somalier-paarbetsmarknaden---har-sverige-nagot-att-lara
} 
pertinent elements for refugee success in the labor market. However, even after almost a decade (at the time of the interview), being highly qualified and speaking Swedish fluently, Abdi still had few Swedish contacts with whom he interacted daily.

In addition to highly-skilled refugees in general, Abdi worried for the entire Somali community. He explained that in Sweden:

It is very difficult to catch up. People in the Somali and the African community are experiencing a technological dislocation. There are no manual labor jobs ... it is hopeless to think that many of those who are [functionally] illiterate will go through the system and be able to meet the Swedish standard.

In other words, structural issues (existing types of employment) greatly affect the African refugee community. He fears that many coming from Somalia will not possess an educational foundation sufficient to ensure their success in Sweden. Starting over will prove immensely difficult, if not impossible. Irrespective of his education and experience, he was able to secure only a handful of "small jobs," the most promising of which was as a research assistant at Växjö University. There, he worked with a group of scholars studying the Somali community in Sweden. Yet he has still not found stable employment. Like his other jobs, the research assistant position only lasted for half of a year. His experience coincides with Bevelander and Lundh's (2007) finding that refugees have a low probability of finding employment in cities with highly educated populations (e.g., university towns). Växjö is home to Linnaeus University.

Aligned closely to social capital, Abdi also expressed feelings of disconnectedness and a difficulty with finding his identity in Sweden. "There was no archeological item that I saw and that I felt connected to." In his search for a sense of belonging and in response to his difficulties in finding work, Abdi pursued a more 
personal route. He created what he called a "mobile-museum." This project features over 1,500 interviews and photographs of refugees searching for their place in Sweden. Each interview tells a refugee's story, where they came from and how they understood their new lives in Sweden. His project led to another internship with the Utvandrarnas Hus: Kultur Parken Småland which in English is the Immigrant House. Yet his entrepreneurial efforts did not yield any monetary gains. Thus, when he is between "small jobs," he looks for other forms of employment. To his dismay, however, he, his wife, and his three young children all continue to live on state-provided assistance. My interview with Abdi ended on a somber note. When I asked him about his hopes for the future, he told me: "Jeff, the [reality is] I am a 60-year-old man. I am afraid there is no hope for someone my age...the future here is bright for my children, but for me, what can I do?"

Tony and Abdi are both well-educated and carry with them a wealth of experience. In addition, Abdi is fluent in Swedish and Tony is well on his way to being fluent. However, neither have been able to bridge out of their direct ethnic communities. While Tony remains more optimistic about his future, Abdi has accepted that his options are limited, at best. From these interviews, it seems clear that even for those with tertiary education and decades of experience, entering the labor market can be difficult, if not impossible, for older migrants. Regardless of arriving during different times (pre-andpost etableringsplan), both refugees faced similar difficulties related to structural issues of evaluation and placement and have yet to cultivate meaningful social capital with Swedes. Despite their ages, even if they do not have a long future in the workforce, it would be a drain on resources and a lost opportunity if a way cannot be found for individuals such as these to become more autonomous and put their skills to better use. 


\section{4d. Non-Swedish Human Capital: Accessing Social Capital and Employment}

Given age seems to be an almost impossible factor to overcome (highlighted in particular by Abdi), this section explores how two successful participants who earned the majority of their human capital outside of Sweden, and arrived within the last five years, have progressed.

The first participant, Laticia, I met through contacts at OpenSkåne, a stiftelsen or community organization in Malmö that brings together local authorities, NGOs, and private industry. Laticia, who at the time of the interview was 23 years of age, originally fled with her family from the Democratic Republic of Congo to Uganda in late 2009. After spending two years in a refugee camp, she was interviewed by the Swedish embassy in Kampala and offered a place in Sweden:

When I arrived, there was a delegation of people [from the] IOM group; different municipalities take different groups. They were stranded the whole night. They had only the refugee status. The police took us to a small [shelter for asylumseekers], but it was ridiculous. We had all our stuff. My first impression was not very good. We had to live there for two weeks. We felt insecure, and in a sense doomed.

Along with a difficult initial reception, the biggest struggle for Laticia was the culture shock. "I felt frustrated for ... days or weeks. I can't remember specifically. It was very hard to meet Swedish people. It was so hard to talk to them and you had to approach them." Like many of the other participants, she felt Swedes were standoffish and making friends was difficult.

When asked from where she received the most help and the types of jobs she saw others within the refugee community finding, she told me: 
In Sweden, the most help comes from the state. When we first arrived, we received a lot of help from [the government]. [State run authorities] give you money for food, housing, and clothing. Any basic needs, plus free education, healthcare, and a transport card to get around. However, this is supposed to end after two years.

Yet state assistance is not unitarily sufficient. Laticia received most of her information from the local Eritrean community in Hassleholm, Malmö Hogskola University, and civil society (such as OpenSkåne). Given her status as a refugee, her ability to speak English and her rapid acquisition of Swedish, in relatively short period of time, Laticia accessed and utilize different forms of social capital. Compared to those of others, her transition was smooth, at least in terms of language acquisition and networking. Yet like many others with whom I spoke, she feared the two-year goal set by the integration plan to be an unrealistic goal due to two factors:

[First], the labor market in Sweden is very weak. Irrespective of Swedish language, or at the very least, English language capabilities, it is very hard to find a job...most men and women work in elderly care. It is the easiest to get. Some clean, [but] most immigrants do not want to do those jobs. [Second], what [refugees] want most are jobs with their education, so they will often just sit at home and wait for something they want to come about.

Temporary employment like elderly care is not leading to stable employment. Providing refugees with jobs specifically suited to their education and skillsets is difficult. Without a plurality of opportunities, it seems that keeping refugees motivated to continue to acculturate and venture beyond their ethnic enclave will be a challenge.

At the time of the interview, Laticia had lived in Sweden for three years; she shared lodging with her brother and mother in Hassleholm, one hour outside of Malmö. She currently holds an internship with OpenSkåne, a local umbrella organization that brings together actors in civil society, local governmental bodies, and industry. Like 
Helalia and Saba, Laticia has worked in elderly care. With her unique skillset, interest in helping others, and desire to move beyond intermittent internships, she has also created a program to help other refugee women find work. Since she believes that many of the jobs offered through PES actually serve to dissuade refugees from looking for employment, she endeavors to meet with individual refugee women to discover what they hope to achieve and would prefer to do for work. From there, with the help of Open Skåne, she builds networks with those who may be able to either employ the woman or help her set up an entrepreneurial venture. One such instance (which, unfortunately, has since closed), was a beauty salon run by three young Somali women. When reconsidering chapter 5 , Laticia's experience illustrates how local CSOs and its connections, can build social networks among local authorities, industry, and refugee women. Piecing together the integration puzzle from all sectors, Laticia's experience highlights the utility of the state during reception, the importance of ethnic social capital to help navigate potential "smalljobs," the role of civil society in giving her a platform to work with other refugees and the its role in bringing Swedes and refugees into an environment where relationships may come about naturally.

Like Laticia, Mulhalm (29, Syrian) also made a successful transition in a very short period of time. Making his way from Lebanon, Mulhalm arrived in 2014 and went through the same process as other refugees:

When I arrived, I went through Migrationsverket. They did not give [me] much help. After the reception process, I received most of my help from friends. They helped me navigate Sweden and gave me a place to stay in Stockholm. I also used Meetup and Facebook to network. Through online networks, I attended several parties and made Swedish friends. 
For Mulhalm and other young refugees looking to start over in Sweden, having a social base is important. For him, social networking, rather than working directly with his case handler was more important. Mulhalm explained:

While the state does offer many of the essentials needed for the integration process, social capital becomes extremely crucial later. Making the right relationships greatly increases the chance of employability. Cultivating these new relationships is, however, part and parcel left to chance.

Meeting the right individual with the appropriate network and social capital to employ individuals and help marginalized populations gain access to the labor market is difficult to plan for and currently is at best, haphazard. Unlike older participants, through programs provided by the state (e.g., SFI and korta vägen), Mulhalm was able to have his qualifications verified and obtain an internship; this later became his fulltime job. Currently, he is a structural engineer working on the new Karolinska hospital. While etableringsplan has led to a more systematized approach, the steps and variables that eventually led Mulhalm to his current position are complex and described like that of Saba as coincidence or chance.

Systemization provides access to the labor market, but like Mulhalm, the individuals who enjoy the greatest success tend to be those with patience and a positive demeanor. Understanding how to navigate online social networking and the ability to speak English also help. Like those of others, Mulhalm's experience suggests that while the state provides immediate assistance, it is not enough to fully integrate individuals into the labor market. Networks and social information matter differently depending on when one arrives. For new arrivals (young and old) they seem to carry great significance when transitioning away from what is provided by the state. This is one explanation for why 
many of the older, highly skilled refugees are unable to find long-term employment. For younger refugees that received the majority of their human capital in characteristically Swedish neighborhoods, social networking may be less important as it should take place as they age. On the other hand, however, as shown by previous research (Szulkin \& Jonsson 2007; Bohlmark \& Lindahl 2007; Andersson et al. 2010), these networks may be similarly as important for refugees being educated and living in segregated neighborhoods. Given the importance of the socialization process, especially for those who arrived already having completed their education and training, more needs to be done to bring communities together at several levels: at the micro level, ethnic and native communities need to find ways to interact; and at the meso-level private enterprise, nonprofit (CSO) and public institutions (PES etc.), need to work closer together.

While civil society's role is becoming more prominent and many are working to forge relationships and disseminate information, my findings suggest that social connections continue to evolve on their own, from more natural and organic interactions and separate from institutional mechanisms. For example, when he first arrived in 2012 with his parents, Jack (21, Syria), received significant help from his aunt and uncle. "We lived with them for a while, as we waited for our residency. We did not receive any special help. All the credit goes to my aunt and uncle." Despite the life-altering transition, Jack did not seem to be deeply affected:

Actually, I have not had a big challenge here. I have enjoyed doing everything Sweden has given me. I did not have this in Lebanon [(where they first fled to from Syria)]. All my friends are from the Middle East, but I work [for a national chain restaurant]. I meet people there and it's cool. 
Unlike Saba and Helalia, Jack did not have many Swedish contacts. However, he did not feel like he suffered from discrimination, nor did he seem worried about his place in Sweden. While more should be done through institutions, there is no clear way to bring merge communities.

Traversing between groups, especially those with influence and local contacts, is of immense help to refugees seeking employment. While the state provides refugees with more direct, subsidized benefits and programs, social capital provides them with in-kind, immeasurable types of assistance. Through my analysis of the selected candidates, this research offers insights into the lived experiences of refugees that are not visible in other broad, generalizable research studies. The analysis above suggests that where one receives their education may not be the most significant factor. Rather, social networking may prove much more invaluable than other studies have suggested (Scott 1999; Bevelander 2000; Duvander 2001). In terms of impeding the likelihood of employment for high skilled refugees, age appears most significant. Given the difficulty in finding long term employment, the following explores one potential avenue of employmententrepreneurship.

\section{4e. Moving Forward: Entrepreneurship and Market Reform}

What became clear throughout my field work is that many refugees wanted to start their own businesses. Two of the participants discussed above, Laticia and Abdi, sought out opportunities for entrepreneurship as a means of helping themselves and others within the refugee community. In a country like Sweden, allowing refugees to pursue entrepreneurial avenues presents several challenges. It runs the risk of conflicting with 
the central goal of the social contract. Swedish welfare is premised on equality and high levels of economic participation (Fredlund-Blomquist 2014). Several migration scholars have studied the utility of entrepreneurship (Hjerm 2004; Fong et al. 2007; Slavnic 2004, 2013; Andersson \& Hammarstedt 2015), but in a heavily regulated economy such as Sweden it may not be as feasible as in other places in the EU, such as Germany or Great Britain. Currently, there are several state-run programs that help to finance entrepreneurial ventures.

ALMI, a state-run micro-lending venture, is available to foreign-born residents who would not otherwise have access to loans. After careful consideration, ALMI finances ideas believed to have economic potential. Rami, a consultant with ALMI, told me that the biggest challenge facing newly-arriving entrepreneurs is:

Their understanding of the Swedish market. They lose perspective that many of their ideas have been here for 25 years. It has been done. The market cleans itself. What we do is help them gain perspective.

Before any risk is assumed, each idea is vetted and analyzed. If an idea is approved, it moves on to the next phase: document preparation. After the documents are prepared (e.g., a budget, business proposal, scouting for locations, etc.), the completed forms are submitted to a financial advisor. An individual micro-loan could be for up to 200,000 SEK (23,000 USD). As security for the micro-loan, a limited personal guarantee of 10 percent is required. Lastly, because of a guarantee provided by the European Investment Fund, which is financed by the EU program for Employment and Social Innovations (EASI), each loan has a repayment plan of up to 72 months, as well as a grace period of 
12 months before loan repayment must commence. ${ }^{50}$ While Rami noted that he was being very subjective, he found that:

Syrians coming now are extremely driven. They are tough. They come here and they do not want to go on welfare. Many have told me "we want to contribute." Just yesterday, we had three come in. The types of businesses that they want to start differ; however, many look to start restaurants. One project we recently financed that I may disclose is Shamiat restaurant at Möllevägen.

ALMI serves as a means of advising refugees and offering startup capital to those who may not otherwise have access. Given the difficulties described by my participants in finding employment, entrepreneurship seems to be an alternative productive mode of entrance into the labor market.

The state's formal approach (serviced by ALMI) for starting new ventures is great for foreign born entrepreneurs, but for various reasons (feasibility of business, knowledge of local markets, a feeling that they may be turned down, etc.), it may not be an accessible resource for many. Instead, others opt to borrow capital from friends or the community. Several Syrians I spoke with expressed their desire to start their own business or knew people who were working in a self-start industry. When asked about what opportunities other Syrians had found, Ahmed (50, Syria) explained:

Some of them are working in their own private business. [For example], some of them have a car repair company, or place for baking for pizza. They are working. It is a new a life; it is a new lifestyle. Maybe if I was younger here, I could do something else and be in private society. But now, you know, a lot of people are looking for jobs.

\footnotetext{
${ }^{50}$ For more information, please refer to ALMI's website entitled "Microloans-At start-up and young companies" at http://www.almi.se/Stockholm-Sormland/Erbjudanden/Mikrolan/
} 
Similarly, Daad, a 50-year-old Syrian who obtained her dentistry certificate in Aleppo in 1986 and practiced dentistry for the last 25 years in Syria and Saudi Arabia described how:

Dentists [in my community] are all suffering in this together. I would like to open a practice with other dentists in Sodertalje, but it is very difficult for Sweden to accept my qualifications. To become a dentist again, I must go back to school. However, they do not accept all of us. They accept very few. So now, me and other dentists wait for another term.

This suggests, regardless of the risk, many want to find some way of becoming autonomous. Because educational attainment and work experience is not expedited, the process to re-establish oneself as a dentist is arduous. Even though she continues to learn Swedish, she has not yet made any substantial Swedish contacts. Obtaining pertinent information on how to set up an enterprise that meets local legal, health, and safety standards requires local knowhow. Given her age (50), the structure of the requalification program, and the time required to learn Swedish, the likelihood of Daad and many others succeeding in returning to their previous careers is slim. While high-skilled refugees would like to start their own practices, given the regulatory nature of Sweden, entrepreneurship is more likely to come about in lower-skilled enterprises such as the restaurant industry or other repair services (automobile, bicycle, etc.). Likewise, given the nature of these types of businesses (typically to serve a direct ethnic community), less formal routes are sought to finance and establish the enterprise.

Beyond the Syrians I interviewed, others who had been in Sweden for more than a decade had also pursued entrepreneurship and other less-formal modes of employment. Ali, now in his mid-40s, fled Iraq and came to Sweden in 2001. He is best described as a serial entrepreneur. Upon arrival, he swiftly received his residence permit; however, he 
was unable to find work so he went the informal route. He was first employed as a black market taxi driver. In Sweden, "if you want a job in the black market, just go on the street and ask around. You can get a car for 5,000 SEK [approximately \$1,200 USD) and you can start work immediately." Though Ali ran into some trouble with authorities, he drove a black taxi for five years; he has since moved on to operating his own business. The need to seek out an informal economy suggests that there is a structural conflict between new economic trends (migration and market shifts) and old regulatory frameworks (Slavnic 2010). Today, he runs a $\backslash$ bicycle repair shop in Malmö. Now his struggle is centered not so much on his own employment, but rather his desire to help others.

Eva came to Sweden from Iraq at the beginning of 2015. At the time of our meeting, Eva had been living in a refugee camp for 13 months. At a meeting with myself and Eva, Ali told me: "I would like to hire her and other newly arriving refugees, but it is simply too expensive. They need to reform the labor law to make it easier on refugees who just arrived." Ali's complaint was not dissimilar from many I heard throughout my interviews. Often, individuals had a parent or relative with a business, or had started an enterprise themselves. For instance, Nor (a 20-year-old dental student originally from Iraq), had a father who started a barbershop in Malmö; he has run it successfully since 2001. Ivan, a 27-year-old Iraqi who was working for a local CSO at the time I met him, had at one point opened his own pizza parlor. Unfortunately, his restaurant was not successful. Nevertheless, what was important to him was the sense of autonomy and the opportunity to pursue a vocation about which he felt passionate. Entrepreneurship assumes substantial risk. After all, immigrant-owned small businesses have a high rate of failure in Sweden (Slavnic 2004). Rate of failure should not be the sole reason for 
disregarding its utility. Starting an enterprise provided many of my participants with a feeling of autonomy. Instead, programs like ALMI should be expanded to help guide and consult refugees looking to start their own legitimate enterprises.

The facilitation of long-term labor market integration is complicated. While Sweden's integration program does provide refugees with short term internships, much more needs to be done to provide more steady, long term types of employment. Based on my findings, creating additional mechanisms to support entrepreneurs seems like a useful addition to the existing program. For the future of Sweden's economy, not only must refugees become employed, but if they are going to prosper, the government should provide opportunities leading to greater independence.

\section{Conclusion}

Labor market integration for refugees is one of the most widely debated issues in Europe today. This research assumes that if refugees are to become gainfully employed (and thus, autonomous), they will need to be able to bridge out from their ethnic community and become acculturated with their host society. The state has proven to be efficient in meeting immediate needs, but the long process of securing gainful employment appears to rely more on the refugee and their ability to navigate the market. Information is essential to accessing pathways to a satisfying career, but how this information is tapped remains an understudied aspect of the integration process.

Via lived experiences, the primary goal of this chapter was to provide insight into how integration takes place for high-skilled refugees. While it was divided by several key components (e.g., age and location of educational attainment), the chapter was motivated 
by one primary assumption: while the state is a necessary for integrating its incoming refugees, it is not sufficient for doing so on its own. Harking back to previous groups in the 1970s (Ugandan Asians) and the 1980s (Iranians and Iraqis), when Sweden's labor market structure and society was significantly different (e.g., significantly more lowskilled jobs and an overall smaller size of incoming refugees), a centralized approach to employment was more amenable. Today, however, privatization and globalization has altered this reality. A purely centralized approach is no longer adequate. Ergo, looking beyond policy and institutional mechanisms, the research assumed that beyond immediate resources and integration programs, social capital plays one of the most significant yet understudied components of refugee labor market integration in Sweden and to a larger extent, Europe.

To summarize how refugees navigate the local labor market (e.g., access available resources and obtain employment) and the extent to which bridging takes place, my central findings from the perspective of my participants are:

a. If employed, very few of the respondents described their employment as fulfilling.

b. Nearly all respondents felt that due to language constraints, it was an extremely long process to enter the economy.

c. All of the participants who arrived to Sweden before adulthood were able to navigate the Swedish system. For instance, all had hopes of attending some form of post-secondary education. Though, many also intended to leave Sweden after they received their education.

d. For high-skilled refugees over the age of 50, long term stable employment seems unlikely.

e. For new arrivals, speaking English and having social networking knowhow (digitally or otherwise) is extremely useful.

f. High skillsets did not guarantee labor market entrance.

g. Social capital seems to play a vital, yet not fully understood, part in the employment process.

h. As with civil society, more needs to be done to help bridge communities. Though how to do this requires further research. 
i. Entrepreneurship seems to be a very valuable path to employment. Supervision and greater investment should come from the state and civil society to encourage refugees to become self-employed.

My findings suggest that age, social contacts, locality, and personal outlook all play a considerable role in refugees' rates of success. All participants had received the type of aid one would expect from the state (health care, access to education and housing, etc.). While CSOs are becoming more active in the process of labor market integration, aside from ethnic associations, they are not necessarily sought out. One explanation is that information on the resources available is not readily accessible.

From the dozens of interviews I conducted, and several other informal conversations, it is clear that language remains one of the greatest challenges for refugees. Beyond language acquisition, other barriers vary from person to person. For those with high skillsets, the obstacles are legitimation and contacts. It takes time for documents to be adjudicated, and forming the right social network can prove to be difficult. Of the younger participants, all had reported regular interaction with native Swedes. For older individuals, bridging remained more difficult. Indeed, there are many challenges to overcome when entering a new labor market, but for those like Mulhalm, who have already completed their university education, speak English, are efficient with social networking mediums, and have a relatively positive and outgoing disposition and no familial attachment to Sweden, there is still a real chance of bridging with the Swedish community and obtaining long term, fulfilling employment.

Out of my sample, age trumped all else. Irrespective of his human capital and ability to rapidly acculturate, Abdi was still unable to find steady employment. Conversely, all who arrived before the age of eighteen were able to find employment or 
seemed likely to do so following the completion of their education. Along with age, gender may also hinder labor market integration. Notably, however, this is only for women coming from potentially oppressive religious or culture backgrounds. On the bright side, however, while in general, refugee women have a more difficult time accessing the market, there is evidence that programs within civil society help them when possible. For example, Yalla Sofielund an organization initially established to work uniquely with women, discussed in chapter five, and women working in civil society, like Laticia, was not only able to access the labor market herself, but also worked to facilitate the process of market integration for other women, as well.

A reorientation of Sweden's economic structure to be more welcoming to refugees faces considerable challenges. One possible solution is to work toward facilitating fair and monitored access to capital for highly vetted entrepreneurial ventures. However, as Eva Wikström (in Bevelander 2009) found, one's subjective outlook is significant to whether or not one succeeds in the program and accesses employment. While illustrated by several of the participants, measuring an individual's objective outlook remains difficult. Thus, my findings confirm Scott's (1999) in three ways. (1) It is clear that the economic shift toward more service-based forms of employment is making it increasingly difficult for those I interviewed to find work. This is because the evaluation process is long, there are very few low-skill forms of employment available (a mismatch between jobs available and the type of incoming labor), and speculatively, motivating private enterprise to employ refugees seems unlikely. This was found to be true regardless of when the particular refugee arrived. (2) Culture matters. Based on my participants' responses concerning their social networks, the level of difficulty they faced 
in establishing strong connections with natives varied. (3) Having a tertiary education does not guarantee entrance into Sweden's labor market, but for those who acquire their education and skills in Sweden, becoming employed is highly likely.

For refugees who arrive as adults, social capital seems to play a critical role in finding employment. These findings are in line with the Granovetter's seminal work (1983) and several other previous studies investigating the relationship between social capital and employment for non-native residents in Europe and the West (Yukobovich 2005; Torezani et al. 2008; Wells 2011). Intuitively, there are two key reasons it seems likely that the relative value of social capital/networks would be more significant than country-specific human capital (education, language access, cultural knowledge) for newly arriving refugees who obtained the majority of their education and skills outside of Sweden. First, we can assume that interacting with locals helps newcomers to feel more welcome. This was clearly the case for Mulhalm, who connected with locals primarily through online social networking platforms. Second, relationships with natives of the host country help in language and information acquisition, both of which facilitate the acquisition of stable employment.

While many refugees come to Sweden (and Europe, in general) with employable skills, there appears to be a disparity in how information is accessed and the ways in which individuals navigate the local market. If weak ties are more useful, then we should assume that human capital is only a part of how refugees find employment. Along with the SFI (since language acquisition is key to employment), policies should be reoriented to take into greater consideration the utility of weak ties. Measuring social capital and developing effective programs remains a challenge, but as highlighted in Chapter 5, civil 
society and the eradication of harmful legislation (e.g., eliminating permanent residency) are good places to start. Even if refugees are able to acquire appropriate social capital, other challenges such as cultural incompatibility plague many.

Culture remains a major, yet largely unaddressed, topic in examinations of refugee integration. Culture-related tensions were expressed by several participants who had received the majority of their human capital in Sweden. As expressed by Saba:

Sometimes I [feel] really bad in Sweden; after finishing school, these will be my last days here. It probably would not be a good idea to go back to Afghanistan, but somewhere where I can feel my culture [would be good]. Maybe I will go to Turkey...I do not know, but I have this feeling warmer places have warmer people.

Even after a decade, a cultural disconnect may persist, even for those who receive all of their relative human capital in Sweden (e.g., fluent Swedish, tertiary credentials, and awareness of cultural norms). This sentiment is not unique to my findings; it comports with several other studies (Wiklund et al. 2000; Bursell 2012; Montesino 2012; Lundborg 2013). Without increased bridging between refugees and native Swedes, it seems that a sense of belonging may be permanently out of reach. While the findings are in line with Frykman's (2012), who posited that the longer a refugee remains in their host country, the higher their chances of finding jobs, my data also suggest that Sweden and other European states, may find it challenging to retain its highly skilled refugee population. This introduces a topic for future study: if Sweden loses a substantial portion of its highly-trained, young refugee population, what will the effects be on its welfare state?

Beyond policy, facilitating a sense of belonging via employment, which seems to require cross-cultural social capital, is essential for ensuring the wellbeing of refugees in Sweden as well as the rest of Europe. We should assume that highly-skilled refugees are 
an essential resource for many in their communities; however, further research is needed to determine how greater social capital can be acquired. In sum, much more needs to be done to engage and inform refugee populations. For now, uncertainty seems to be the best description for many of those with whom I spoke:

I do not know what is going to happen. I miss my home, I miss my office. I miss my country. It is a normal feeling, but what can I do? If everything would go right in my country, maybe I could go back. I hope that everything is going to be alright, but I am not sure about that. [As for my son] who is 21 years old, he studies music. The young will find their way here, but I am hesitant. I must be patient and see what is going to happen (Tony, 50, Syria).

While many newcomers feel uncertain, it must be noted that a hopeful regard persists for the younger refugees in Sweden. 


\section{Chapter 7. What Can We Say About Refugee's Labor Market Integration Today?}

In the last five years, refugee integration has become one of the most salient challenges facing Europe. Much of the debate has concerned their reception, most notably, the end of the Dublin II reception agreement and the debates surrounding the Common European Asylum System. Yet for many this issue remains widely unaddressed. For this study, Sweden was selected as a case study; as a nation active in refugee relocation, it has received the highest number of asylum seekers per capita $(163,000$ or 1,600 for every 100,000 people in the country ${ }^{51}$ ) in Europe and is a vanguard concerning the expansiveness of its welfare state and level of human rights advocacy.

While many now associate Sweden with immigration, it did not actually receive refugees from outside of Europe until well after the end of the Second World War. It was not until the 1970s that refugee reception truly began to characterize Sweden's integration policy. Throughout the 1950s and 1960s, immigration to Sweden was laborbased. By the 1970s, at the height of its welfare state expansion, Sweden was still able to adequately employ the rather small number of refugees relocating there. Up to and through the 1990s, refugees (in particular, Bosnians) continued to enjoy a relatively high rate of employment. Since 2000 , the situation has been significantly different. A more liberalized Sweden is now facing extensive hurdles in bringing its refugees into the labor market. This research operated under the assumption that globalization has altered the Swedish socio-economic landscape. In other words, the effect of international markets constraining government policy, the rise of competition (requiring a highly-qualified population), and global humanitarian crises (resulting in the greatest number of asylum

\footnotetext{
${ }^{51}$ Data provided by the Pew Research Center.
} 
seekers to date), now demand that others beyond that of the Swedish government take part in refugee assistance (such as CSOs). Hence this research asked the following questions: what roles do CSOs play in the process of refugee labor market integration, and how has their position transformed since the 1990s? What are the obstacles they face in engaging with the refugee community? How do refugees gain access to available resources, and what are the difficulties most commonly experienced in this process? To what extent do refugees bridge out of their ethnic/refugee community and into the local/native Swedish culture?

While individual programs and activities promoted by civil society and the general process of socialization are not categorically oriented to the labor market, this research approaches the study of labor market integration via the notion that all are pertinent to the process of achieving independence. All steps throughout a refugee's integration should lead to a sense of autonomy within their host society, of which gainful employment is arguably the most important signifier. This final chapter lays out this project's findings and limitations, and concludes with a call for further research concerning perceptions of refugees and their impact on the welfare state. More research is needed on ways for low-skilled refugees to overcome the language barriers that keep them from acquiring social and human capital and, consequently, adequate employment. To pursue these goals, this study analyzed how the process of integration is transforming Sweden's social democratic setting, in spite of competing global forces (e.g., the fiscal demands of integration and the free movement of people). Given the immediacy of this issue, it is my hope that this research and future studies will not only contribute to the 
ongoing academic debate, but also allay some of the misunderstandings surrounding refugees and the labor market for those working in policy, as well as the wider public.

\section{Approach to the Study of Refugee Labor Market Integration}

To analyze this topic, this research applied a qualitatively based, mid-range approach, bridging two bodies of literature - the welfare state and economic sociology - which frame and address labor market integration. Welfare state literature investigates the impact of policies and institutions, whereas economic sociology focuses on social aspects such as social capital and relationship building. Mixed-embeddedness (Kloosterman et al. 1999), expanding upon Portes (1995) and Granovetter (1973), targets two areas of study: institutional constraints and effects, and social reality. At the micro-level, groups and individuals are embedded in their own interactions and everyday activities (e.g., life within their own communities). At the meso-level, they are entrenched in social forces (organizations, associations, and other communities). At the macro level, they are rooted in the surrounding economy and legal framework, as expressed through economic interactions with other participants in the market, and public policy.

In relation to the theoretical implications, welfare state literature studies specific welfare policies and their outcomes. For instance, it considers the effects of existing political constraints on refugee labor market integration. Economic sociology, on the other hand, seeks a better understanding of the effects of social relations. For instance, from the perspective of the refugee, how do relationships affect employment opportunities? Thus, institutions are not the only determining factor of refugees' success;

their outcomes vary based on a multitude of extraneous variables. While social capital 
remains concretely under-defined, analyzing relationships and socialization among groups offers insights into how communities within Sweden engage with one another. A better understanding of such social interactions will help us come to understand why refugees are currently not succeeding in penetrating the Swedish labor market.

While the research for this work relied upon two bodies of literature that guided the fieldwork through an historical outlay, the primary method of data acquisition was a series of in-depth, semi-structured, narrative interviews with members of civil society, the refugees themselves, and select state-level elites. I obtained a relatively near-equal number of refugees from each target group and a balance between the number of male and female participants, but there was one profound limitation. Due to funding issues, I was not able to employ translators to speak with low-skilled refugees. Thus, this remains a fruitful space for future research.

\section{An Overview of Sweden's Integration Policy}

To guide the empirical fieldwork, this research project was framed within an historical institutionalist approach to analyze the economic, political, and social transformations in Sweden since the 1970s. Through a historical application, this study examined three critical junctures in Swedish history. Until 1970, migration to Sweden was characteristically labor-oriented and European-sourced. However, after a slowdown and virtual rejection of certain labor migrants, the country began to receive its first refugees. This period is marked by the introduction of Sweden's integration policy and a continual shoring up of its welfare regime. Due to the structure of the nation's economic policy, in the 1970 s refugees were frequently placed in industry, and there most often in factories. 
For example, Ugandan-Asians were the first refugees to arrive to Sweden, followed shortly thereafter by those from Chile.

It is worth noting that irrespective of Sweden's economic orientation and opportunity structure, these groups had starkly different labor market outcomes. Scholars have differed on the reasons for their varying levels of success with integration. One finding suggests that a group's self-perception (e.g., where they saw themselves within the local context, as well as the extent to which they regarded the longevity of an ongoing conflict back home) was the defining trait. A positive outlook toward ongoing conflict in their native country (e.g., resolution is on the horizon and reentrance is feasible) and integration in their host state are inversely related. Ugandan-Asians found the situation in Uganda to be futile and return impossible, and hence were proactive in restarting their lives in Sweden. Conversely, Chileans believed that reconciliation within Chile was on the horizon. During this time, they were categorically reluctant to make any long-term plans in Sweden.

Because of differences in the groups arriving in the 1970s, Swedish policymakers eventually conceded that they would need to formalize the nation's integration policy. No longer would the mode of integration be as organic as it once has been. In other words, as the origin of immigrants shifted from primarily European labor migrants at the ends of the 1960 s, to asylum seekers from around the world, a more regulated stance was needed. Its initial plan was firm in its intent that all refugees would receive equal access to services in Sweden's welfare state, and this outlook continues today. However, the increased level of globalization and other market factors have forced Sweden's immigration policies to evolve. In the 1980s, the country faced more refugees and 
internal fiscal issues. The Iran-Iraq war brought a substantial wave of immigrants, and family reunification of individuals from the Middle East, Southeast Asia, South America, and Europe continued this trend. But to recall, the level of refugees during this two decades are relatively incomparable to those of today. For instance, when looking at the largest arriving groups during these two decades, we see that only 18,000 Chileans came between 1973-1989, and likewise a mere 27,000 Iranians and 7,000 Iraqis came to Sweden during the 1980s. By the end of the 1980s, as a result of economic downturns, Sweden's opportunity began to gravitate away from its state-run type of employment which had been at its height in the 1970s, when levels of refugees were at their lowest.

Due to this economic instability and rise in asylum seekers, the 1990s spawned an era of reform. With the economic crisis and election of Bildt's conservative party, 1991 formally demarcated a new era of fiscal and political reform in Sweden. This second juncture, which ran from 1990 to 2010, is characterized by the war in the Balkans and the large number of refugees arriving from the former Republics of Yugoslavia and Macedonia (a little more than 100,000 primarily Bosnians came over the course of the $1990 \mathrm{~s}),{ }^{52}$ as well as fiscal and political reorientation toward greater privatization, which moved Sweden to a more service-based economy and in effect reduced access to the types of employment typically favored by marginalized groups. Yet at this point, reception and integration policies in Sweden had not markedly changed. At the end of the first war in the Balkans, all refugees from Bosnia were instantly granted permanent resident status, which allowed for immediate family reunification. At the heart of this was

\footnotetext{
${ }^{52}$ Migrationsverket. https://www.migrationsverket.se/English/About-the-Migration-Agency/Facts-andstatistics-/Facts-on-migration/History.html.
} 
the understanding that refugees would not be able to return home. Creating a stable environment and giving them access to social services allowed them to start their lives over in Sweden. Given Sweden's economy and social contract, and provided with permanent residency status, it was expected that refugees would become economically active. In other words, while labor market integration had always been central to the refugee integration platform, in the 1990s, it became essential.

It is important to note that while this era was marked by economic struggle, refugees (both male and female), primarily from Bosnia, integrated into Swedish society relatively well. After a decade, they had achieved employment levels relative to those of native Swedes (Södersten 2004). From 2000 to 2010, Sweden was met with another humanitarian crisis that many attribute to the beginning of the War in Iraq in 2003. Refugees from the Middle East (the largest group, from Iraq-roughly 121,000 Iraqi's were in Sweden by 2010, Statistics Sweden) who came to Sweden typically already had family members there. With this in mind, it is curious that their rate of unemployment is still almost three times that of native Swedes. It is possible that this group is afflicted by what Putnam (2007) refers to as "hunkering down." As seen in other research (Warman 2007; Szulkin \& Jonsson 2007; Browning 2009) having a deep in-country network of people from the refugee's native land may actually prove harmful to their integration into the host society. One such indicator of this is the high level of segregation in Sweden (the highest in the OECD). This is an interesting correlation, but determining why refugees actually remain unemployed is a much more complex and nuanced puzzle than cannot be revealed by figures alone. 
This leads us to the final juncture, during which reform efforts were put in place to solve or at least delineate the problem, in an effort to reconfigure and more systematically design a program for refugee employment. Up to 2010, several attempts were made by the state to encourage labor integration, but these programs were all at the municipality level. Because of the lack of consistency among municipalities, in 2009 Riksdag introduced a new platform run by the state. Ratified in December of 2010, Etableringsplan marks a new era in refugee labor market integration. In this program, each case is monitored by a state-employed caseworker who works with the individual to construct a two-year program for everything from language training and other educational initiatives, to securing an internship (pratique), and hopefully long-term, sustainable employment. The latter, however, has proven difficult to achieve. This effort began just before the most recent onslaught of refugees, sparked primarily by the ongoing civil war in Syria, but also by instability in the Middle East and Africa. For instance, in 2016 Afghans surpassed Syrians as the largest group arriving in Sweden, and those from Eritrea are on the rise. Matching refugees with resources appropriate to their skill level so they can engage in language acquisition and retraining, as well as mend any trauma experienced by their journey, all take time.

The aim of the historical institutionalist component of this research was to provide a descriptive interpretation of the process of refugee integration, and more specifically, how labor market integration has occurred over time. This helps to contextualize the Swedish model in terms of norms and shifts that have affected policy. As noted above, since the 1970s, Sweden has shifted away from the height of its welfare regime. High levels of immigration and diversity (18\% of Sweden's current population is foreign- 
born - double that of 1970 s percentage $)^{53}$ have altered the socioeconomic and political directive typically associated with Sweden's means of government. What remains consistent across all decades included in this research, and should be expected by any regional (Norden) scholars, is the impact of the philosophical underpinnings of folkhemmet. Because of the long reign of the Social Democratic Party (SAP), its expansive welfare state, and the rise of the socio-ideological framing of folkbildning and folkhemmet, folk remains a primary normative directive shaping policy today.

One clear characteristic of the Swedish model is its ability to continually evolve. Not only has the influence of the SAP lessened, but the increase in market reform toward greater liberalization has caused substantial shifts in the economy. Due to Sweden's socioeconomic orientation, employment has always been a central focus of integration plans. In response to the high rate of unemployment, since 2010 the state's integration policy has focused specifically on the labor market. However, the problem persists. This is in large part due to the substantial number of refugees who have arrived in the past three years. I assume that as Sweden applies more resources to the project and as CSOs become more active, we will begin to see more positive (or at least less dire) outcomes.

\section{Adapting to the Retreat of the State: The Rise of Civil Society}

This research assumed globalization (international competition and rising levels of refugee) would directly affect how refugee integration takes place in Europe. Ergo, aside from state mandated policy reformation, integration would require participation from

53 "Population 2000-2016 and forecast 2017-2060 by Swedish and Foreign Born," Statistics Sweden. http://www.scb.se/en/finding-statistics/statistics-by-subject-area/population/populationprojections/population-projections/pong/tables-and-graphs/the-future-population-of-sweden20162060/population-and-forecast-by-swedish-and-foreign-born/ 
civil society, and that given liberalization of its market, social capital would play a vital role in determining whether refugees would become employed. Indeed, associational memberships and civic participation are central to Swedish society. Given the country's social democratic values, one might expect to see significant non-governmental participation. However, until the most recent crisis, labor market integration practices were almost entirely left to the state. Because of the recent surge in refugees, CSOs are becoming more active, helping the government accomplish the substantial task of evaluating and meeting refugees' needs. While the state has been proactive in terms of immediate reception and enrolling refugees in the mandated integration program, my findings suggest that civil society will have a longer-term, more in-depth role.

My data cultivation and subsequent analysis began with events occurring at the end of the 1990s. I selected this point because it is where the looming effects of globalization, such as the effects of global competition and flow of people on the makeup of Sweden's political and economic structure, become clear. By the end of the 1990s, the SAP was less dominant than at any time since before WWII. Also by this time, Sweden had received hundreds of thousands of refugees from both inside and outside of Europe. Though civil society is an amalgamation of potential actors and associations, this analysis focused on CSOs; for organizational purposes, these were further divided into ethnic associations, Swedish NGOs, international organizations, and faith-based groups. Associations and organizations were selected according to their participants (e.g., Iraqi, Syrian, Somali, Afghani, etc.), and other local organizations were chosen because they worked directly or indirectly (such as in an advisory role) with refugees. After the initial contact and interviews, snowballing techniques were employed to access additional 
participants working with other groups. Based on fieldwork consisting of 25 in-depth, semi-structured interviews, my research highlights the usefulness of these organizations to refugees pursuing labor market integration.

One major challenge for CSOs is a lack of consistent funding, which makes it difficult to plan and hire for the future. Hence, most organizations working with refugees rely heavily on volunteers. Ethnic organizations serve as a point of contact. However, based on my interviews, these also can be inconsistent. While they may help to establish relationships, they may not be directly associated with the labor market. Yalla Sofielund, IM, and similar projects working to directly engage with refugees are promising. Not only do they offer asylum seekers a way of venturing outside their ethnic enclaves, they also help train refugees in skills that will help them become labor-market ready. My findings indicate that these programs are especially useful for women. For instance, AWEP works directly to empower Afghan women. Larger international organizations like the Red Cross continue to be actively involved, as well. While their role is more pronounced in the reception phase, the Red Cross, provides internships that can help with cultivating wider social networks.

My findings indicate that CSOs are active throughout the process of integration. However, they also suggest that these organizations are underutilized and not yet fully trusted by the state. This is evidenced by inconsistencies in funding. Yet their role is becoming more systematized and better supported, especially with regards to native-run, non-religious, non-ethnic associations. For example, Refugees Welcome Sweden is now able to gain direct access to refugee camps whose locations remain inaccessible from most other CSOs, especially ethnic organizations. Moreover, funding for local Swedish 
CSOs like Sensus, Yalla Sofielund, Rådrum, and IM are becoming more consistent. The system is imperfect, but trust in the third sector is increasing.

Ethnic organizations, while clearly important for helping refugees feel welcome and providing them with useful information, remain less of a force in labor market penetration. Greater contact should be pursued between these organizations and the state. Fostering connections between refugees and native Swedes remains difficult, as does the more complex issue of ensuring access to necessary information. One of the greatest obstacles to the latter is the lack of organic intersection among groups. If the state could work with civil society to bring together ethnic and native organizations, more joint meeting places would present themselves. This would also improve bridging between communities and significantly expand the likelihood of finding sustainable employment.

At this point in time, however, there is also a perceivable disconnect with the nongovernmental sector. The challenge is not merely one of hierarchy, or allocation of funds. Rather, other horizontal challenges persist. This is visible from several angels, but based on these findings, two-distinct realities are undeniable. First, based on the interviews, ethnic organizations do not appear to regularly interact. If the ethnic communities could come together, then they should be able to develop a more unified platform to voice their concerns. For instance, Sallhuddin's Islamic Academy would have much further reach, if they could bring together community members and leaders to discuss challenges faced within the ethnic communities and facilitate more interaction between organizations and the community, then we should see greater rates of employment. In other words, greater interaction between those with access to employment with those who do not should help mitigate unemployment among refugee communities. Second, there is a clear disconnect 
between native (Swedish-run) and ethnic organizations. While there may be a growing community of native civil society organizations, they appear to have minimal contact with refugees themselves. This was evidenced in virtually all of the converstaions I had with civil society representatives. It would seem for these organizations to have the greatest impact, rather than applying what they believe are "best-practices," they should instead be working directly with refugees to learn about specific challenges and needs

Because of increased liberalization and flexibility in its market, state-assisted integration appears to not be as effective as it once was (Valenta and Bunar 2010). However, to verify this, additional comparative work is needed. What is becoming increasingly apparent, though, but similarly requires additional research, is the tendency that highly-developed welfare states may succumb to discrimination against marginalized populations (Mestheneos and Ioannidi 2002). If this is the case, then the challenges for Sweden will become increasingly greater for at least two reasons. First, this would mean irrespective of the effort made throughout their integration program, the opportunities within the private sector, while available/advertised, will not be offered to refugees. In other words, despite any refugee's capability and human capital, they will not have access to the same opportunities as native Swedes. This would confirm some of the findings in Hjerm (2005) and Koopmans (2010), who both find that those who argue that the social democratic welfare state is better at integrating newcomers is inherently amiss. Second, higher levels of discrimination (hidden or not), will likely increase a sense of alienation and decrease the likelihood of proactive, self-motivated integration-thus, reducing any sense of autonomy. To abate potential discrimination, more needs to be done to foster relationships between the native Swedish and its refugee community. 
However, a significant challenge exists in communication between organizations themselves as well as in their ability to access refugee communities. What is more, my findings also suggest a disconnect between the ideal state guided approach, and how employment actually occurs in a highly advanced, quasi-privatized labor market.

Several civil society organizations have expressed a desire to become a more formal means of helping refugees gain access to native Swedes, cultivate networks, and participate in training programs. These groups and flash organizations serve as pipelines of information and facilitate essential education. However, since many have only existed since 2013, their overall effect remains to be seen. It is likely, though, that they will be beneficial in two ways. First, building social networks through activities and outreach allows asylum seekers to feel like a part of the local community. Becoming grounded and feeling welcome often determines the likelihood of success in the subsequent steps. For instance, a feeling of acceptance may encourage newcomers to learn Swedish and other appropriate skills, as well as make contacts that will lead to gainful employment. Second, expanding one's network to encompass those outside of their community also expands the possibility of finding stable employment. As alluded to by one of the interview respondents, Abdi, 'to feel stable, one must feel autonomous'. As he, Tony, and several other participants explained, refugees do not want to rely on state assistance, but for many, at least for a time (often, upwards of five years), there is no other choice. Several new programs now exist to help refugees find training programs, but it is not yet clear if this will translate into stable employment.

In sum, my findings suggest that some of the obstacles keeping civil society from having a larger role in refugee integration include funding, community accessibility, 
information dissemination, discrimination, cooperation with the PES, and tangential relationship building between förbunds (civil society-based informal education providers and ethnic organizations). The role of larger organizations is in the reception process, while asylum seekers reside in camps. Flash movements such as Refugees Welcome Sweden, Kontra Punkt, and others assist during times of crisis, but their effect can be fleeting. Kontra Punkt is an exception, in that it has transitioned to a permanent actor. As better integration persists as both a challenge and a need, local CSOs must continue to adapt to eliminate gaps. Rådrum and Yalla Sofielund are just getting started, but given the progress they have made and the increasing number of participants they are attracting, it is likely that they will continue to become more active.

To conclude, the state has traditionally been the primary facilitator of refugee integration in Sweden. With the influx of refugees in the early 1990s and the economic and political pressures of the financial crisis in 1991, I assumed that non-state actors would become more prevalent in the process of labor market integration. After numerous interviews conducted with members of civil society, my findings suggest that their role is becoming more systematic; however, as described by several state representatives as well as actors in civil society, the third sector is still far from being fully utilized. The state continues to provide most assistance, but due to the most recent migration of asylum seekers in 2011, reliance on civil society is increasing. As more and more refugees filter through etableringsplan and CSOs (bringing the two closer together), I expect CSOs will continue to increase in importance. 


\section{Micro Refugee Perspective: Social Networking, Obstacles, and Employment}

While the state and civil society play a crucial role in the integration process, the research hypothesized that they are not sufficient on their own. Rather, social capital (bridging refugees with the native community) is additionally required in this process. To gain insight on this often-overlooked aspect of integration, and to shed light on how refugees access resources available to them beyond the state mandated etableringsplan (carried out by PES), the project conducted 45 interviews with highly-skilled refugees. The reason for selecting this group was twofold. First, this project was limited in that access to lowskilled groups was not possible. Second, a focus on the highly skilled allowed for the

consideration of explanations for this rate of unemployment (beyond the workforce lacking skill). To have as diverse a group as possible, interviewees were selected from the largest refugee groups: Iraqis, Syrians, Afghanis, and Somalis. Refugees from the Congo and Eritrea were also interviewed. This research strove to include both men and women, and a near gender balance was achieved. The underlying assumption was that to become gainfully employed and obtain some semblance of autonomy, refugees would need to bridge out from their ethnic communities and become more active in the host society. As explained above, the state has proven effective in meeting immediate needs (though in the winter of 2015, this also came into question with the housing crisis), but the long process of securing gainful employment appears to rely more on the refugees themselves and their ability to navigate the market. Information is essential to accessing satisfying careers, but how this information is made available remains an understudied aspect of the integration process; hence, this research analyzed one major element social capital. 
The underlying theoretical conditions in an exploration of social capital are complicated. The concept of social capital is often criticized for being difficult to measure, as there is no single accepted description of how it is employed. Yet its use in a study of labor market access is helpful because it explains how relationships are cultivated across groups. Understanding relationship cultivation and network building, expressed here by the term 'social capital', is essential to understanding employment for citizens as much as refugees. Due to changes in Sweden's sociopolitical structure, the state can no longer efficiently grant employment. Thus, there is no single, well-defined process by which refugees find work, as evidenced by the high level of unemployment among those who came to Sweden after 2000.

From the dozens of interviews I conducted and several other informal conversations, it became clear that language remains one of the greatest challenges for refugees. However, language provides both, human and social capital and is indisputably crucial to integration. Beyond language acquisition, other barriers vary from person to person. For those with high skillsets, the obstacles are related to verification and networking. It takes time for documents to be adjudicated, and forming the appropriate social networks can prove difficult. Of the younger participants, all reported having regular interactions with native Swedes. For older individuals, bridging remained more problematic. There are many challenges to overcome when entering a new labor market, but for individuals like Mulhalm, who have already completed their university educations, speak English, are efficient with social networking mediums, and have positive and outgoing dispositions and few familial attachments to Sweden, there is a real chance of bridging with the Swedish community. 
While human capital plays a considerable role in the integration process, out of my sample, the component age trumped all others. These findings confirm Westin (2006), who noted mastering the Swedish language and acquiring the human capital required to break into the local labor market was typically out of reach for middle-aged and elderly immigrants. Nevertheless, outliers who possess viable skills, and have fully acculturated, like Abdi, were still unable to find steady employment. This suggests that appropriate human capital does not guarantee employment and Sweden's integration policy should do more to take into account the necessity of social capital (especially for those who are older where making new relationships may not be as feasible). Conversely, all who arrived before the age of eighteen where able to find work or seemed likely to do so (following the completion of their education).

These findings are similar to those of Scotts (1999) in three ways. First, it is clear that the economic shift toward more service-based forms of employment is making it increasingly difficult for those I interviewed to find work. This is because the evaluation process is long and there are very few low-skill jobs available. Second, culture matters. Hidden discrimination exists for some, and based on my participants' responses concerning their social networks, establishing strong connections with natives could be problematic. Third, having a tertiary education does not guarantee entrance into Sweden's labor market, but for those who acquire their education and skills in Sweden, becoming employed after university attendance is more likely.

Per my findings, it seems difficulties in accessing employment for high-skilled refugees are more attached to institutional constraints than they are to human capital. Translating previous education and experience to Swedish employers seems to be an 
extremely arduous process. This may be because when etableringsplan was developed, it only expected to be used by 34,000 new refugees to take part in the program, far less than the number presently in Sweden. In addition, steep regulation and flexible hiring practices (particularly in the private sector), may also help explain the elevated rates of unemployment and difficulties cultivating relationships. The challenges rooted in Sweden's economic orientation, which continues to grapple with the trend of increased privatization, are considerable. One possible solution is to work toward facilitating fair and monitored access to capital for vetted immigrant entrepreneurial ventures.

Beyond the strictures of regulation, a more subjective interpretation of how refugees enter the labor market remains. Inherent to the central assumptions of this research is an acknowledgment that we should not take policy and their outcomes as given. Instead, as Eva Wikström (2009) found, one's subjective outlook can greatly affect the likelihood of success. Like her findings, mine indicate that it was not so much where refugees obtained their education and skills, but rather their age, ability to cultivate networks, and general personal disposition to their situation that also determined the likelihood of finding employment. Put another way, regardless of their human capital, how one views their situation matters. Compounded with other factors, this may be one explanation for why it is harder for older refugees to find employment. This is because older refugees may not have the same accessibility to social networks (as much of the youth maybe eventually enrolled in tertiary education programs with native-Swedes as their pupils) or knowhow related to digital networking as younger refugees do, as exemplified by Mulhalm (a recent arrival from Syria). Nevertheless, aside from the 
determinate factors those previously stated, like Frykman (2012) and Ryan (2011), my findings also indicate that securing suitable employment may be in part left to chance.

When looking more closely at gender specific outcomes, the data showed that women have a more difficult time accessing the labor market, but encouragingly there are programs within civil society that help them when possible (Yalla Sofielund and Yalla Trappen most specifically). Individuals like Laticia were found to not only be capable of accessing the labor market herself, but she also now works to facilitate the process for other women. This was evidenced by her program with OpenSkåne, where she carried out an internship and helped develop a program to bring refugee women into the market. One contribution she made was tailoring her program to be more attentive to the refugees themselves. Instead of just telling the participants what to do, she asked them what they wanted and worked from there. Nevertheless, because of the cultural norms and practices of certain groups (e.g., those coming from strict Muslim societies or places where women are not expected/allowed to be educated), we may assume that women have a much harder road ahead and are less likely to enter the labor market. Notwithstanding, greater research into such an assumption is certainly needed.

To sum up, the research was interested in exploring two primary research questions. First, how have the roles of the state and civil society adjusted over time in relation to the process of integrating refugees, especially since the founding of the first integration policy in 1975? Second, how are resources actually provided by each element of society (the state and civil society alike), and accessed by the refugees themselves? These findings suggest outcomes varied by age, personal outlook (self-motivation), and in part chance. Ergo, most refugees arriving as adolescents should be able to become 
employed (in both public and private sectors). However, as noted by Duvander (2001), while country specific knowledge is helpful in becoming employed, a lack of is not entirely sufficient in explaining labor market disadvantage in Sweden, to which she also highlights discrimination as another potential factor delaying labor market integration. It is therefore, well within reason to posit that human capital does not necessarily result in employment. Other underlying, less discernable, factors exist, which require further investigation.

In relation to the assumptions posed in this research, social capital, especially for participants who arrived as adults, did play a significant role in determining whether refugees they became employed. However, it appears as one ages, the likelihood of accessing useful social capital appears to become much more difficult. Put another way, the older a refugee was, the lower the likelihood of them making useful Swedish contacts beyond representatives of the state or at times CSO representatives. In addition, given the difficulties in evaluation (skills and education) as well as accessing local social settings, age was the greatest impediment. Upon reflection, the difficulties are combination of the state's inability to expediently evaluate and match suitable candidates with available employment, personal attributes of refugees (e.g., age, disposition toward their situation, and to an extent, luck), as well as the inability of other non-state organizations to connect with refugee populations and bridge groups and networks alike. All participants had received the type of aid one would expect from the state (health care, access to education and housing, etc.). While CSOs are becoming more active in the process of labor market integration, aside from ethnic associations, they are not necessarily sought out. One explanation is that information on the resources available is not readily accessible. 
Because of several of these competing factors and given the current climate (high levels of unemployment and by many indicators, heavy segregation), Sweden may find it challenging to retain its highly-skilled refugee population. It is still too early to tell how well Sweden's new integration platform will perform. Certainly, more research is needed.

\section{Future Work}

Additional research should be conducted with refugees who have received little or no formal education. This will, however, require additional resources to cover the cost of translators. I assume, though, that as more and more refugees enter the labor market and more relationships are established between refugees and Swedes, finding personnel with these capabilities will become easier. Of the refugees I spoke to, nearly all wanted to assist other refugees in any way they could. Yar, one of my participants from Afghanistan, was deeply passionate about helping newly arriving Afghanis find their place in Sweden. Similarly, Nor and Ivan, both from Iraq, found it necessary to assist others in their group.

Due to Swedish regulations, the likelihood of refugees starting their own businesses is low. This, however, is not only because of the low rate of success among refugee entrepreneurs, but also because of the high taxes that must be paid by business owners for every person they employ (among various other Swedish regulations). It is ironic that Sweden's high level of equality actually impedes the ability of some to become employed. Thus, the question must be asked: what does it mean to be formally equal in an increasingly diverse society? How can we research the intersectionality of Sweden's cultural values and those of refugees, most of whom come from radically 
different societies to that of Sweden or the European Union? How can Sweden meet the challenge of not only fully employing refugees, but also altering their value structures (so that economic progress is at the center) and providing them with the necessary education? In a state that prides itself on tolerance, how can we begin to analyze the effects of hidden discrimination? As alluded to in other research (Carlsson \& Rooth 2007) and seen in the interviews conducted here, even with all efforts to the contrary, discrimination may still impede refugees from accessing the labor market.

In addition to this study which focused on Sweden, additional comparative research is needed that broadens the scope to other countries, such as Germany which had the largest intake in total number of refugees. For one, more needs to be understood about the European Union and how other states are bringing their refugees into the labor market. Following the virtual collapse of Dublin II, several other EU-level attempts to redistribute refugees to other Member States were made. The new scheme launched in September 2015 aimed to relocate 160,000 refugees from Greece and Italy. Like Dublin II, this scheme has also been ineffective. In a Global Memo from the Council on Foreign Relations, as of April 2016, only 1100 refugees had been resettled from Greece and Italy to other EU Members. Due to the lack of cooperation, the relocation scheme was later reduced to $98,255 .{ }^{54}$ One explanation for the continual lack of cooperation is the resistance of several states, as evidenced by the dispute between France and the U.K. concerning the "Jungle" in Calais, and the absolute rejection by the Visegrad Four (Poland, Slovakia, Czech Republic, and Hungary) to work with the EU on refugee

\footnotetext{
54 "Questions and Answers" European Commission Press Release Data Base, March 2, 2017, accessed June 25, 2017 http://europa.eu/rapid/press-release_MEMO-17-349 en.htm.
} 
resettlement, to name a few. Since then, the EU also worked out an agreement with Turkey. In exchange for visa-free travel to the EU, a renewed discussion on their eventual accession and three billion euros, Greece would be able to return those who arrived irregularly on its shores after March 20, 2016 and Turkey would send already resettled Syrians to Europe. As of 27 February 2017, the number of migrants returned to Turkey was $3,565 .{ }^{55}$ Given the current tumult in Turkey (e.g., Erdogan's Executive Presidential status) and the rising tensions in Central Europe over Dublin II and the redistribution scheme, the EU-Turkey deal is far from an effective response.

It is undeniable that the resettlement project cannot be soloed by one or two member states alone. Greater cooperation across member states is needed. Also, more attention should be paid to determining if entrepreneurship could offer an avenue for refugees, since many scholars and politicians have found it to be a reliable pathway to gainful employment, especially in the most marginalized communities. Then, researchers could investigate implementation schemes and how they might compete with national agendas. This would be challenging in Sweden, as any talk of deregulation goes directly against its heavily regulated framing. Yet with a significant number of refugees remaining unemployed, the need to cultivate long-lasting forms of employment is more important than ever; all possible avenues of change should be pursued.

\footnotetext{
${ }^{55}$ Kondylia Gogou, “The EU-Turkey Deal: Europe's Year of Shame," Amnesty International, March 20, 2017, accessed June 25, 2017, https://www.amnesty.org/en/latest/news/2017/03/the-eu-turkey-dealeuropes-year-of-shame/.
} 


\section{Conclusion}

This research suggests there are several hurdles facing CSOs and refugees in the integration process. First, Sweden has become more privatized. This, coupled with the requirement that most job-seekers be highly educated, means that refugees have a difficult time finding jobs. After traveling throughout Sweden, especially in the suburbs surrounding city centers, it is clear that self-segregation is very much a component of the Swedish lifestyle. Along with this lack of natural intermixing, insufficient access to information and other recourses also impede refugees' progress. Developing a solution to the lack of organic spaces where refugees can interact with Swedes will require the participation of both groups. One side cannot foster contacts on their own.

Thus, labor market integration is an ongoing project. Unemployment remains staggeringly high for some groups (e.g., the Somali population suffers the most, with only 20 percent finding employment after a decade in Sweden). Civil society has become more active in the process of refugee labor market integration, and different types of organizations facilitate different roles. The most active are those that are native. One explanation for this is that the state has greater trust in their capabilities. Ethnic organizations participate in community building, organizing local activities that revolve around bringing people together in salon-type environments. In direct relation to the labor market, what they offer is less tangible. They provide a place for refugees and locals to come together by hosting guest lectures or just designating spaces for people to sip coffee and make new friends. Yet while abstract, the utility of these types of organizations is unquestionable. Conversely, the role of international organizations is concrete. Primarily, their role is to facilitate reception and provide other organizations with aid and assistance. 
This is evident in the way the Red Cross assists in refugee camps, where other non-state actors are not allowed (though this may be changing, as seen with Refugees Welcome Sweden).

For many asylum seekers, two factors are primary impediments to labor integration: discrimination and time (both the time it takes to learn Swedish and the long wait for paying work). However, my data shows that the determining factor in employment is age. Irrespective of skill and education, my findings suggest that if you are over age fifty and a refugee in Sweden, you have a very, very low chance of ever becoming employed. This presents refugees with immense existential and economic hurdles. The feeling of alienation makes motivation to learn the language elusive. How this impacts the overall community is unknown, but we can assume that if these older refugees have children and are unable to integrate (e.g., learn Swedish and find employment, either inside or outside their own community), then the children will be negatively affected. Cultural plurality improves society, but lacking native attachés deleteriously impacts the future opportunity structure of the children.

In sum, this study contributes to the literature in three distinct ways. For welfare state research, this work offers insights into how institutional mechanisms are transforming within liberalized welfare states like Sweden. As in Valenta and Bunar (2010), my findings suggest a highly-regulated marketplace may impede refugee employment. Indeed, transforming market regulations is easier said than done, but it is something to consider for the future. To alleviate some of the pressure associated with bringing refugees into Sweden's labor market, especially with regards to potentially pronounced levels of hidden discrimination, future policy should first work to facilitate 
well-vetted entrepreneurial ventures. Second, it is clear that civil society is now an essential actor in the refugee integration process. That being said, however, there still exists a considerable gap in how organizations communicate with one another and how they access refugee communities. Additional funding should be allocated to hiring resettled refugees and translators to work with refugee communities and provide them with information on the resources and services available to them. In other words, these individuals should serve as civil ambassadors. To enhance communication between organizations, more municipal consortiums should be established. Giving organizations a forum in which actors can regularly come together would significantly enhance the capabilities of the third sector. Finally, human capital is not everything. While the origin of educational attainment does matter, many of the participants under the age of 35 who received their education outside of Sweden were able to find employment. Hence, these findings suggest that social capital may play an equally, if not potentially more important role in determining whether refugees are able to become gainfully employed. Without a doubt, bonding outside of ethnic communities is difficult, but cultivating relationships with natives will greatly enhance the probability of refugee labor market integration in any EU host nation.

At this time, the impact of the large number of refugees flowing into Sweden remains unknown. The transformation in its economic structure, specifically in the rise to inequality vis-à-vis refugees and natives, may indicate that Swedish exceptionalism is coming to an end (Lindvall and Rothstein 2006; Rothstein 2014). Using mixedembeddedness as a conceptual directive for a study of refugee labor market integration in Sweden has proved useful. First, the theoretical framing justified bringing together two 
bodies of literature, which often study similar phenomena yet often neglect one another. In general, literature concerning the welfare state is more affixed to analyzing policy and therefore, often overlooks social aspects. Vice-versa, economic sociology and social capital related research typically discount much of the relevant policy and legislation affecting the communities of interest. As a result, it allowed for a more comprehensive approach to the study, bringing in several perspectives affected by the consequences of globalization.

To conclude, the refugee crisis is not going to end anytime soon. True solutions must come from cooperation within the international system to assist host states. This research offers a call to researchers and policy makers to begin thinking critically about how non-state actors participate in this process (e.g., the types of resources they offer and the difficulties they describe in providing assistance). The research also offers a clear picture of the very real issues facing refugees. More must be done to assist them in cultivating relationships, which should help refugee communities procure useful knowledge from the host community. More participation is essential from native Swedes. Cultivating useful relationships should not be viewed as a one-sided issue. Regardless of policy, education, or skills, if refugees are not able to acquire useful relationships, then acquiring long-term employment appears futile. Civil society, too, is vital. The challenge is too vast and complex to approach it in the same manner as in the past. Policies matter, but good intent is not enough. This research sheds light on some of the many challenges facing Sweden and its refugee population, and paves the way for future research concerning refugees, civil society, labor market integration, and the welfare state. Its findings should be taken into consideration by those restructuring policy to better meet 
the needs of the rising number of refugees that will certainly come to Sweden and the European Union in the years to come.

\section{References}

Adhikari, Krishna Prasad, and Patricia Goldey. "Social capital and its "downside": the impact on sustainability of induced community-based organizations in Nepal." World Development 38, no. 2 (2010): 184-194.

Adler, Emily Stier, and Roger Clark. An invitation to social research: How it's done. Cengage Learning, 2014.

Adler, Paul S., and Seok-Woo Kwon. "Social capital: the good, the bad, and the ugly." Knowledge and social capital 89 (2000).

Adler, Paul S., and Seok-Woo Kwon. "Social capital: Prospects for a new concept." Academy of management review 27, no. 1 (2002): 17-40. http://www.csee.wvu.edu/ xinl/library/papers/social/social_capital.pdf

Ager, Alastair, Wendy Ager, and Lynellyn Long. "The differential experience of Mozambican refugee women and men." Journal of Refugee Studies 8, no. 3 (1995): 265287.

Alba, Richard, and Victor Nee. "Rethinking assimilation theory for a new era of immigration." International migration review (1997): 826-874.

Aldén, Lina, and Mats Hammarstedt. "Integration of immigrants on the Swedish labour market: recent trends and explanations." (2014).

Aldridge, Stephen, David Halpern, and Sarah Fitzpatrick. "Social capital: A discussion paper." London: Performance and Innovation Unit (2002).

Ålund, Aleksandra. "Ethnic entrepreneurs and other migrants in the wake of globalization." International Review of Sociology/Revue Internationale de Sociologie 13, no. 1 (2003): 77-87.

Anders Gustafsson, Björn. "Social assistance among immigrants and natives in Sweden." International Journal of Manpower 34, no. 2 (2013): 126-141. 
Andersson, Roger. "Ethnic residential segregation and integration processes in Sweden." Residential segregation and the integration of immigrants: Britain, the Netherlands and Sweden (2007): 61.

Andersson, Roger, Åsa Bråmå, and Emma Holmqvist. "Counteracting segregation: Swedish policies and experiences." Housing studies 25, no. 2 (2010): 237-256.

Andersson, Lina, and Mats Hammarstedt. "Ethnic Enclaves, Networks and SelfEmployment among Middle Eastern Immigrants in Sweden." International Migration 53, no. 6 (2015): 27-40.

Anderson, J., and Jens Hoff. Democracy and citizenship in Scandinavia. Springer, 2001.

Andrews, Molly, Corinne Squire, and Maria Tamboukou, eds. Doing narrative research. Sage, 2013.

Arts, Wil, and John Gelissen. "Three worlds of welfare capitalism or more? A state-ofthe-art report." Journal of European social policy 12, no. 2 (2002): 137-158.

Åslund, Olof. "Integration of refugees in the Swedish labor market-policies and neighborhoods." Presentation at MIT. web. edu/CIS/www/migration/dec05workshop/presentations/Aslund_dec9_2005_CIS. pdf-, accessed Feburary 20 (2005): 2007.

Åslund, Olof, and Oskar Nordström Skans. "Will I see you at work? Ethnic workplace segregation in Sweden, 1985-2002." ILR Review 63, no. 3 (2010): 471-493.

Atkinson, Rowland, and John Flint. "Accessing hidden and hard-to-reach populations: Snowball research strategies." Social research update 33, no. 1 (2001): 1-4.

Babones, Salvatore J. Methods for quantitative macro-comparative research. Sage Publications, 2013.

Bäckström, Urban. "What Lessons Can Be Learned from Recent Financial Crises? The Swedish Experience." In Proceedings of a Symposium. 1997.

Banting, Keith, and Will Kymlicka. "Is there really a retreat from multiculturalism policies? New evidence from the multiculturalism policy index." Comparative European Politics 11, no. 5 (2013): 577-598.

Barthes, Roland, and Lionel Duisit. "An introduction to the structural analysis of narrative." New literary history 6, no. 2 (1975): 237-272.

Baumol, William J. The free-market innovation machine: Analyzing the growth miracle of capitalism. Princeton university press, 2002. 
Becker, Gary Stanley. The age of human capital. na, 2002.

Becker, Gary S.Human capital: A theoretical and empirical analysis, with special reference to education. University of Chicago Press, 2009.

Bennett, Andrew, and Jeffrey T. Checkel. "Process tracing: from philosophical roots to best practices." Simons Papers in Security and Development 21 (2012): 30.

Berg, Sven. "Snowball sampling_-I." Encyclopedia of statistical sciences(1988).

Bergh, Andreas. "The universal welfare state: Theory and the case of Sweden." Political studies 52, no. 4 (2004): 745-766.

Bergh, Andreas. "Towards a New Swedish Model?." In Population Ageing-A Threat to the Welfare State?, pp. 109-119. Springer Berlin Heidelberg, 2010.

Bergh, Andreas, and Gissur Ó. Erlingsson. "Liberalization without retrenchment: Understanding the consensus on Swedish welfare state reforms." Scandinavian Political Studies 32, no. 1 (2009): 71-93.

Bergh, Andreas. Sweden and the revival of the capitalist welfare state. Edward Elgar Publishing, 2014.

Berman, Sheri, and Sheri Berman. The social democratic moment: Ideas and politics in the making of interwar Europe. Harvard University Press, 2009.

Betts, Alexander, and Gil Loescher, eds. Refugees in international relations. Oxford University Press, 2011.

Bevelander, Pieter, and Christer Lundh. "Employment integration of refugees: The influence of local factors on refugee job opportunities in Sweden." (2007).

Bevelander, Pieter, Mirjam Hagström, and Sofia Rönnqvist. Resettled and included? The employment integration of resettled refugees in Sweden. Malmö Institute for Studies of Migration, Diversity and Welfare (MIM), Malmö University, 2009.

Bevelander, Pieter, and Ravi Pendakur. "The labour market integration of refugee and family reunion immigrants: A comparison of outcomes in Canada and Sweden." Journal of Ethnic and Migration Studies 40, no. 5 (2014): 689-709.

Bevelander, Pieter. "The employment integration of resettled refugees, asylum claimants, and family reunion migrants in Sweden." Refugee Survey Quarterly 30, no. 1 (2011): 2243. 
Bevelander, Pieter. "Integrating refugees into labor markets." IZA World of Labor (2016).

Bijvoet, Ellen. "Near nativeness and stylistic lexical competence in Swedish of first and second generation Finnish immigrants to Sweden." International Journal of Bilingualism 6, no. 1 (2002): 39-51.

Black, Richard, and Khalid Koser, eds. The end of the refugee cycle?: refugee repatriation and reconstruction. Vol. 4. Berghahn Books, 1999.

Blid, Henry. Education by the People--Study Circles. 1989.

Blume, Kræn, and Mette Verner. "Welfare dependency among Danish immigrants." European Journal of Political Economy 23, no. 2 (2007): 453-471.

Borevi, Karin. "Multiculturalism and welfare state integration: Swedish model path dependency." Identities 21, no. 6 (2014): 708-723.

Brekke, Jan-Paul. "The Dilemmas of Temporary Protection-the Norwegian Experience." Policy Studies 22, no. 1 (2001): 5-18.

Brochmann, Grete, and Anniken Hagelund. "Migrants in the Scandinavian welfare state." Nordic Journal of Migration Research 1, no. 1 (2011): 13-24.

Brochmann, Grete, and Anniken Hagelund. Immigration policy and the Scandinavian welfare state 1945-2010. Palgrave Macmillan, 2012.

Bruner, Jerome. "Culture and human development: A new look." Human development 33, no. 6 (1990): 344-355.

Bijl, Rob. Measuring and monitoring immigrant integration in Europe: integration policies and monitoring efforts in 17 European countries. Netherlands Institute for Social Research/SCP, 2012.

Blomqvist, Paula. "The choice revolution: privatization of Swedish welfare services in the 1990s." Social Policy \& Administration 38, no. 2 (2004): 139-155.

Blomström, Magnus, Ari Kokko, and Fredrik Sjöholm. "Growth and innovation policies for a knowledge economy: Experiences from Finland, Sweden, and Singapore." Background paper for the LAC Flagship Report. Washington, DC: World Bank (2002).

Bolin, Niklas, Gustav Lidén, and Jon Nyhlén. "Do Anti-immigration Parties Matter? The Case of the Sweden Democrats and Local Refugee Policy."Scandinavian Political Studies 37, no. 3 (2014): 323-343. 
Brochmann, Grete, and Anniken Hagelund. Immigration policy and the Scandinavian welfare state 1945-2010. Palgrave Macmillan, 2012.

Browning, Christopher R. "Illuminating the downside of social capital: Negotiated coexistence, property crime, and disorder in urban neighborhoods." American Behavioral Scientist 52, no. 11 (2009): 1556-1578.

Bursell, Moa. "Name change and destigmatization among Middle Eastern immigrants in Sweden." Ethnic and Racial Studies 35, no. 3 (2012): 471-487.

Carlsson, Magnus, and Dan-Olof Rooth. "Evidence of ethnic discrimination in the Swedish labor market using experimental data." Labour Economics 14, no. 4 (2007): 716-729.

Castles, Stephen. "How nation-states respond to immigration and ethnic diversity." Journal of Ethnic and Migration Studies 21, no. 3 (1995): 293-308.

Chambers, Simone, and Jeffrey Kopstein. "Civil society and the state." The Oxford handbook of political theory 1 (2006).

Cnossen, Taeke. "Integration of Refugees." International Migration 2, no. 2 (1964): 135153.

Coffey, Amanda, and Paul Atkinson. Making sense of qualitative data: Complementary research strategies. Sage Publications, Inc, 1996.

Coleman, James. "Relational analysis: the study of social organizations with survey methods." Human organization 17, no. 4 (1958): 28-36.

Coleman, James S. "Social capital in the creation of human capital."American journal of sociology (1988): S95-S120.

Colic-Peisker, Val, and Iain Walker. "Human capital, acculturation and social identity: Bosnian refugees in Australia." Journal of Community \& Applied Social Psychology 13, no. 5 (2003): 337-360.

Colic-Peisker, Val, and Farida Tilbury. "Employment niches for recent refugees: Segmented labour market in twenty-first century Australia." Journal of refugee studies 19, no. 2 (2006): 203-229.

Connor, Phillip. "Explaining the refugee gap: Economic outcomes of refugees versus other immigrants." Journal of Refugee Studies 23, no. 3 (2010): 377-397. Czarniawska, Barbara. Narratives in social science research. Sage, 2004. 
Dacyl, Janina W. "Protection seekers from Bosnia and Herzegovina and the shaping of the Swedish model of time-limited protection." International Journal of Refugee Law 11, no. 1 (1999): 155-192.

Dahlstedt, Magnus, and Anders Neergaard. "Whither Swedish Exceptionalism? Concluding reflections." (2015).

Dahlstedt, Inge, and Pieter Bevelander. "General versus vocational education and employment integration of immigrants in Sweden." Journal of Immigrant \& Refugee Studies 8, no. 2 (2010): 158-192.

Daiute, Colette. Narrative inquiry: A dynamic approach. Sage Publications, 2013.

Danzer, Alexander M., and Firat Yaman. "Do Ethnic Enclaves Impede Immigrants' Integration? Evidence from a Quasi-experimental Social-interaction Approach." Review of International Economics 21, no. 2 (2013): 311-325.

Dewey, John. Democracy and education. Courier Corporation, 2004.

"Displacement the New $21^{\text {st }}$ Century Challenge: UNHCR Global Trends 2012." UNHCR (2012): 2-47

Doraï, Mohamed Kamel. "Palestinian Emigration from Lebanon to Northern Europe: Refugees, Networks and Transnational Practices." Refuge 21, no. 2 (2003): 23-31.

Dörr, Silvia, and Thomas Faist. "Institutional conditions for the integration of immigrants in welfare states: a comparison of the literature on Germany, France, Great Britain, and the Netherlands." European Journal of Political Research 31, no. 4 (1997): 401-426.

Drees, Mr Burkhard, and Ceyla Pazarbasioglu. The Nordic banking crisis: pitfalls in financial liberalization. No. 161. International monetary fund, 1998.

Drever, Eric. Using Semi-Structured Interviews in Small-Scale Research. A Teacher's Guide. 1995.

Dumont, Christophe-Jean, and Scrapetta, Stefano. "Migration Policy Debates." OECD, September 2015. https://www.oecd.org/migration/Is-this-refugee-crisis-different.pdf.

Duvander, Ann-Zofie E. "Do country-specific skills lead to improved labor market positions? An analysis of unemployment and labor market returns to education among immigrants in Sweden." Work and Occupations 28, no. 2 (2001): 210-233.

Eastmond, Marita. "Nationalist discourses and the construction of difference: Bosnian Muslim refugees in Sweden." Journal of Refugee Studies 11, no. 2 (1998): 161-181. 
Edin, Per-Anders, Peter Fredriksson, and Olof Åslund. "Ethnic enclaves and the economic success of immigrants-Evidence from a natural experiment." The quarterly journal of economics 118, no. 1 (2003): 329-357.

Edwards, Bob, and Michael W. Foley. "Civil society and social capital beyond Putnam." American Behavioral Scientist 42, no. 1 (1998): 124-139.

Eger, Maureen A. "Even in Sweden: the effect of immigration on support for welfare state spending." European Sociological Review (2009): jcp017.

Ekberg, Jan. "Immigrants in the welfare state." In Globalization and the Welfare State, pp. 195-212. Palgrave Macmillan UK, 2004.

Ekman, Iver. "Stockholm Syndrome How Immigrants Are Changing Sweden's Welfare State." Foreign Affairs 19 (2014).

Elliott, Jane. Using narrative in social research: Qualitative and quantitative approaches. Sage, 2005.

Englund, Peter. "The Swedish banking crisis: roots and consequences." Oxford review of economic policy 15, no. 3 (1999): 80-97.

Envall, A. "Monitoring Integration in Sweden." Measuring and monitoring immigrant integration in Europe: Integration policies and monitoring efforts in 17 (2012): 313-325.

Esping-Andersen, Gosta. The three worlds of welfare capitalism. John Wiley \& Sons, 2013.

Evergeti, Venetia, and Elisabetta Zontini. "Introduction: Some critical reflections on social capital, migration and transnational families." Ethnic and Racial Studies 29, no. 6 (2006): 1025-1039.

Farchy, Emily, and Liebig, Thomas. "Finding the Way: A Discussion of the Swedish Migrant Integration System.” OECD, (2014).

Feldman, Martha S., Kaj Sköldberg, Ruth Nicole Brown, and Debra Horner. "Making sense of stories: A rhetorical approach to narrative analysis." Journal of Public Administration Research and Theory 14, no. 2 (2004): 147-170.

Fischer, Manfred M. "The new economy and networking." Innovation, Networks, and Knowledge Spillovers: Selected Essays (2006): 95-115.

Fölster, Stefan, and Johan Kreicbergs. "Twenty five years of Swedish reforms." Institute R ed. Stockholm: Reform Institute (2014). 
Fong, Eric, Wenhong Chen, and Chiu Luk. "A comparison of ethnic businesses in suburbs and city." City \& Community 6, no. 2 (2007): 119-136.

Foucault, Michel. "Power/Knowledge, ed. Colin Gordon." New York: Pantheon (1980).

Freeman, Mark. Rewriting the self: History, memory, narrative. Vol. 2. Routledge, 2015.

Fredlund-Blomst, Sofie. "Assessing immigrant integration in Sweden after the May 2013 riots." Migration Policy Institute 16 (2014).

Friedman, Milton. Capitalism and freedom. University of Chicago press, 2009.

Goulbourne, Harry, Tracey Reynolds, John Solomos, and Elisabetta Zontini. Transnational families: Ethnicities, identities and social capital. Routledge, 2010.

Frykman, Maja Povrzanović. "Struggle for recognition: Bosnian refugees' employment experiences in Sweden." Refugee Survey Quarterly 31, no. 1 (2012): 54-79.

Fylan, Fiona. "Semi structured interviewing." A handbook of research methods for clinical and health psychology (2005): 65-78.

Geertz, Clifford. The interpretation of cultures. Vol. 5019. Basic books, 1973.

Gergen, Kenneth J. "The social constructionist movement in modern psychology." American psychologist 40, no. 3 (1985): 266.

Gerring, John. "Mere description." British Journal of Political Science 42, no. 4 (2012): 721-746.

Ginsburg, Helen Lachs, and Marguerite G. Rosenthal. "Sweden: Temporary detour or new directions." G. Schaffner Goldberg, \& MG Rosenthal, Diminishing Welfare: A Cross-National Study of Social Provision (2002): 103-48.

Givens, Terri, and Adam Luedtke. "The politics of European Union immigration policy: institutions, salience, and harmonization." Policy Studies Journal 32, no. 1 (2004): 145165.

Givens, Terri E. "Immigrant integration in Europe: Empirical research." Annu. Rev. Polit. Sci. 10 (2007): 67-83.

Goodhart, David. "Too diverse?." Prospect magazine 95, no. 30 (2004): 7.

Granovetter, Mark S. "The strength of weak ties." American journal of sociology 78, no. 6 (1973): 1360-1380. 
Granovetter, Mark. "Economic action and social structure: The problem of embeddedness." American journal of sociology 91, no. 3 (1985): 481-510.

Green-Pedersen, Christopher., and Jesper Krogstrup. "Immigration as a political issue in Denmark and Sweden." European journal of political research 47, no. 5 (2008): 610634.

Griffin, Rosemary Holly. "Refugee Resettlement: Social Capital, Civil Society, and the Integration Processes of Former Refugees." (2012).

Griffiths, David, Nando Sigona, and Roger Zetter. "Integrative paradigms, marginal reality: refugee community organisations and dispersal in Britain." Journal of Ethnic and Migration Studies 32, no. 5 (2006): 881-898.

Grundström, Karin, and Irene Molina. "From Folkhem to lifestyle housing in Sweden: segregation and urban form, 1930s-2010s." International Journal of Housing Policy 16, no. 3 (2016): 316-336.

Guest, Greg, Arwen Bunce, and Laura Johnson. "How many interviews are enough? An experiment with data saturation and variability." Field methods 18, no. 1 (2006): 59-82.

Gustafsson, Björn, Katarina Katz, and Torun Österberg. "Residential Segregation from Generation to Generation: Intergenerational Association in Socio-Spatial Context Among Visible Minorities and the Majority Population in Metropolitan Sweden." Population, Space and Place 23, no. 4 (2017).

Hamel, Jacques, Stéphane Dufour, and Dominic Fortin. Case study methods. Vol. 32. Sage, 1993.

Hammar, Tomas. "Cradle of freedom on earth': Refugee immigration and ethnic pluralism." West European Politics 14, no. 3 (1991): 182-197.

Hammarstedt, Mats. "Immigrant self-employment in Sweden-its variation and some possible determinants." Entrepreneurship \& Regional Development 13, no. 2 (2001): 147-161.

Hansen, Jorgen, and Magnus Lofstrom. "Immigrant Assimilation and Welfare Participation Do Immigrants Assimilate Into or Out of Welfare?." Journal of Human Resources 38, no. 1 (2003): 74-98.

Harvey, John H., Shelly K. Stein, Nils Olsen, and Richard J. Roberts. "Narratives of loss and recovery from a natural disaster." Journal of Social Behavior and Personality 10, no. 2 (1995): 313 .

Hart, Keith. "The informal economy." Cambridge Anthropology (1985): 54-58. 
Hart, Keith. "Informal income opportunities and urban employment in Ghana." The journal of modern African studies 11, no. 1 (1973): 61-89.

Hatch, J. Amos, and Richard Wisniewski. "Life history and narrative: Questions, issues, and exemplary works." Life history and narrative (1995): 113-135.

Hatton, Timothy J. "Asylum Policy in the EU: the case for deeper integration."CESifo Economic Studies 61, no. 3-4 (2015): 605-637.

Haug, Sonja. "Migration networks and migration decision-making." Journal of Ethnic and Migration Studies 34, no. 4 (2008): 585-605.

Hedetoft, Ulf. Multiculturalism in Denmark and Sweden. DIIS, 2006.

Hedström, Peter, and Petri Ylikoski. "Causal mechanisms in the social sciences." Annual Review of Sociology 36 (2010): 49-67.

Hegel, Georg Wilhelm Friedrich. The philosophy of right. Hackett Publishing, 2003.

Hjerm, Mikael. "Immigrant entrepreneurship in the Swedish welfare state. "Sociology 38, no. 4 (2004): 739-756.

Hjerm, Mikael. "Integration into the social democratic welfare state." Social Indicators Research 70, no. 2 (2005): 117-138.

Holmlund, Bertil. "The rise and fall of Swedish unemployment." (2003).

Hort, Sven. Social policy, welfare state, and civil society in Sweden. Vol. 1: History, policies, and institutions 1884-1988. Arkiv förlag \& tidskrift, 2014.

Inkpen, Andrew C., and Eric WK Tsang. "Social capital, networks, and knowledge transfer." Academy of management review 30, no. 1 (2005): 146-165.

Ives, Nicole. "More than a "good back": Looking for integration in refugee resettlement." Refuge: Canada's Journal on Refugees 24, no. 2 (2007).

Jacobsen, Karen. "Factors influencing the policy responses of host governments to mass refugee influxes." International migration review (1996): 655-678.

Jonung, Lars, and Thomas Hagberg. How costly was the crisis of the 1990s? A comparative analysis of the deepest crises in Finland and Sweden over the last 130 years. No. 224. Directorate General Economic and Financial Affairs (DG ECFIN), European Commission, 2005. 
Jonung, Lars, Jaakko Kiander, and Pentti Vartia, eds. The great financial crisis in Finland and Sweden: the Nordic experience of financial liberalization. Edward Elgar Publishing, 2009.

Joppke, Christian. "Beyond national models: Civic integration policies for immigrants in Western Europe." West European Politics 30, no. 1 (2007): 1-22.

Joppke, Christian. "Transformation of citizenship: status, rights, identity." Citizenship studies 11, no. 1 (2007): 37-48.

Joppke, Christian, and Ewa Morawska. "Integrating immigrants in liberal nation-states: policies and practices." In Toward assimilation and citizenship: Immigrants in liberal nation-states, pp. 1-36. Palgrave Macmillan UK, 2014.

Jovchelovitch, Sandra, and Martin W. Bauer. "Narrative interviewing." Qualitative researching with text, image and sound (2000): 57-74.

Kalengayi, Faustine Kyungu Nkulu, Anna-Karin Hurtig, Annika Nordstrand, Clas Ahlm, and Beth Maina Ahlberg. "Perspectives and experiences of new migrants on health screening in Sweden." BMC health services research 16, no. 1 (2016): 14.

Kanas, Agnieszka, Frank Van Tubergen, and Tanja Van der Lippe. "Immigrant selfemployment: Testing hypotheses about the role of origin-and host-country human capital and bonding and bridging social capital." Work and Occupations 36, no. 3 (2009): 181208.

Katznelson, Ira. "Structure and configuration in comparative politics." Comparative politics: Rationality, culture, and structure (1997): 81-112.

Kesler, Christel. "Social policy and immigrant joblessness in Britain, Germany and Sweden." Social Forces 85, no. 2 (2006): 743-770.

Khosravi, Shahram. "White masks/Muslim names: immigrants and name-changing in Sweden." Race \& Class 53, no. 3 (2012): 65-80.

Kivisto, Peter, and Östen Wahlbeck. "Debating multiculturalism in the Nordic welfare states." In Debating multiculturalism in the Nordic welfare states, pp. 1-21. Palgrave Macmillan UK, 2013.

Klinthäll, Martin. "Refugee return migration: return migration from Sweden to Chile, Iran and Poland 1973-1996." Journal of Refugee Studies 20, no. 4 (2007): 579-598.

Kloosterman, Robert, Joanne Van Der Leun, and Jan Rath. "Mixed embeddedness:(in) formal economic activities and immigrant businesses in the Netherlands." International journal of urban and regional research 23, no. 2 (1999): 252-266. 
Kjellberg, Anders. "The Swedish Ghent system and trade unions under pressure." Transfer: European Review of Labour and Research 15, no. 3-4 (2009): 481504.

Knocke, Wuokko. "Integration or segregation? Immigrant populations facing the labour market in Sweden." Economic and Industrial Democracy 21, no. 3 (2000): 361-380.

Koopmans, Ruud, ed. Contested citizenship: Immigration and cultural diversity in Europe. Vol. 25. U of Minnesota Press, 2005.

Koopmans, Ruud. "Trade-offs between equality and difference: Immigrant integration, multiculturalism and the welfare state in cross-national perspective." Journal of ethnic and migration studies 36, no. 1 (2010): 1-26.

Korpi, Tomas, and Michael Tåhlin. "Changing work-life inequality in Sweden: Globalization and other causes." Globalized labour markets and social inequality in Europe: A comparative analysis (2011): 177-210.

Kuisma, Mikko, and Magnus Ryner. "Third Way decomposition and the rightward shift in Finnish and Swedish politics." Contemporary Politics 18, no. 3 (2012): 325-342.

Kymlicka, Will. Multicultural citizenship: A liberal theory of minority rights. Clarendon Press, 1995.

Kymlicka, Will. "The rise and fall of multiculturalism? New debates on inclusion and accommodation in diverse societies." International social science journal 61, no. 199 (2010): 97-112.

Kymlicka, Will. "Neoliberal multiculturalism." Social resilience in the neoliberal era (2013): 99-125.

Kymlicka, Will, and Eva Pföstl, eds. Multiculturalism and minority rights in the Arab world. OUP Oxford, 2014.

Lamba, Navjot K. "The employment experiences of Canadian refugees: measuring the impact of human and social capital on quality of employment*." Canadian Review of Sociology/Revue canadienne de sociologie 40, no. 1 (2003): 45-64.

Lancee, Bram. "The Economic Returns of Immigrants' Bonding and Bridging Social Capital: The Case of the Netherlands1." International Migration Review 44, no. 1 (2010): 202-226. 
Lancee, Bram, and Anne Hartung. "Turkish Migrants and Native Germans Compared: The Effects of Inter-Ethnic and Intra-Ethnic Friendships on the Transition from Unemployment to Work." International Migration 50, no. 1 (2012): 39-54.

Larsson, Staffan. "Seven aspects of democracy as related to study circles."International Journal of Lifelong Education 20, no. 3 (2001): 199-217.

Larsson, Staffan. "Study circles as democratic utopia: a Swedish perspective." Civil society, citizenship and learning (2001).

Larsson, Göran. "Apostasy in the West: A Swedish Case Study." Accusations of Unbelief in Islam: A Diachronic Perspective on Takfir (2015): 381.

Larsson, Staffan, and Henrik Nordvall. Study circles in Sweden: An overview with a bibliography of international literature. Linköping University Electronic Press, 2010.

Lidén, Gustav, and Jon Nyhlén. "Explaining local Swedish refugee policy."Journal of International Migration and Integration 15, no. 3 (2014): 547-565.

Lieberman, Evan S. "Causal inference in historical institutional analysis: A specification of periodization strategies." Comparative Political Studies 34, no. 9 (2001): 1011-1035.

Lindbom, Anders. "Dismantling Swedish housing policy." Governance 14, no. 4 (2001): 503-526.

Linde, Charlotte. "Narrative and social tacit knowledge." Journal of knowledge management 5, no. 2 (2001): 160-171.

Lindgren, Joakim. "Diaspora biographies balancing ideology and utopia On future orientations of immigrant youth in a segregated Sweden." Young 18, no. 2 (2010): 177195.

Lindström, Jonas. "Can only rich people study? Youth, segregated suburbs and higher education: experience from Sweden." Widening Participation and Lifelong Learning 8, no. 2 (2006): 6-13.

Lindvall, Johannes, and Joakim Sebring. "Policy reform and the decline of corporatism in Sweden." West European Politics 28, no. 5 (2005): 1057-1074.

Lindvall, Johannes, and Bo Rothstein. "Sweden: The fall of the strong state." Scandinavian Political Studies 29, no. 1 (2006): 47-63.

Lin, Nan (1999) http://www.insna.org/PDF/Connections/v22/1999_I-1-4.pdf

Linton, Martin. The Swedish Road to Socialism. No. 503. Fabian Society, 1985. 
Lister, Ruth. "A Nordic nirvana? Gender, citizenship, and social justice in the Nordic welfare states." Social Politics: International Studies in Gender, State \& Society 16, no. 2 (2009): 242-278.

Liversage, Anika. "Finding a path: investigating the labour market trajectories of highskilled immigrants in Denmark." Journal of Ethnic and Migration Studies 35, no. 2 (2009): 203-226.

Lundberg, S. (1989). Flyktingskap. Latinamerikansk exil i Sverige och Västeuropa. Lund: Arkiv

Lundberg, Erik, Erik Amnå, Pia Brundin, and Emanuela Bozzini. "European civil societies and the promotion of integration: Leading practices from Sweden, Great Britain, the Netherlands and Italy." In Social Rights, Active Citizenship and Governance in the European Union, pp. 121-133. Nomos Verlagsgesellschaft mbH \& Co. KG, 2011.

Lundborg, Per. "Refugees' employment integration in Sweden: Cultural distance and labor market performance." Review of International Economics21, no. 2 (2013): 219-232.

Magnusson Turner, Lena, and Lina Hedman. "Linking integration and housing career: A longitudinal analysis of immigrant groups in Sweden."Housing Studies 29, no. 2 (2014): 270-290.

Mair, Peter. "Party organizations: from civil society to the state." How parties organize: Change and adaptation in party organizations in Western democracies (1994): 1-22.

Malet, David, and Miriam J. Anderson, eds. Transnational Actors in War and Peace: Militants, Activists, and Corporations in World Politics. Georgetown University Press, 2017.

Malik, Kenan. "The failure of multiculturalism: Community versus society in Europe." Foreign Aff. 94 (2015): 21.

McAdams, Dan P. The stories we live by: Personal myths and the making of the self. Guilford Press, 1993.

Mella, Orlando. Chilenska flyktingar $i$ Sverige. Centrum för forskning om internationell migration och etniska relationer (CEIFO), 1990.

Merton, Robert King. On sociological theories of the middle range [1949]. na, 1949.

Mestheneos, Elizabeth, and Elizabeth Ioannidi. "Obstacles to refugee integration in the European Union member states." Journal of Refugee Studies 15, no. 3 (2002): 304-320. 
Miller, Peggy J. "Narrative practices: Their role in socialization and selfconstruction." The remembering self: Construction and accuracy in the self-narrative 6 (1994): 158-179.

Mills, C. Wright. White collar: The American middle classes. Vol. 3. Oxford University Press on Demand, 1951.

Milne, Richard. "Sweden's Immigrants Struggle with Jobs and Integration." Financial Times (London, U.K.), March 26, 2017.

Mishler, Elliot G. "Models of narrative analysis: A typology." Journal of narrative and life history 5, no. 2 (1995): 87-123.

Montesino, Norma. "Social disability: Roma and refugees in Swedish welfare." International Journal of Migration, Health and Social Care 8, no. 3 (2012): $134-145$.

Musterd, Sako, and Wim Ostendorf, eds. Urban segregation and the welfare state: Inequality and exclusion in western cities. Routledge, 2013.

Nannestad, Peter, Gunnar Lind Haase Svendsen, and Gert Tinggaard Svendsen. "Bridge over troubled water? Migration and social capital." Journal of Ethnic and Migration Studies 34, no. 4 (2008): 607-631.

Nordin, Martin. Ethnic School Segregation and Second-generation Immigrants' Human Capital. No. 2011: 14. 2011.

Nordin, Martin. "Immigrant school segregation in Sweden." Population Research and Policy Review 32, no. 3 (2013): 415-435.

Oberg, Kjell. "Treatment of immigrant workers in Sweden." Int'l Lab. Rev. 110 (1974): 1.

Odmalm, Pontus. "Civil society, migrant organisations and political parties: theoretical linkages and applications to the Swedish context." Journal of Ethnic and Migration Studies 30, no. 3 (2004): 471-489.

Palys, Ted. "Basic Research." The Sage encyclopedia of qualitative research methods (2008): 58-60.

Paxton, Pamela. "Social capital and democracy: An interdependent relationship." American sociological review (2002): 254-277.

Pontusson, Jonas. "At the end of the third road: Swedish social democracy in crisis." Politics \& Society 20, no. 3 (1992): 305-332. 
Peromingo, Miguel. "Work and refugee integration in Sweden." Forced Migration Review 48 (2014): 76.

Peters, B. Guy, Jon Pierre, and Desmond S. King. "The politics of path dependency: Political conflict in historical institutionalism." The journal of politics 67, no. 4 (2005): 1275-1300.

Pierre, Jon, ed. The Oxford Handbook of Swedish Politics. Oxford University Press, 2015.

Pio, Edwina. "Islamic sisters: spirituality and ethnic entrepreneurship in Sweden." Equality, diversity and inclusion: an international journal 29, no. 1 (2010): 113-130.

Polkinghorne, Donald E. Narrative knowing and the human sciences. Suny Press, 1988.

Polkinghorne, Donald E. "Narrative configuration in qualitative analysis." International journal of qualitative studies in education 8, no. 1 (1995): 5-23.

Portes, Alejandro, ed. The economic sociology of immigration: Essays on networks, ethnicity, and entrepreneurship. Russell Sage Foundation, 1995.

Portes, Alejandro. "The two meanings of social capital." In Sociological forum, vol. 15, no. 1, pp. 1-12. Springer Netherlands, 2000.

Portes, Alejandro. "Downsides of social capital." Proceedings of the National Academy of Sciences 111, no. 52 (2014): 18407-18408.

Portes, Alejandro, and Rubén G. Rumbaut. Immigrant America: a portrait. Univ of California Press, 2006.

Portes, Alejandro, and Patricia Landolt. "The downside of social capital." (1996).

Prop. 1988/89: Chapter 2 Section 4Ny utlänningslag m.m. (Government Bill, New Aliens Act etc.).

Redwood-Campbell, Lynda, Harpreet Thind, Michelle Howard, Jennifer Koteles, Nancy Fowler, and Janusz Kaczorowski. "Understanding the health of refugee women in host countries: lessons from the Kosovar re-settlement in Canada." Prehospital and Disaster Medicine 23, no. 4 (2008): 322-327.

"Regeringskansliet 2012: korta fakta om myndighetens verksamhet." Regeringskansliet (2012): 5-60. 
Regeringen (2012b) Integration och Jämställdhet. Proposition 2012/13: 1. Utgiftsområde 13. Förslag till statens budget för 2012. Accessed at: http://goo.g1/cqHX16

Riessman, Catherine Kohler. "Performing identities in illness narrative: Masculinity and multiple sclerosis." Qualitative Research 3, no. 1 (2003): 5-33.

Robinson, Vaughan. "Defining and measuring successful refugee integration." In Proceedings of ECRE International conference on Integration of Refugees in Europe. 1998.

Rojas, Mauricio. "Sweden after the Swedish Model." From Tutorial State to Enabling State. Timbro, Stockholm (2005): 9-20.

Rooth, Dan-Olof. "Refugee Immigrants in Sweden-educational investments and labour market integration." Lund Economic Studies (1999).

Rosholm, Michael, Marianne Roed, and Pål Schøne. "Are new work practices and new technologies biased against immigrant workers?." (2006).

Rothstein, Bo. "The end of Swedish exceptionalism." Foreign affairs (2014).

Ryan, Louise. "Transnational relations: Family migration among recent Polish migrants in London." International Migration 49, no. 2 (2011): 80-103.

Rydgren, Jens. "Mechanisms of exclusion: ethnic discrimination in the Swedish labour market." Journal of Ethnic and Migration Studies 30, no. 4 (2004): 697-716.

Sainsbury, Diane. "Immigrants' social rights in comparative perspective: welfare regimes, forms in immigration and immigration policy regimes."Journal of European Social Policy 16, no. 3 (2006): 229-244.

Sak, Güven, Timur Kaymaz, Omar Kadkoy, and Murat Kenanoğlu. "Forced Migrants: Labour Market Integration and Entrepreneurship." (2017).

Sanders, Jimy M., and Victor Nee. "Limits of ethnic solidarity in the enclave economy." American Sociological Review (1987): 745-773.

Sanders, Jimy M., and Victor Nee. "Immigrant self-employment: The family as social capital and the value of human capital." American sociological review (1996): 231-249.

Schall, Carly Elizabeth. The Rise and Fall of the Miraculous Welfare Machine: Immigration and Social Democracy in Twentieth-century Sweden. Cornell University Press, 2016. 
Schierup, Carl-Ulrik. "The duty to work': The theory and practice of refugee policy in Sweden." Journal of Ethnic and Migration Studies 16, no. 4 (1990): 561-574.

Schuster, Liza. "A comparative analysis of the asylum policy of seven European governments." Journal of Refugee Studies 13, no. 1 (2000): 118-132.

Schütze, Fritz. "Die Technik des narrativen Interviews." Bielefeld (Manuskript) (1977).

Schütze, Fritz. "Biographieforschung und narratives Interview." neue praxis13, no. 3 (1983): 283-293.

Schiff, Martin. "Swedish Social Welfare Policy and the Foreign Resident."Scandinavian Studies (1974): 31-46.

Schioppa, Fiorella Padoa. Mismatch and labour mobility. Cambridge University Press, 2009.

Schnyder, Gerhard. "Like a phoenix from the ashes? Reassessing the transformation of the Swedish political economy since the 1970s." Journal of European Public Policy 19, no. 8 (2012): 1126-1145.

Scott, Kirk. The Immigrant Experience: Changing Employment and Income Patterns in Sweden, 1970-1993. Vol. 9. Lund University, 1999.

Shah, Prakash, and Marie-Claire Foblets, eds. Family, religion and law: Cultural encounters in Europe. Routledge, 2016.

Sianesi, Barbara. "An evaluation of the Swedish system of active labor market programs in the 1990s." Review of Economics and statistics 86, no. 1 (2004): 133-155.

Sidanius, Jim, Colette Van Laar, Shana Levin, and Stacey Sinclair. "Ethnic enclaves and the dynamics of social identity on the college campus: the good, the bad, and the ugly." Journal of personality and social psychology 87, no. 1 (2004): 96.

Slavnic, Zoran. Immigrant and small business research in Sweden: An overview. Linköping University Electronic Press, 2004.

Smith, Craig, and David Nylund, eds. Narrative therapies with children and adolescents. Guilford Press, 2000.

Snow, David A., and Danny Trom. The case study and the study of social movements. Vol. 16. Minneapolis: University of Minnesota Press, 2002.

Södersten, Bo, ed. Globalization and the welfare state. Springer, 2004. 
Soininen, Maritta. "The 'Swedish model' as an institutional framework for immigrant membership rights." Journal of Ethnic and Migration Studies 25, no. 4 (1999): 685-702.

Somers, Margaret R. "Narrativity, narrative identity, and social action: Rethinking English working-class formation." Social Science History 16, no. 4 (1992): 591-630.

Somers, Margaret R. "The narrative constitution of identity: A relational and network approach." Theory and society 23, no. 5 (1994): 605-649.

Somers, Margaret R. "Narrating and naturalizing civil society and citizenship theory: the place of political culture and the public sphere." Sociological theory (1995): 229-274.

Spring, Marline, Joseph Westermeyer, Linda Halcon, Kay Savik, Cheryl Robertson, David R. Johnson, James N. Butcher, and James Jaranson. "Sampling in difficult to access refugee and immigrant communities." The Journal of nervous and mental disease 191, no. 12 (2003): 813-819.

Steinmo, Sven. "Globalization and taxation challenges to the Swedish welfare state." Comparative Political Studies 35, no. 7 (2002): 839-862.

Steinmo, Sven, Kathleen Thelen, and Frank Longstreth, eds. Structuring politics: historical institutionalism in comparative analysis. Cambridge University Press, 1992.

Stiglitz, Joseph E. "Capital market liberalization, economic growth, and instability." World development 28, no. 6 (2000): 1075-1086.

Strauss, Anselm Leonard, and Juliet Corbin. "Basics of qualitative research (Vol. 15)." (1990).

Svallfors, Stefan. "A bedrock of support? Trends in welfare state attitudes in Sweden, 1981-2010." Social Policy \& Administration 45, no. 7 (2011): 806-825.

Svallfors, Stefan, ed. Contested welfare states: Welfare attitudes in Europe and beyond. Stanford University Press, 2012.

Thiel, Markus. European Civil Socciety and Human Rights Advocacy. University of Pennsylvania Press, USA, 2017.

Tilton, Timothy A. "A Swedish road to socialism: Ernst Wigforss and the ideological foundations of Swedish social democracy." American Political Science Review 73, no. 2 (1979): 505-520.

Tilton, Timothy Alan. The political theory of Swedish Social Democracy: through the welfare state to socialism. Oxford University Press, USA, 1990. 
Tongco, Ma Dolores C. "Purposive sampling as a tool for informant selection." Ethnobotany Research and Applications 5 (2007): 147-158.

Torezani, Silvia, Val Colic-Peisker, and Farida Fozdar. "Looking for a "Missing Link": Formal employment services and social networks in refugees' job search." Journal of Intercultural Studies 29, no. 2 (2008): 135-152.

Trägårdh, Lars, ed. State and civil society in Northern Europe: The Swedish model reconsidered. Vol. 3. Berghahn Books, 2007.

Traub, James. "The Death of the Most Generous Nation on Earth." Foreign Policy 10 (2016).

Tselios, Vassilis, Inge Noback, Jouke Dijk, and Philip McCann. "Integration of immigrants, bridging social capital, ethnicity, and locality." Journal of Regional Science 55, no. 3 (2015): 416-441.

Uddman, R. "Study Circles in Sweden." Lifelong Education for Adults: An International Handbook (2014): 242.

Valenta, Marko, and Nihad Bunar. "State assisted integration: Refugee integration policies in Scandinavian welfare states: the Swedish and Norwegian experience." Journal of Refugee Studies (2010): feq028.

Valtonen, Ms Kathleen. Social work and migration: Immigrant and refugee settlement and integration. Ashgate Publishing, Ltd., 2012.

Valenta, Marko, and Zan Strabac. "State-assisted integration, but not for all: Norwegian welfare services and labour migration from the new EU member states." International Social Work (2011): 0020872810392811.

Valtonen, Ms Kathleen. Social work and migration: Immigrant and refugee settlement and integration. Ashgate Publishing, Ltd., 2012.

Van Selm, Joanne. "Immigration and asylum or foreign policy: the EU's approach to migrants and their countries of origin." Migration and the externalities of European integration (2002): 143-160.

Valutis, Tadas. "Understanding the role of NGOs for immigrant integration in Sweden: a case study of Tamam." (2013).

https://lup.lub.lu.se/student-papers/search/publication/3801181

Viotti, Paul R., Mark V. Kauppi, R. Viotti Paul, and V. Kauppi Mark. International relations and world politics: Security, economy, identity. No. 327. Prentice-Hall;, 1997. 
Vogel, Joachim. Associational life in Sweden: General welfare, social capital, training in democracy. Statistiska centralbyran, 2003.

Vu, Thuy Quoc. "Refugee welfare dependency: The trauma of resettlement." (1990).

Waldinger, Roger, Howard Aldrich, and Robin Ward. "Ethnic Entrepreneurs: Immigrant and Ethnic Business in Western Industrial Societies." Beverly Hills: Sage (1990).

Wauters, Bram, and Johan Lambrecht. "Refugee entrepreneurship in Belgium: Potential and practice." The International Entrepreneurship and Management Journal 2, no. 4 (2006): 509-525.

Warman, Casey. "Ethnic enclaves and immigrant earnings growth." Canadian Journal of Economics/Revue canadienne d'économique 40, no. 2 (2007): 401-422.

Webster, Leonard, and Patricie Mertova. Using narrative inquiry as a research method: An introduction to using critical event narrative analysis in research on learning and teaching. Routledge, 2007.

Wells, Karen. "The strength of weak ties: the social networks of young separated asylum seekers and refugees in London." Children's Geographies9, no. 3-4 (2011): 319-329.

Westin, Charles, and Elena Dingu-Kyrklund. "Reducing Immigration." Reviewing Integration. An (1997).

Westin, Charles. "The Ugandan Asians in Sweden-Twenty-five Years after the Expulsion." In Ethnicity and Economy, pp. 121-141. Palgrave Macmillan UK, 2002.

Westin, Charles. "Sweden: Restrictive immigration policy and multiculturalism." (2006).

Wigerfelt, Anders, and Berit Wigerfelt. "A challange to multiculturalism: everyday racism and hate crime in a small Swedish town." (2014).

Whiteley, Paul F. "Economic growth and social capital." Political studies 48, no. 3 (2000): 443-466.

Wiesbrock, Anja. "The integration of immigrants in Sweden: A Model for the European Union?." International Migration 49, no. 4 (2011): 48-66.

Wickström, Mats. "Conceptual Change in Postwar Sweden: The Marginalization of Assimilation and the Introduction of Integration." In Debating Multiculturalism in the Nordic Welfare States, pp. 110-139. Palgrave Macmillan UK, 2013. 
Wiklund, Helena, Abdulaziz S. Aden, Ulf Högberg, Marianne Wikman, and Lars Dahlgren. "Somalis giving birth in Sweden: a challenge to culture and gender specific values and behaviours." Midwifery 16, no. 2 (2000): 105-115.

Williams, Colin C., and Jan Windebank. "The formalisation of work thesis: a critical evaluation." Futures 31, no. 6 (1999): 547-558.

Woolcock, Michael. "Social capital and economic development: Toward a theoretical synthesis and policy framework." Theory and society 27, no. 2 (1998): 151-208.

Xie, Yu, and Margaret Gough. "Ethnic enclaves and the earnings of immigrants." Demography 48, no. 4 (2011): 1293-1315.

Yakubovich, Valery. "Weak ties, information, and influence: How workers find jobs in a local Russian labor market." American sociological review 70, no. 3 (2005): 408-421.

Yin, Robert K. Case study research: Design and methods. Sage publications, 2013. 


\section{VITA}

\section{JEFFREY D. MASLANIK}

Born, Denver, Colorado

2005-2008

B.A., International Studies \& French Language

Colorado State University

Fort Collins, Colorado

2009-2011

M.A, Transatlantic Studies

Jagiellonian University

Krakow, Poland

2015-2016

Visiting Researcher

Lund University

Lund, Sweden

2016

Visiting Studies Fellow

RSC, Univeristy of Oxford

Oxford, United Kingdom

2013-2017

Ph.D., International Relations

Florida International University

Miami, Florida

\section{PUBLICATIONS AND PRESENTATIONS}

Thiel, Markus and Jeffrey Maslanik. "Transnational Actors." Oxford Encyclopedia of International Studies, OUP. (2017): 1-38.

Round Table with Hon. Annette Klein Consul General of the Federal Republic of Germany, "Refugee Integration, Germany and Beyond," October 5, 2017, Miami Florida.

UACES 47 ${ }^{\text {th }}$ Annual Conference, September 4-6, 2017 Kraków Poland, "Contested Realities: The Common European Asylum System and the Member States."

EUSA, May 5, 2017, Miami Florida, "Brexit Lessons for Scandinavia."

Oxford University Working Paper Series November 7 2016, “An Historical Institutionalist Approach to Refugee Integration in Sweden." 
Council for European Studies Conference, Sciences Po July 8-10 2015, “A Cosmopolitan Polity? Exploring Cosmopolitanism Legitimacy in the EUs Immigration \& Asylum Policies."

EUCE, Miami Florida, FIU, February 23 \& 24 2015, "Progressive Cosmopolitanism: the Role of Civil Society in Sweden."

ISA West, Pasadena California September 26 \& 27 2014, "A Theoretical Analysis of the post-Westphalian State: Tolerance and Pluralism in New Europe."

Academic conference organized by the U.S. Department of State at the University of Bielsko Biała: Route 66: 2000 miles or more of American Myth exemplified in Literature, Film and Art, (March 12, 2011). 